\title{
Design, synthesis, and evaluation of donepezil-like compounds as AChE and BACE-1 inhibitors
}

Paola Costanzo $^{\dagger}$, Luca Cariati ${ }^{\dagger}$, Doriana Desiderio ${ }^{\ddagger}$, Roberta Sgammato ${ }^{\S, \|}$, Anna Lamberti ${ }^{\S}$, Rosaria Arcone $^{\S, ~}$, Raffaele Salerno $^{\dagger}$, Monica Nardi ${ }^{\perp}$, Mariorosario Masullo ${ }^{\S, l}$ and Manuela Oliverio ${ }^{\dagger *}$.

${ }^{\dagger}$ Dipartimento di Scienze della Salute, Università degli Studi della Magna Græcia Viale Europa, Loc. Germaneto (CZ), 88100 , Italy.

" Dipartimento di Bioscienze e Territorio, Università del Molise, Contrada Fonte Lappone, 86090 Pesche (IS), Italy.

${ }^{\S}$ Dipartimento di Scienze Motorie e del Benessere, Università di Napoli "Parthenope", Via Medina 40, 80133 Napoli, Italy.

" CEINGE, Biotecnologie Avanzate, S.C. a R.L., Via G. Salvatore 486, 80145 Napoli, Italy.

${ }^{\perp}$ Dipartimento di Chimica e Tecnologie Chimiche, Università della Calabria, Via P. Bucci 12 C, 87037, Arcavacata di Rende (CS), Italy.

\section{SupplementaryInformations}




\section{Table of Contents}

\section{Experimental}

General Information

General protocol for Q-Tube assisted synthesis of indanones (Figure S1)

General protocol for synthesis of N-benzylpiperidine-4-carboxaldehydes (Figure S2)

- Alkylation

- Reduction/oxidation

General procedure for synthesis of compounds 17-26

General Protocol for demethylation of compounds 17-20

Enzymatic and viability assays (Table S1, Figure S3, Figure S4)

Characterization of compounds

\section{HRMS Spectra:}

- Sample 13a/13b 16

- Sample $14 \quad 17$

- Sample $15 \quad 18$

- Sample $16 \quad 19$

- Sampe $17 \quad 20$

- Sample $18 \quad 21$

- Sample $19 \quad 22$

- Sample $20 \quad 23$

- Sample $21 \quad 24$

- Sample 22 25

- Sample 23

- Sample $24 \quad 27$

- Sample 25

- Sample $26 \quad 29$

${ }^{1}$ H-NMR Spectra

- Sample 13a/13b 30

- Sample $14 \quad 31$

- Sample 15

- Sample $16 \quad 33$

- Sample $17 \quad 34$

- Sample $18 \quad 35$

- Sample 19

- Sample $20 \quad 37$

- Sample $21 \quad 38$

- Sample 22

- Sample $23 \quad 40$

- Sample 24

- Sample 25

- Sample $26 \quad 43$ 
- Sample 13a/13b

- Sample 14

- Sample 15

- Sample 16

- Sample 17 48

- Sample 18 49

- Sample 19 50

- Sample 20 51

- Sample 21 52

- Sample 22 53

- Sample 23 54

- Sample 24 55

- Sample 25 56

- Sample 26 57

NOESY Spectra

- Sample 15 58

- $\quad$ Sample 17 59

- $\quad$ Sample 18 60

- Sample 19

61

- Sample 20 62 


\section{Experimental}

\section{General Information}

All chemicals were obtained from Aldrich Chem. Co or Acros Organics and used as received. QTube assisted reactions were performed in a $\mathrm{Q}-\mathrm{Tube}^{\mathrm{TM}}$ safe pressure reactor from Labtech, equipped with a cap/sleeve, a pressure adapter (120 psi), a needle adapter/needle, a borosilicate glass tube, a teflon septum and a catch bottle. US-assisted reactions were performed in a highpower US-bath $(19.6 \mathrm{kHz})$ made by Danacamerini (Torino). Reactions were monitored by a GCMS Thermo Fisher Scientific workstation, composed by a Focus GC (Thermo TR- 5ms SQC 15m X $0.25 \mathrm{~mm}$ ID X $0.25 \mu \mathrm{m}$, working on split mode, $1.2 \mathrm{~mL} / \mathrm{min}$ He as carrier gas) and a DSQ II mass detector. Functionalization of unvolatile compound using BSA was performed according to the following procedure: $0.1 \mathrm{mg}$ of compound were solubilized in $50 \mu \mathrm{l}$ AcOEt and $50 \mu \mathrm{l}$ of BSA were added under stirring. The mixture was reacted at $65^{\circ} \mathrm{C}$ for 35 minutes, diluted 1:1000 with AcOEt and injected in the GC/MS apparatus. The $[\mathrm{M}+72]^{+} \mathrm{m} / \mathrm{z}$ value was detected for each desired product. TLC were performed using silica plates $60-\mathrm{F}_{264}$ on alumina, commercially available from Merk. Liquid flash chromatography was performed on a Supelco VERSA FLASH HTFP station using silica cartridges commercially available from Supelco. ${ }^{1} \mathrm{H}-\mathrm{NMR}$ and ${ }^{13} \mathrm{C}-\mathrm{NMR}$ spectra were recorded on a Bruker WM 300 instrument on samples dissolved in $\mathrm{CDCl}_{3}$ (compounds 13, 15, 1726) or in $d_{6}$-DMSO (compounds 14 and 16). NOESY spectra were recorded on a Bruker Avance $500 \mathrm{MHz}$ instrument $\left({ }^{1} \mathrm{H}: 500.13 \mathrm{MHz}\right)$, using a standard $5 \mathrm{~mm}$ double resonance broadband (BBO) probe. Chemical shifts are given in parts per million ( $\mathrm{ppm})$ from tetramethylsilane as the internal standard (0.0 ppm). HRMS measurements were realized on a Thermo Scientific QExactive (Thermo Fisher, Milan, Italy) mass spectrometer working in positive mode at 35,000 resolving power, operating in SIM mode by flow injection (flow rate $15 \mu \mathrm{L} / \mathrm{min}$ for each stock solution). Stock solutions at a concentration of $1 \mathrm{mg} / \mathrm{mL}$ were prepared in UHPLC-MS grade $\mathrm{MeOH}$ for each analytes separately. Prior to analysis, each solution was diluted 1:1000 (v/v) in a vial to obtain a concentration of $1 \mathrm{mg} / \mathrm{L}$. Detection of the targeted compounds was based on theoretical exact mass. Data were evaluated by Xcalibur 2.2.SP1(Thermo Fisher Scientific, Bremen, Germany). The mass accuracy, directly calculated from Xcalibur, is defined by the formula $\Delta(\mathrm{ppm})=[$ (theoretical mass - measured mass)/theoretical mass] $\times 1.000 .000$.

eeAChE, hAChE from human erythrocytes, BuChE, acetylthiocholine, butyrylthiocholine, 5',5'dithiobis-2-nitrobenzoic acid (DTNB), and donepezil, were purchased from Sigma-Aldrich.

The fluorescent peptide substrate containing the Lys-Met/Asn-Leu mutations of the amyloid precursor protein (APP) $\beta$-secretase cleavage site was purchased from Sigma-Aldrich. Mouse BACE-1 (recombinant) and BACE-1 Inhibitor I, were from Life Technology; BACE-1 inhibitor IV solution (10 mM in DMSO) was from Calbiochem. Stock solutions of the synthesized compounds were prepared in DMSO at $100 \mathrm{mM}$ final concentration. 
General protocol for Q-Tube assisted synthesis of indanones

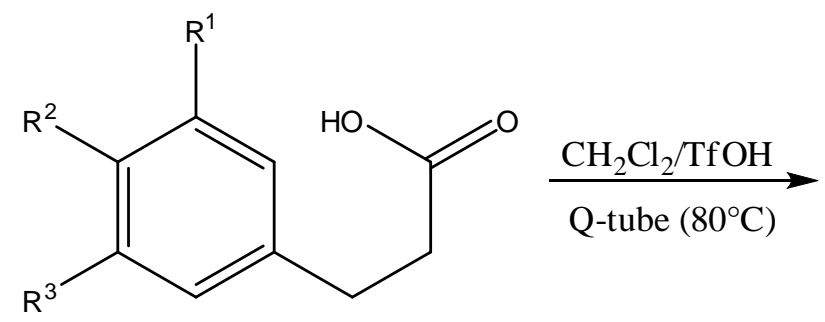<smiles>[R]c1c([2H])cc2c(c1[R])C(=O)CC2</smiles>

1: $\mathrm{R}^{1}=\mathrm{H} ; \mathrm{R}^{2}=\mathrm{R}^{3}=\mathrm{OCH}_{3} ; \mathbf{2}: \mathrm{R}^{1}=\mathrm{R}^{3}=\mathrm{H} ; \mathrm{R}^{2}=\mathrm{OCH}_{3} \quad$ 5: $\mathrm{R}^{1}=\mathrm{H} ; \mathrm{R}^{2}=\mathrm{R}^{3}=\mathrm{OCH}_{3} ; \mathbf{6}: \mathrm{R}^{1}=\mathrm{R}^{3}=\mathrm{H} ; \mathrm{R}^{2}=\mathrm{OCH}_{3}$

3: $\mathrm{R}^{1}=\mathrm{OCH}_{3} ; \mathrm{R}^{2}=\mathrm{R}^{3}=\mathrm{H}$;

4: $\mathrm{R}^{1}=\mathrm{H} ; \mathrm{R}^{2}=\mathrm{R}^{3}=\mathrm{O}-\mathrm{CH}_{2}-\mathrm{O}$ 7: $\mathrm{R}^{1}=\mathrm{OCH}_{3} ; \mathrm{R}^{2}=\mathrm{R}^{3}=\mathrm{H} ; \mathbf{8}: \mathrm{R}^{1}=\mathrm{R}^{2}=\mathrm{H} ; \mathrm{R}^{3}=\mathrm{OCH}_{3}$ 9: $\mathrm{R}^{1}=\mathrm{H} ; \mathrm{R}^{2}=\mathrm{R}^{3}=\mathrm{O}-\mathrm{CH}_{2}-\mathrm{O}$

\section{Figure S1}

In a $12 \mathrm{~mL}$ Q-Tube ${ }^{\mathrm{TM}}$ pressure tube, furnished by Q Labtech, trifluoromethan sulfonic acid (3 eq) was gently added to a cooled $\left(0^{\circ} \mathrm{C}\right)$ solution of a 3 -Phenyl propionic acid $(0.5 \mathrm{mmol})$ in dry dichloromethane $(1.0 \mathrm{~mL})$. Temperature was raised to room temperature. A teflon septum was placed on the top of the tube and the appropriate cap with a pressure adapter were used. The mixture was heated in a oil bath at $80^{\circ} \mathrm{C}$. The reaction was monitored by TLC and GC/MS until disappearance of the reactant. The mixture was poured into ice and extracted three times with dichloromethane. The organic phase collected were dried on $\mathrm{Na}_{2} \mathrm{SO}_{4}$, filtered and concentrated under vacuum. The desired pure product was separated from the crude by flash chromatography. See Ref 22 for spectral characterization of products. 

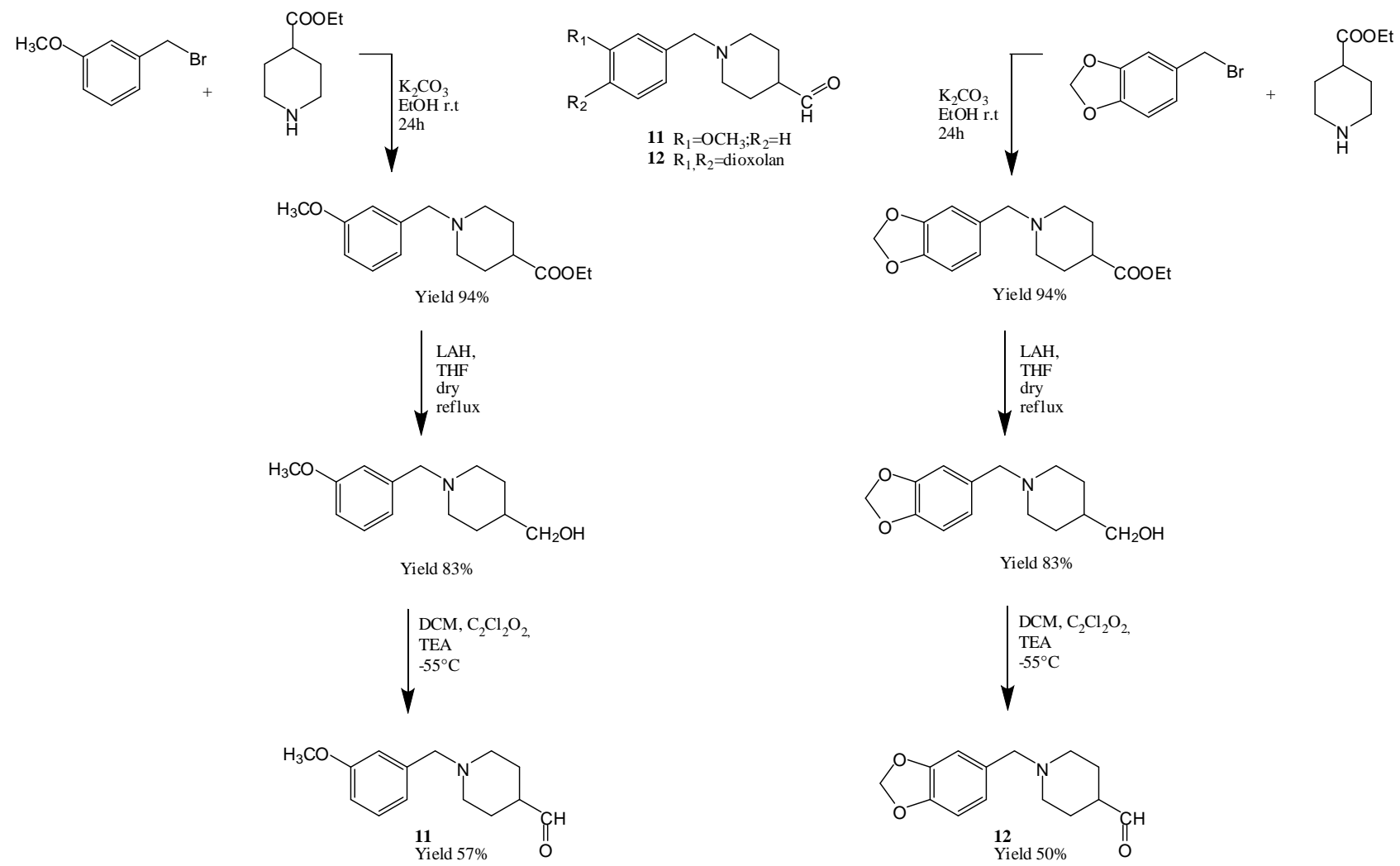

Figure S2

\section{Alkylation}

To a solution of ethyl isonipecotate $(0.997 \mathrm{~g}, 6.35 \mathrm{mmol})$ and $\mathrm{K}_{2} \mathrm{CO}_{3}(2.1 \mathrm{~g}, 15.3 \mathrm{mmol})$ in EtOH $(32.5 \mathrm{~mL})$, an excess of bromide $(7.6 \mathrm{mmol})$ is added portion wise and under stirring. The mixture is reacted for 24 hours at room temperature and monitored by TLC. At the end of reaction the solution is diluted with water and extracted three times with AcOEt. The organic phases were collected, dried with $\mathrm{Na}_{2} \mathrm{SO}_{4}$, filtered and evaporated under reduced pressure. The product is separated from the crude by flash chromatography (Hexane /AcOEt 8:2 v/v).

\section{Reduction/Oxidation}

A solution of $\mathrm{N}$-alkyl-piperidine-4-ethyl carboxylate $(1.3 \mathrm{mmol})$ coming from the previous step in $2.2 \mathrm{ml}$ of dry THF is added under stirring to a suspension of LiAlH4 (0.2087 g, $5.2 \mathrm{mmol})$ in dry THF $(4.3 \mathrm{~mL})$ previously cold down at $0{ }^{\circ} \mathrm{C}$. The mixture is heated until room temperature and stirred for 1 hour, then refluxed for 4 hours. The reaction is monitored by TLC; at the end the mixture is cold down at room temperature and $\mathrm{H}_{2} \mathrm{O}(5 \mathrm{~mL})$ and a solution of $\mathrm{NaOH} 2 \mathrm{~N}(1.3 \mathrm{~mL})$ are gently added. The resulting mixture is extracted three times with AcOEt; the organic phases collected are dried on $\mathrm{Na}_{2} \mathrm{SO}_{4}$, filtered and the solvent is evaporated under reduced pressure. The crude, analyzed by GC/MS after BSA derivatization in order to verify the formation of the desired product, is used in the oxidation step without purification. To a solution of ossalic chloride (2.16 mmol, $0.274 \mathrm{~g}$ in $5.38 \mathrm{ml}$ of dry DCM) previously cold down at $-48{ }^{\circ} \mathrm{C}$ and maintained at this actual temperature for 10 minutes, DMSO $(2.52 \mathrm{mmol}, 0.196 \mathrm{~g})$ is added drop wise. To the mixture, a solution of the crude in dry dichloromethane $(1.08 \mathrm{mmol}$ in $0.6 \mathrm{ml}$ of DCM dry) is added and the 
reaction is stirred at $-55^{\circ} \mathrm{C}$ for 15 minutes. After the addition of $0.575 \mathrm{ml}$ of trimethylamine, the mixture is heated until room temperature and stirred for 24 hours. After completion the mixture is diluted with $\mathrm{CHCl}_{3}$ and extracted three times with water. The organic phases were collected, dried with $\mathrm{Na}_{2} \mathrm{SO}_{4}$, filtered and evaporated under reduced pressure. The product is separated from the crude by flash chromatography (DCM / MeOH 9.5:0.5v/v). See Ref 24 for spectral characterization of products. 
The synthesis of donepezil precursor 17-26 was realized by US-assisted aldol condensation between indanones $\mathbf{5 - 9}$ and the correspondent N-benzylpiperidine-4-carboxyaldehydes 10-12, itself synthesized according to the procedure reported, ${ }^{2}$ when needed.

For a typical synthesis, $0.33 \mathrm{~g} / \mathrm{mL}$ of resin and methanol $(3 \mathrm{~mL})$ were charged in a round bottom flask and stirred at room temperature. $0.5 \mathrm{mmol}$ of 1 -indanone and $0.6 \mathrm{mmol}$ of aldheyde were then added. The flask was closed with a silicone cup and equipped with a needle. The mixture was reacted in a high-power US-bath $(19.6 \mathrm{kHz})$ made by Danacamerini with a nominal power $250 \mathrm{~W}$. The temperature was maintained at $40-50{ }^{\circ} \mathrm{C}$. The reaction temperature was controlled by a continuous water steam. The reaction was monitored by TLC until the reactant disappeared. After cooling to room temperature the mixture was filtered, and the resin was washed with dichloromethane, dried and reused for three reaction cycles. Solvent was then evaporated and the dried crude products were crystallized from methanol or purified by flash chromatographic purification where needed. All the compounds were identified by HRMS and characterized by ${ }^{1} \mathrm{H}-$ NMR and ${ }^{13} \mathrm{C}-\mathrm{NMR}$ by comparison with the data reported (See Supporting Information).

\section{General Protocol for demethylation of compounds 17-20}

In a two neck round bottom flask, equipped with magnetic stirrer, $0.26 \mathrm{mmol}$ of donepezil precursor were dissolved in $3 \mathrm{ml}$ of wet DMF and 15 equivalents of iodocyclohexane were added under $\mathrm{N}_{2}$ atmosphere. The mixture was refluxed at the DMF boiling point and continuously controlled by TLC. A total amount of 45 to 60 equivalents of iodocyclohexane was added at portion of 15 equivalents in a total time ranging from 6 to 10 hours depending on the case. At the end of reaction $10 \mathrm{ml}$ of water was added and the mixture was extracted three times with $10 \mathrm{ml}$ of dichloromethane. The collected organic phases were washed with a hypertonic $\mathrm{NaHSO}_{4}$ solution $(30 \mathrm{ml}$ x 3 ) and a brine solution ( $30 \mathrm{ml} \times 3$ ). The organic phases were finally dried on $\mathrm{Na}_{2} \mathrm{SO}_{4}$, filtered and the solvent was evaporated under reduced pressure. The DMF eventually still present was evaporated by azeotropic distillation with toluene. The products $\mathbf{1 3 a} / \mathbf{1 3 b}, \mathbf{1 4}, \mathbf{1 5}$, and 16 were separated by chromatographic purification and characterized by HRMS, ${ }^{1} \mathrm{H}-\mathrm{NMR}$ and ${ }^{13} \mathrm{C}-\mathrm{NMR}$.

\footnotetext{
${ }^{1}$ Oliverio, M.; Nardi, M.; Costanzo, P.; Cariati, L.; Cravotto, G.; Giofrè V. S.; Procopio, A. Non-conventional methodologies in the synthesis of 1-indanones, Molecules. 2014, 19, 5599-5610.

${ }^{2}$ Caruso, A.; Garofalo, A.; Grande, F.; Aiello, F.; Anzini, M.; Ortuso, F.; Alcaro, S.; Panno, A.; Saturnino, C; Sinicropi, M. S. Synthesis and biological evaluation of 1,3-idandione derivatives as acetylcholinesterase inhibitors.

Pharmacologyonline. 2009, 1, 264-277.
} 


\section{Enzymatic and viability assays}

Cholinesterase activity was assayed by the Elmann method $^{3}$ using acetylthiocholine or butyrylthiocoline as substrate for $\mathrm{AChE}$ or $\mathrm{BuChE}$, respectively. The reduction of dithiobisnitrobenzoate by the thiocholine, produced by the enzymatic hydrolysis of thiolated substrates, was followed colorimetrically $(412 \mathrm{~nm})$ at room temperature $\left(22-27^{\circ} \mathrm{C}\right)$. The reaction mixture $(500 \mu \mathrm{L})$ contained $330 \mu \mathrm{M}$ DTNB and the appropriate amount of substrate, in $0.1 \mathrm{M}$ sodium phosphate buffer, $\mathrm{pH}$ 7.1. The reaction was started by the addition of $100 \mathrm{mU} / \mathrm{ml}$ or 200 $\mathrm{mU} / \mathrm{ml}$ of $\mathrm{AChE}$ or BuChE, respectively, and the initial rate of the reaction was derived from the linear portion of the kinetics.

The reversibility of the inhibition was assessed using a dilution method described previously ${ }^{4,5}$. Briefly, the enzyme was pre-incubated for $20 \mathrm{~min}$ with the inhibitors or with DMSO, as a vehicle control; after a 100-fold dilution of the incubation mixture, the residual enzyme activity was measured as reported above.

The concentration of inhibitor required to reduce the enzymatic activity to $50 \%\left(\mathrm{IC}_{50}\right)$ was derived from semi-logarithmic plots in which the residual cholinesterase activity was determined at different concentration of inhibitor, using a thiolated substrate concentration of $500 \mu \mathrm{M}$. Linear curve fits were obtained with the least-squares method, and the significance of the correlation was estimated from the squared correlation coefficient $r^{2}$, which was always higher than 0.95 .

The kinetic parameters of the enzymatic reaction $K_{\mathrm{m}}$ and $V_{\max }$, were derived from the determination of the enzyme activity at 6 different acetylthiocholine or butyrylthiocholine concentration $(80-500$ $\mu \mathrm{M})$, chosen in order to give the similar weight in the regression. The data were either interpolated in the Michaelis-Menten equation or treated with the Lineweaver-Burk equation giving similar results.

The inhibition constant $K_{\mathrm{i}}$ was derived by measuring the kinetic parameters in the presence of different inhibitor concentration, $0.2-30 \mu \mathrm{M}$ for AChE or $3-100 \mu \mathrm{M}$ for BuChE. The values of $K_{\mathrm{i}}$ were derived from the equation $K_{\mathrm{m}}{ }^{\prime}=K_{\mathrm{m}}\left(1+[\mathrm{I}] / K_{\mathrm{i}}\right)$, in case of competitive inhibition or $V_{\max }{ }^{\prime}=$ $V_{\max } /\left(1+[\mathrm{I}] / K_{\mathrm{i}}\right)$, in case of non competitive inhibition, or with both in the case of mixed inhibition. In these equations $K_{\mathrm{m}}{ }^{\prime}$ and $V_{\max }{ }^{\prime}$ represent the values of $K_{\mathrm{m}}$ and $V_{\max }$ measured at the [I] concentration of inhibitor. Values of $\mathrm{IC}_{50}$ and $K_{\mathrm{i}}$ reported were the mean of at least 4 different determinations.

BACE-1 activity was assayed by a fluorimetric method $^{6}$ using the Enspire ${ }^{\mathrm{TM}}$ Multimode Plate Reader (Perkin-Elmer) in the kinetic Fluorescence method. The assay was performed in black polystyrene 96-well microtiter plates. The reaction mixtures contained $2.1 \mathrm{ng} / \mu 1$ mouse BACE-1 in $50 \mathrm{mM}$ ammonium acetate buffer, $\mathrm{pH} 4.5$ supplemented with $1 \mathrm{mM}$ triton $\mathrm{X}-100$, and the appropriate amount of the inhibitor. The mixture was incubated for $10 \mathrm{~min}$ at room temperature (22$25^{\circ} \mathrm{C}$ ), the reaction started by adding $100 \mathrm{nM}$ final concentration of the fluorescent peptide substrate, and the increase in fluorescence was followed kinetically. The enzymatic cleavage of the

\footnotetext{
${ }^{3}$ Ellman, G. L.; Courtney, K. D.; Andres, V.; Featherstone, R. M.; A new and rapid colorimetric determination of acetylcholinesterase activity. Biochem. pharmacol. 1961, 7, 88-95.

${ }^{4}$ Sohn, J.; Kiburz, B.; Li, Z.; Deng, L.; Safi, A.; Pirrung, M. C.; Rudolph, J. Inhibition of Cdc25 phosphatases by indolyldihydroxyquinones, J. Med. Chem. 2003, 46, 2580-2588(2003).

${ }^{5}$ Lavecchia, A; Di Giovanni, C.; Pesapane, A.; Montuori, N.; Ragno, P.; Martucci, N. M.; Masullo, M.; De Vendittis, E.; Novellino, E.; Discovery of new inhibitors of Cdc25B dual specificity phosphatases by structure-based virtual screening. J. Med. Chem. 2012, 55,4142-4158.

${ }^{6}$ Mancini, F.; Naldi, M.; Cavrini, V.; Andrisano, V. Multiwellfluorometric and colorimetric microassays for the evaluation of beta-secretase (BACE-1) inhibitors. Anal. Bioanal. Chem. 2007, 388, 1175-11831.
} 
peptide led to the appearance of a fluorescence signal using excitation and emission wavelength of 320 and $420 \mathrm{~nm}$, respectively. The rate was derived from the linear portion of the kinetics, usually in the first $30 \mathrm{~min}$ of the reaction. The known Inhibitors $\mathrm{I}\left(\mathrm{IC}_{50}, 240 \mathrm{nM}\right){ }^{7}$ and $\mathrm{IV}\left(\mathrm{IC}_{50}, 15 \mathrm{nM}\right)^{8}$ were used as positive controls.

The effect of the synthesized compounds on cell viability was assessed in SH-SY5Y neuroblastomacells. Cells were grown in Roswell Park Memorial Institute medium (RPMI) supplemented with $2 \mathrm{mM}$ L-glutamine, $100 \mathrm{UI} / \mathrm{mL}$ penicillin, $100 \mu \mathrm{g} / \mathrm{mL}$ streptomycin and $10 \%$ (v/v) fetal bovine serum. Cells were maintained in culture dishes at $37{ }^{\circ} \mathrm{C}$ in a saturated humidity atmosphere containing $95 \%$ air and $5 \% \mathrm{CO}_{2}$. Cells were seeded at an initial density of $104 \mathrm{cells} / \mathrm{cm}^{2}$ in culture dishes. At a confluence of $80 \%$, cells were detached by trypsin treatment, suspended in fresh medium without FBS and transferred to multiwell (24 or 96 wells). After $24 \mathrm{~h}$ from seeding, cells were incubated in the absence or in the presence of the synthesized compounds, and their viability was evaluated after $48 \mathrm{~h}$ treatment as mitochondrial activity using the MTT assay. ${ }^{9}$ Briefly, after the treatment the medium was removed and cells were incubated with $100 \mu \mathrm{l}$ MTT $(0.5$ $\mathrm{mg} / \mathrm{ml}$ ) for $1 \mathrm{~h}$. After that, the solution was removed, the formazan formed solubilized in $100 \mu \mathrm{l}$ of $0.1 \mathrm{~N} \mathrm{HCl}$ in $90 \%(\mathrm{v} / \mathrm{v})$ 2-propanol and the absorbance measured at $570 \mathrm{~nm}$ using a microplate reader (BioRad). Results were expressed as percentage of cell survival vs. control cells, which have been cultured in the presence of the inhibitor vehicle $(0.01 \%(\mathrm{v} / \mathrm{v}) \mathrm{DMSO})$.

Table S1. IC $\mathrm{I}_{50}$ of synthesized cumpounds on the BACE-1 activity. ${ }^{\text {a }}$

\begin{tabular}{|c|c|c|c|}
\hline Inhibitor & $\mathrm{IC}_{50}(\boldsymbol{M M})$ & SD & p \\
\hline Donepezil & 0.143 & 0.025 & $<0.0005$ \\
\hline $13 a, b$ & 2.241 & 0.420 & $<0.05$ \\
\hline 14 & 1.553 & 0.022 & $<0.05$ \\
\hline 15 & 0.608 & 0.019 & $<0.05$ \\
\hline 16 & 0.669 & 0.100 & $<0.005$ \\
\hline 17 & 0.697 & 0.248 & $<0.05$ \\
\hline 18 & 1.335 & 0.091 & $<0.05$ \\
\hline 19 & 0.845 & 0.019 & $<0.005$ \\
\hline 20 & 0.333 & 0.104 & $<0.0005$ \\
\hline 21 & 0.529 & 0.012 & $<0.05$ \\
\hline 22 & 0.873 & 0.283 & $<0.05$ \\
\hline 23 & 0.996 & 0.229 & $<0.05$ \\
\hline 24 & 2.128 & 0.099 & $<0.0005$ \\
\hline 25 & 204.18 & 16.294 & $<0.0005$ \\
\hline 26 & 14.662 & 2.649 & $<0.005$ \\
\hline
\end{tabular}

a Data were derived from semi-logarithmic plots of BACE-1 activity determined at three different inhibitor concentration.

\footnotetext{
${ }^{7}$ May, P. C. Dean, R. A.; Lowe, S. L.; Martenyi, F.; Sheehan, S. M.; Boggs, L. N.; Monk, S. A.; Mathes, B. M.; Mergott, D. J.; Watson, B. M.; Stout, S. L.; Timm, D. E.; Smith Labell, E.; Gonzales, C. R.; Nakano, M.; Jhee, S. S.; Yen, M.; Ereshefsky, L.; Lindstrom, T. D.; Calligaro, D. O.; Cocke, P. J.; Greg Hall, D.; Friedrich, S.; Citron, M.; Audia, J. E. Robust central reduction of amyloid- $\beta$ in humans with an orally available, non-peptidic $\beta$-secretase inhibitor, J Neurosci. 2011, 31, 16507-16516.

${ }^{8}$ Stachel, S. J.; Coburn, C. A.; Steele, T. G.; Jones, K. G. Loutzenhiser, E. F.; Gregro, A. R.; Rajapakse, H. A.; Lai, M. T.; Crouthamel, M. C.; Xu, M.; Tugusheva, K.; Lineberger, J. E.; Pietrak, B. L.; Espeseth, A. S.; Shi, X. P.; ChenDodson, E.; Holloway, M. K.; Munshi, S.; Simon, A. J.; Kuo, L.; Vacca, J. P. Structure-based design of potent and selective cell-permeable inhibitors of human beta-secretase (BACE-1),J Med Chem. 47, 6447-6450(2004).

${ }^{9}$ Mossman, T.; Rapid colorimetric assay for cellular growth and survival: application to proliferation and cytotoxicity assays. J. Immunol. Methods. 1983, 65,55-63.
} 


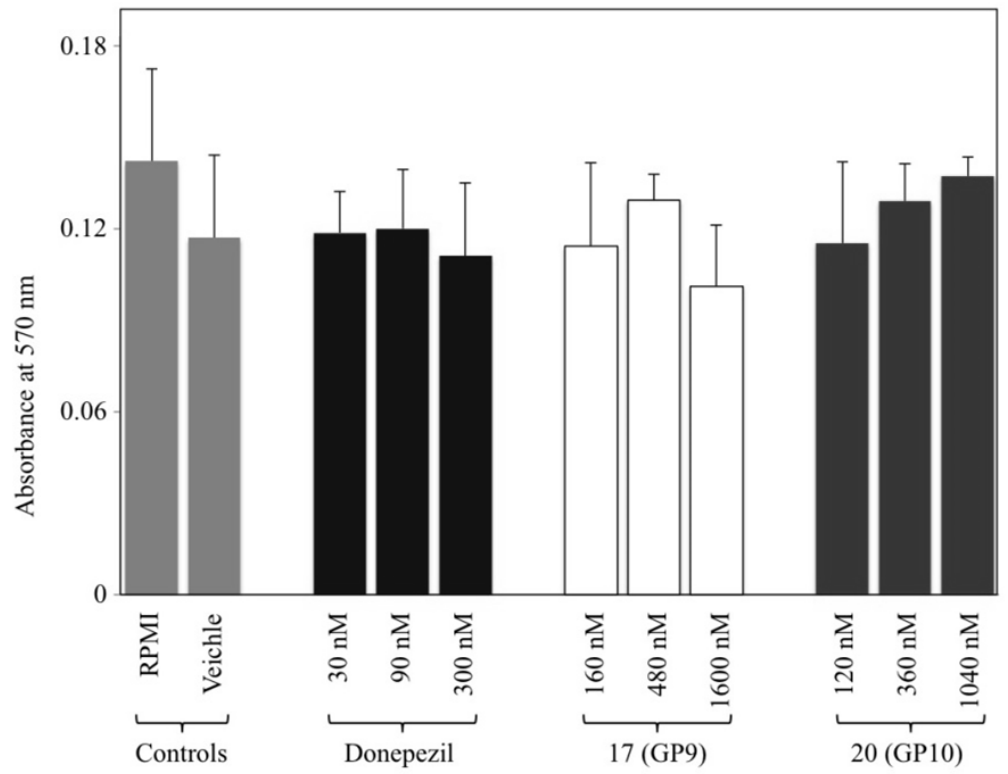

Figure S3. Effect of compounds 17 and 20 on cell viability.

The effect of tested compounds on SH-SY5Y cell viability was evaluated on $3 \times 10^{4}$ cells at the indicated final concentration, falling in the 3 - 30 times range of the correspondig $\mathrm{IC}_{50}$ exhibited towards hAChE activity. As controls, RPMI medium in the absence or in the presence of $0.1 \%$ DMSO, were used. 

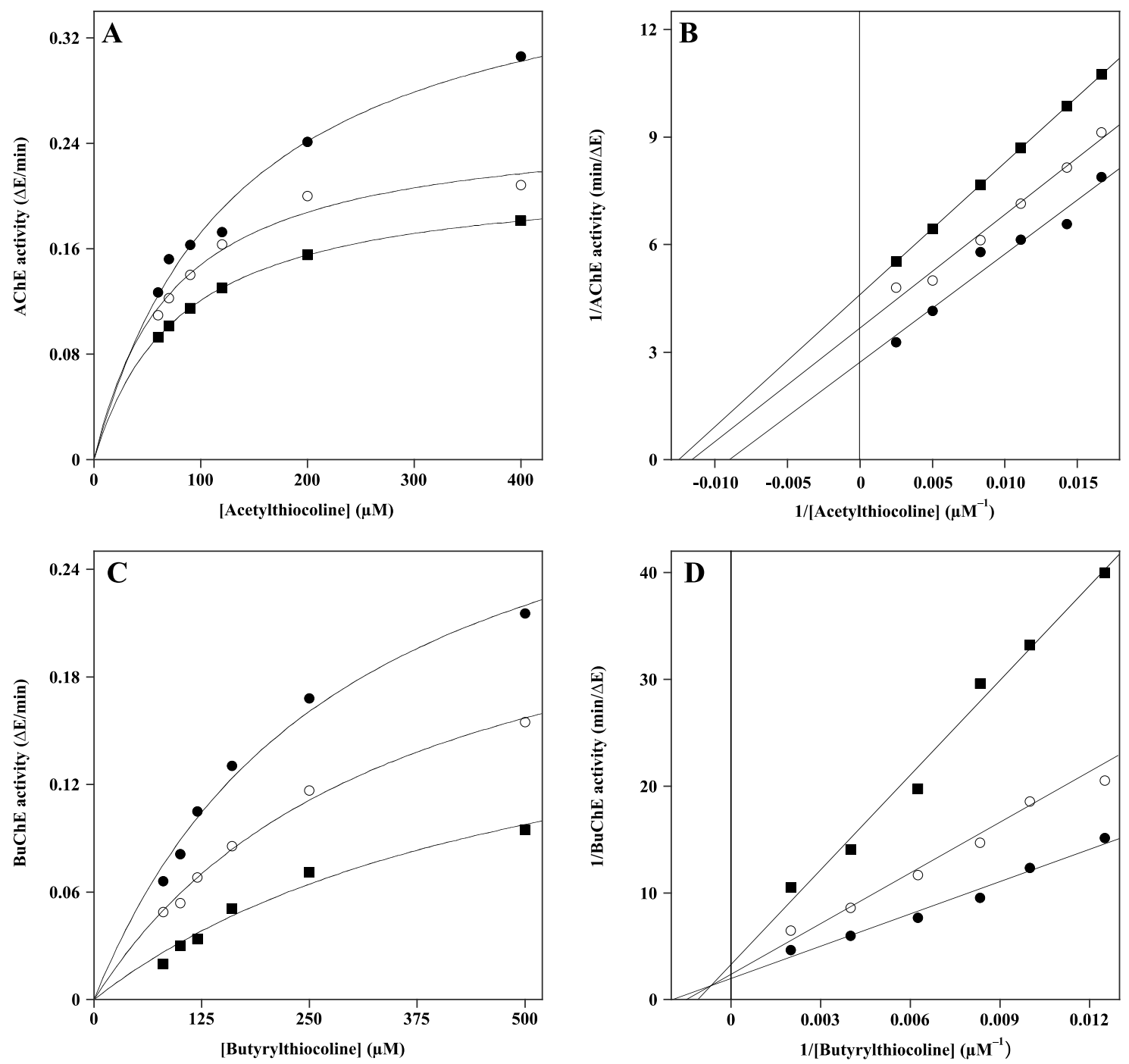

Figure S4. Determination of the inhibition parameters of a representative synthesized compound on AChE and BuChE.

The kinetic parameters $\mathrm{Km}$ and Vmax were derived by both interpolation on the Michaelis-Menten equation (Panels $\mathrm{A}$ and $\mathrm{C}$ ) or by Lineweaver-Burk equation. The cholinesterase activity was determined as reported in the Experimental section at different concentration of the specific substrate in the absence (3) or in the presence of 15 (4) and $30 \mathrm{nM}$ (5) or 1 (4)) and $4 \mu \mathrm{M}$ (5) compound 17 for AChE (Panel A and B) and BuChE (Panel C and D), respectively. 


\section{Characterization of compounds}

(E)-2-((1-benzylpiperidin-4-yl)methylene)-6-hydroxy-5-methoxy-2,3-dihydro-1H-inden-1-one, (13a), (E)-2-((1-benzylpiperidin-4-yl)methylene)-5-hydroxy-6-methoxy-2,3-dihydro-1H-inden1-one (13b) Isomeric mixture: Yellow oil, Yield 45\%, $\mathrm{R}_{f}=($ Chloroform-Methanol 9.5:0.5) 0.13; HRMS: $[\mathrm{M}+\mathrm{H}]^{+} \mathrm{m} / \mathrm{z} 364.1906$ (theoretical $\left.[\mathrm{M}+\mathrm{H}]^{+} \mathrm{m} / \mathrm{z} 364.1907\right) ;{ }^{1} \mathrm{H}$ NMR $\delta$ (ppm) (300MHz, $\left.\mathrm{CDCl}_{3}\right): 7.48-7.20(\mathrm{~m}, 12 \mathrm{H}), 6.96(\mathrm{~s}, 1 \mathrm{H}), 6.88(\mathrm{~s}, 1 \mathrm{H}), 6.83(\mathrm{~s}, 1 \mathrm{H}), 6.65(\mathrm{~d}, J=9.5 \mathrm{~Hz}, 2 \mathrm{H}), 3.98(\mathrm{~s}$, $1 \mathrm{H}), 3.94(\mathrm{~s}, 1 \mathrm{H}), 3.62-3.55(\mathrm{~m}, 2 \mathrm{H}), 2.97(\mathrm{~m}, 4 \mathrm{H}), 2.43-2.27(\mathrm{~m}, 8 \mathrm{H}), 2.20-2.06(\mathrm{~m}, 2 \mathrm{H}), 1.77-1.57$ (m, 4H), 1.44-1.08 (m, 4H); ${ }^{13} \mathrm{C}$ NMR (300MHz, $\left.\mathrm{CDCl}_{3}\right): 192.4,152.7,146.1,145.1,142.9,139.3$, 135.6, 129.3, 128.4, 128.1, 127.1, 110.7, 106.5, 63.1, 56.4, 52.5, 37.1, 29.2, 22.7.

(E)-2-((1-benzylpiperidin-4-yl)methylene)-6-hydroxy-2,3-dihydro-1H-inden-1-one

(14):

Yellow powder, Yield 53\%, $\mathrm{R}_{f}=$ (Chloroform-Methanol 9.5:0.5) $0.22 ;$ HRMS: $[\mathrm{M}+\mathrm{H}]^{+} \mathrm{m} / \mathrm{z}$ 334.1807 (theoretical $\left.[\mathrm{M}+\mathrm{H}]^{+} \mathrm{m} / \mathrm{z} 334.1802\right),{ }^{1} \mathrm{H}$ NMR $\delta(\mathrm{ppm})\left(300 \mathrm{MHz}, \mathrm{d}_{6}\right.$-DMSO): 7.50-7.30 $(\mathrm{m}, 5 \mathrm{H}), 7.14-7.10(\mathrm{~m}, 1 \mathrm{H}), 7.02(\mathrm{~s}, 1 \mathrm{H}), 6.92-6.94(\mathrm{~m}, 1 \mathrm{H}), 6.51(\mathrm{~d}, J=9.8 \mathrm{~Hz}, 1 \mathrm{H}), 5.45$ (s br, $1 \mathrm{H}), 3.85-3.75(\mathrm{~m}, 2 \mathrm{H}), 3.62(\mathrm{~s}, 2 \mathrm{H}), 3.52-2.98(\mathrm{~m}, 4 \mathrm{H}), 2.70-2.40(\mathrm{~m}, 1 \mathrm{H}), 1.80-1.50(\mathrm{~m}, 4 \mathrm{H}) ;{ }^{13} \mathrm{C}$ NMR (300 MHz, $\mathrm{CDCl}_{3}$ ): 192.4, 157.0, 156.9, 156.8, 144.2, 139.1, 137.1, 129.7, 128.5, 128.3, 127.4, 123.3, 108.1, 107.5, 51.7, 40.3, 38.7, 28.4.

(E)-2-((1-benzylpiperidin-4-yl)methylene)-7-hydroxy-2,3-dihydro-1H-inden-1-one (15): Brown oil, Yield 65\%, $\mathrm{R}_{f}=$ (Chloroform-Methanol 9.5:0.5) $0.28 ;$ HRMS: $[\mathrm{M}+\mathrm{H}]^{+} \mathrm{m} / \mathrm{z} 334.1803$ (theoretical $[\mathrm{M}+\mathrm{H}]^{+} \mathrm{m} / \mathrm{z}$ 334.1802), ${ }^{1} \mathrm{H}$ NMR $\delta$ (ppm) $\left(300 \mathrm{MHz}, \mathrm{CDCl}_{3}\right.$ ): 8.02 (s br, 1H), 7.61-7.28 $(\mathrm{m}, 6 \mathrm{H}), 7.04-6.88(\mathrm{~m}, 1 \mathrm{H}), 6.79(\mathrm{~d}, J=8 \mathrm{~Hz}, 1 \mathrm{H}), 6.71(\mathrm{~d}, J=9.5 \mathrm{~Hz}, 1 \mathrm{H}), 3.82(\mathrm{~s}, 2 \mathrm{H}), 3.64(\mathrm{~s}, 2 \mathrm{H})$, 3.46-3.28 (m, 1H), 3.20-3.10 (m, 2H), 3.0-2.80 (m, 2H), 2.55-2.37 (m, 2H), 2.01-1.80 (m, $2 \mathrm{H}) ;{ }^{13} \mathrm{C}$ NMR (300MHz, d $\left.6^{-D M S O}\right): 179.0,158.1,148.9,139.9,137.8,131.1,130.3,129.1,128.8,128.6$, $116.9,113.7,113.6,62.3,52.1,36.2,29.8,29.6$.

(E)-2-((1-benzylpiperidin-4-yl)methylene)-5-hydroxy-2,3-dihydro-1H-inden-1-one (16): Yellow powder, Yield 80\%, $\mathrm{R}_{f}=\left(\right.$ Chloroform-Methanol 9.5:0.5) 0.16; HRMS: $[\mathrm{M}+\mathrm{H}]^{+} \mathrm{m} / \mathrm{z}$ 334.1799 (theoretical $[\mathrm{M}+\mathrm{H}]^{+} \mathrm{m} / \mathrm{z}$ 334.1802); ${ }^{1} \mathrm{H}$ NMR $\delta$ (ppm) (300 MHz, $\mathrm{d}_{6}$-DMSO): 7.70-7.38 (m, 7H), 6.95-6.85 (m, 2H), $6.82(\mathrm{~d}, J=8.3 \mathrm{~Hz}, 1 \mathrm{H}), 4.26$ (s br, 1H), 3.66 (s, 2H), 3.51 (s, 2H), 3.402.52 (m, 5H), 2.10-1.20 (m, 4H); ${ }^{13} \mathrm{C}$ NMR (300 MHz, $\mathrm{d}_{6}$-DMSO): 205.4, 163.9, 163.8, 156.4, 152.4, 131.3, 129.2, 128.6, 127.7, 125.0, 115. 8, 111.8, 59.0, 51.3, 39.0, 29.1, 28.2.

(E)-2-((1-benzylpiperidin-4-yl)methylene)-5,6-dimethoxy-2,3-dihydro-1H-inden-1-one (17). White powder; Yield: $56 \% ; \mathrm{R}_{f}=$ (Dichloromethane-Methanol 9:1) $0.44 ;$ HRMS: $[\mathrm{M}+\mathrm{H}]^{+} \mathrm{m} / \mathrm{z}$ 378.2061 (theoretical $\left.[\mathrm{M}+\mathrm{H}]^{+} \mathrm{m} / \mathrm{z} 378.2064\right) ;{ }^{1} \mathrm{H}$ NMR $\left(\mathrm{CDCl}_{3}, 300 \mathrm{MHz}\right): \delta 7.34-7.21(\mathrm{~m}, 6 \mathrm{H})$, 6.92-6.89 (s, 1H), 6.69-6.63 (d, 1H, J=9.8 Hz), $3.97(\mathrm{~s}, 3 \mathrm{H}), 3.93(\mathrm{~s}, 3 \mathrm{H}), 3.61-3.57(\mathrm{~d}, 2 \mathrm{H}, \mathrm{J}=1.1$ $\mathrm{Hz}), 3.54(\mathrm{~s}, 2 \mathrm{H}), 2.99-2.90(\mathrm{~m}, 2 \mathrm{H}), 2.40-2.25(\mathrm{~m}, 1 \mathrm{H}), 2.13-2.02(\mathrm{~m}, 2 \mathrm{H}), 1.80-1.58(\mathrm{~m}, 4 \mathrm{H}) ;{ }^{13} \mathrm{C}$ NMR $\left(\mathrm{CDCl}_{3}, 300 \mathrm{MHz}\right): \delta 192.5,155.3,149.6,144.4,139.6,135.7,129.3,131.8,129.2,128.2$, 127.0, 107.2, 105.1, 63.3, 56.2, 56.1, 52.9, 37.1, 31.0, 29.5. 
(theoretical $[\mathrm{M}+\mathrm{H}]^{+} \mathrm{m} / \mathrm{z}$ 348.1958); ${ }^{1} \mathrm{H} \mathrm{NMR}\left(\mathrm{CDCl}_{3}, 300 \mathrm{MHz}\right): \delta$ 7.39-7.15 (m, 8H), 6.77-6.70 (d, 1H, J=9.8 Hz), 3.85 (s, 3H), 3.63-3.58 (d, 2H, J=1.1 Hz), 3.53 (s, 2H), 2.99-2.87 (m, 2H), 2.43-

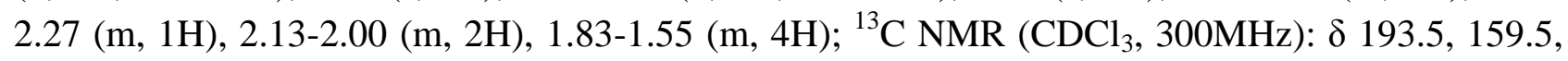
$142.1,141.4,140.0,138.3,135.9,129.1,128.1,126.9,123.8,105.8,63.4,55.6,53.0,37.3,30.1$, 29.0.

(E)-2-((1-benzylpiperidin-4-yl)methylene)-7-methoxy-2,3-dihydro-1H-inden-1-one

Yellow oil; Yield: 48\%; $\mathrm{R}_{f}=\left(\right.$ Chloroform-Methanol 9:1) $0.41 ; \mathrm{HRMS:}[\mathrm{M}+\mathrm{H}]^{+} \mathrm{m} / \mathrm{z} 348.1959$ (theoretical $[\mathrm{M}+\mathrm{H}]^{+} \mathrm{m} / \mathrm{z}$ 348.1958); ${ }^{1} \mathrm{H} \mathrm{NMR}\left(\mathrm{CDCl}_{3}, 300 \mathrm{MHz}\right): \delta$ 7.57-7.46 (m, 1H), 7.38-7.22 $(\mathrm{m}, 5 \mathrm{H}), 7.02(\mathrm{~d}, 1 \mathrm{H}, J=7.5 \mathrm{~Hz}), 6.81(\mathrm{~d}, 1 \mathrm{H}, J=8.2 \mathrm{~Hz}), 6.67(\mathrm{~d}, 1 \mathrm{H}, J=9.5 \mathrm{~Hz}), 3.96(\mathrm{~s}, 3 \mathrm{H}), 3.63$ (s, 2H), 3.55 (s, 2H), 2.99-2.89 (m, 2H), 2.39-2.22 (m, 1H), 2.15-2.02 (m, 2H), 1.77-1.56 (m, 4H); ${ }^{13} \mathrm{C} \mathrm{NMR}\left(\mathrm{CDCl}_{3}, 300 \mathrm{MHz}\right): \delta 191.9,159.2,152.1,139.9,136.5,135.8,129.8,129.1,129.0128 .7$, $127.7,118.3,109.6,63.4,56.2,53.0,37.2,31.0,30.0$.

(E)-2-((1-benzylpiperidin-4-yl)methylene)-5-methoxy-2,3-dihydro-1H-inden-1-one (20). White powder; Yields: 63\%; $\mathrm{R}_{f}=$ (Chloroform-Methanol 9:1)0.76; HRMS: $[\mathrm{M}+\mathrm{H}]^{+} \mathrm{m} / \mathrm{z} 348.1958$ (theoretical $[\mathrm{M}+\mathrm{H}]^{+} \mathrm{m} / \mathrm{z}$ 348.1958); ${ }^{1} \mathrm{H} \mathrm{NMR}\left(\mathrm{CDCl}_{3}, 300 \mathrm{MHz}\right): \delta$ 7.82-7.76 (d, $\left.1 \mathrm{H}, \mathrm{J}=9.2 \mathrm{~Hz}\right)$, 7.38-7.21 (m, 6H), 6.95-6.87 (m, 1H), $6.66(\mathrm{~d}, 1 \mathrm{H}, \mathrm{J}=9.6 \mathrm{~Hz}), 3.88(\mathrm{~s}, 3 \mathrm{H}), 3.63(\mathrm{~s}, 2 \mathrm{H}), 3.52(\mathrm{~s}$, $2 \mathrm{H}), 2.99-2.87(\mathrm{~m}, 2 \mathrm{H}), 2.40-2.26(\mathrm{~m}, 1 \mathrm{H}), 2.12-2.00(\mathrm{~m}, 2 \mathrm{H}), 1.76-1.53(\mathrm{~m}, 4 \mathrm{H}) ;{ }^{13} \mathrm{C} \mathrm{NMR}$ $\left(\mathrm{CDCl}_{3}, 300 \mathrm{MHz}\right): \delta 192.1,165.1,152.1,140.0,138.3,135.5,132.3,129.1,128.1,126.9,126.1$, $115.1,109.8,63.4,55.6,53.0,37.2,31.2,29.9$.

(E)-6-((1-benzylpiperidin-4-yl)methylene)-6,7-dihydro-5H-indeno[5,6-d][1,3]dioxol-5-one (21) White powder; Yield: 64\%; $\mathrm{R}_{f}=$ (Chloroform-Methanol 9:1) 0.6; HRMS: $[\mathrm{M}+\mathrm{H}]^{+} \mathrm{m} / \mathrm{z} 362.1752$ (theoretical $\left.[\mathrm{M}+\mathrm{H}]^{+} \mathrm{m} / \mathrm{z} 362.1751\right) ;{ }^{1} \mathrm{H} \mathrm{NMR}\left(\mathrm{CDCl}_{3}, 300 \mathrm{MHz}\right): \delta 7.38-7.19(\mathrm{~m}, 6 \mathrm{H}), 6.85(\mathrm{~s}, 1 \mathrm{H})$, $6.64(\mathrm{~d}, 1 \mathrm{H}, \mathrm{J}=9.6 \mathrm{~Hz}), 6.06(\mathrm{~s}, 2 \mathrm{H}), 3.56(\mathrm{~s}, 2 \mathrm{H}), 3.53(\mathrm{~s}, 2 \mathrm{H}), 3.00-2.87(\mathrm{~m}, 2 \mathrm{H}), 2.36-2.23(\mathrm{~m}$, 1H), 2.14-1.97 (m, 2H), 1.76-1.55 (m, 4H); ${ }^{13} \mathrm{C} \mathrm{NMR}\left(\mathrm{CDCl}_{3}, 300 \mathrm{MHz}\right): \delta 191.5,154.1,148.6$, $146.6,139.9,135.8,129.2,128.3,127.1,105.6,103.4,102.1,63.6,53.2,37.4,31.5,30.0$.

(E)-5-methoxy-2-((1-(3-methoxybenzyl)piperidin-4-yl)methylene)-2,3-dihydro-1H-inden-1-one (22). Orange powder; Yield: 40\%; $\mathrm{R}_{f}=\left(\right.$ Chloroform-Methanol 9:1) $0.62 ; \mathrm{HRMS}:[\mathrm{M}+\mathrm{H}]^{+} \mathrm{m} / \mathrm{z}$ 378.2061 (theoretical $\left.[\mathrm{M}+\mathrm{H}]^{+} \mathrm{m} / \mathrm{z} 378.2064\right) ;{ }^{1} \mathrm{H} \mathrm{NMR}\left(\mathrm{CDCl}_{3}, 300 \mathrm{MHz}\right): \delta 7.80(\mathrm{~d}, 1 \mathrm{H}, \mathrm{J}=9.2$ $\mathrm{Hz}$ ), 7.28- 7.20 (m, 1H), 6.96-6.88 (m, 4H), 6.84-6.77 (m, 1H), 6.67 (d, 1H, J=9.8 Hz),3.89 (s, 3H), $3,82(\mathrm{~s}, 3 \mathrm{H}), 3.63(\mathrm{~s}, 2 \mathrm{H}), 3.52(\mathrm{~s}, 2 \mathrm{H}), 2.99-2.88(\mathrm{~m}, 2 \mathrm{H}), 2.42-2.26(\mathrm{~m}, 1 \mathrm{H}), 2.14-2.00(\mathrm{~m}, 2 \mathrm{H})$, 1.77-1.55 (m, 4H); ${ }^{13} \mathrm{C} \mathrm{NMR}\left(\mathrm{CDCl}_{3}, 300 \mathrm{MHz}\right): \delta 192.6,165.5,160.0,152.5,140.4,140.2,135.9$, $132.6,129.5,126.5,121.8,115.4,115.0,112.8,110.2$, 63.7, 56.0, 55.6, 53.4, 37.5, 31.5, 30.2.

(E)-6-methoxy-2-((1-(3-methoxybenzyl)piperidin-4-yl)methylene)-2,3-dihydro-1H-inden-1-one (23) Yellow oil; Yield: 40\%; $\mathrm{R}_{f}=\left(\right.$ Chloroform-Methanol 98:2) 0.44;HRMS: $[\mathrm{M}+\mathrm{H}]^{+} \mathrm{m} / \mathrm{z} 378.2061$ (theoretical $\left.[\mathrm{M}+\mathrm{H}]^{+} \mathrm{m} / \mathrm{z} 378.2064\right) ;{ }^{1} \mathrm{H} \mathrm{NMR}\left(\mathrm{CDCl}_{3}, 300 \mathrm{MHz}\right): 87.47-6.77(\mathrm{~m}, 7 \mathrm{H}), 6.74(\mathrm{~d}, 1 \mathrm{H}$, $\mathrm{J}=9.8 \mathrm{~Hz}), 3.85(\mathrm{~s}, 3 \mathrm{H}), 3,82(\mathrm{~s}, 3 \mathrm{H}), 3.61(\mathrm{~s}, 2 \mathrm{H}), 3.52(\mathrm{~s}, 2 \mathrm{H}), 3.00-2.90(\mathrm{~m}, 2 \mathrm{H}), 2.48-1.54(\mathrm{~m}$, $7 \mathrm{H}) ;{ }^{13} \mathrm{C} \mathrm{NMR}\left(\mathrm{CDCl}_{3}, 300 \mathrm{MHz}\right): \delta 192.8,160.5,140.8,29.6,129.5,127.3,124.0,121.9,115.3$, 113.2, 106.9, 63.5, 61.1, 56.1, 49.1, 37.8, 31.8, 29.6. 
(E)-7-methoxy-2-((1-(3-methoxybenzyl)piperidin-4-yl)methylene)-2,3-dihydro-1H-inden-1-one (24) Yellow powder; Yield: 30\%; $\mathrm{R}_{f}=$ (Chloroform-Methanol 98:2) 0.4; HRMS: $[\mathrm{M}+\mathrm{H}]^{+} \mathrm{m} / \mathrm{z}$ 378.2060 (theoretical $[\mathrm{M}+\mathrm{H}]^{+} \mathrm{m} / \mathrm{z}$ 378.2064); ${ }^{1} \mathrm{H}$ NMR $\left(\mathrm{CDCl}_{3}, 300 \mathrm{MHz}\right): \delta 7.51(\mathrm{t}, 1 \mathrm{H}, \mathrm{J}=7.9$ $\mathrm{Hz})$, 7.28-7.25 (m, 1H), 7.04-6.99 (m 1H), 6.94-6.89 (m, 2H), 6.84-6.77 (m, 2H), $6.67(\mathrm{dt}, 1 \mathrm{H}$, $\mathrm{J}=9.6 \mathrm{~Hz}, 2.0 \mathrm{~Hz}), 3.88(\mathrm{~s}, 3 \mathrm{H}), 3,81(\mathrm{~s}, 3 \mathrm{H}), 3.63(\mathrm{~s}, 2 \mathrm{H}), 3.51(\mathrm{~s}, 2 \mathrm{H}), 3.00-2.88(\mathrm{~m}, 2 \mathrm{H}), 2.21-$ $2.40(\mathrm{~m}, 1 \mathrm{H}), 2.18-2.00(\mathrm{~m}, 2 \mathrm{H}), 1.78-1.56(\mathrm{~m}, 4 \mathrm{H}) ;{ }^{13} \mathrm{C} \mathrm{NMR}\left(\mathrm{CDCl}_{3}, 300 \mathrm{MHz}\right): \delta 191.2,161.4$, $160.3,147.2$, 145.9, 140.9, 134.9, 130.9, 129.9, 116.2, 112.9, 112.0, 61.4, 56.3, 56.8, 52.0, 34.5, 29.9.

(E)-2-((1-(benzo[d][1,3]dioxol-5-ylmethyl)piperidin-4-yl)methylene)-6-methoxy-2,3-dihydro1H-inden-1-one (25) White powder; Yield: 30\%; $\mathrm{R}_{f}=$ (Chloroform-Methanol 9:1) 0.5; HRMS: $[\mathrm{M}+\mathrm{H}]^{+} \mathrm{m} / \mathrm{z} 392.1855$ (theoretical $[\mathrm{M}+\mathrm{H}]^{+} \mathrm{m} / \mathrm{z}$ 392.1856); ${ }^{1} \mathrm{H} \mathrm{NMR}\left(\mathrm{CDCl}_{3}, 300 \mathrm{MHz}\right): \delta 7.42-7.14$ $(\mathrm{m}, 4 \mathrm{H}), 6.86(\mathrm{~s}, 1 \mathrm{H})$ 6.78-6.70 (m, 2H), $5.95(\mathrm{~s}, 2 \mathrm{H}), 3.83(\mathrm{~s}, 3 \mathrm{H}), 3.61(\mathrm{~s}, 2 \mathrm{H}), 3.44(\mathrm{~s}, 2 \mathrm{H}), 2.97-$

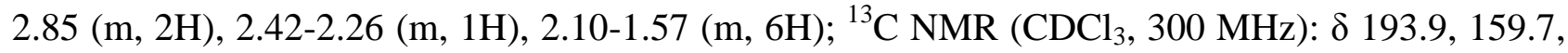
$147.9,146.8,142.4,141.6,140.3,136.2$, 132.2, 127.2, 124.1, 122.5, 109.8, 108.1, 106.0, 101.1, $63.4,55.9,53.1,37.5,31.3,29.3$.

(E)-2-((1-(benzo[d][1,3]dioxol-5-ylmethyl)piperidin-4-yl)methylene)-7-methoxy-2,3-dihydro1H-inden-1-one (26) Yellow Oil; Yield: 30\%; $\mathrm{R}_{f}=($ Chloroform-Methanol 9:1) 0.46; HRMS:

$[\mathrm{M}+\mathrm{H}]^{+} \mathrm{m} / \mathrm{z} 392.1855$ (theoretical $\left.[\mathrm{M}+\mathrm{H}]^{+} \mathrm{m} / \mathrm{z} 378.1856\right) ;{ }^{1} \mathrm{H} \mathrm{NMR}\left(\mathrm{CDCl}_{3}, 300 \mathrm{MHz}\right): \delta 7.55-$ $7.46(\mathrm{t}, 1 \mathrm{H}, \mathrm{J}=7.7 \mathrm{~Hz}), 7.05-6.98(\mathrm{~d}, 1 \mathrm{H}, \mathrm{J}=7.7 \mathrm{~Hz}), 6.89-6.71(\mathrm{~m}, 4 \mathrm{H}), 6,70-6.62(\mathrm{dt}, 1 \mathrm{H}, \mathrm{J}=9.6 \mathrm{~Hz}$, $1.9 \mathrm{~Hz}), 5.94(\mathrm{~s}, 2 \mathrm{H}), 3.96(\mathrm{~s}, 3 \mathrm{H}), 3.62(\mathrm{~s}, 2 \mathrm{H}), 3.43(\mathrm{~s}, 2 \mathrm{H}), 2.97-2.85(\mathrm{~m}, 2 \mathrm{H}), 2.39-2.22(\mathrm{~m}, 1 \mathrm{H})$, 2.10-1.97 (m, 2H), 1.75-1.56 (m, 4H); ${ }^{13} \mathrm{C} \mathrm{NMR}\left(\mathrm{CDCl}_{3}, 300 \mathrm{MHz}\right): \delta 191.9,159.0,152.0,147.8$, $146.8,140.3,136.3,135.5,132.3,127.2,122.4,118.2$, 110.4, 109.8, 109.4, 108.0, 101.1, 63.3, 56.0, $53.1,37.4,31.3,29.9$. 


\section{HRMS Spectra}

\section{Sample 13a/13b}
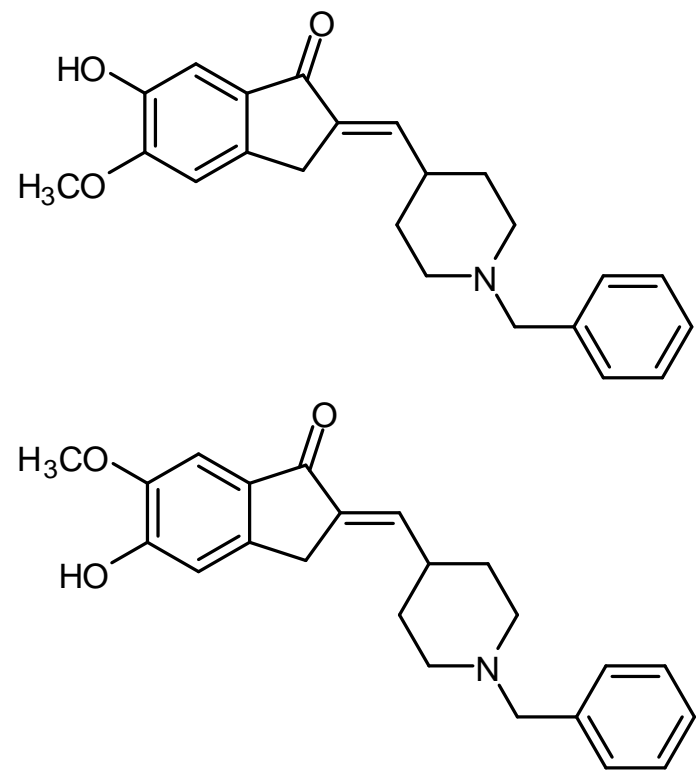

DEMG3MIX10ppmtris3MSMS \#1599-1910 RT: 7.85-9.34 AV: 156 SB: 25 0.53-0.62, 0.90-1.06 NL: $1.42 E 6$
F: FTMS + p ESIFullms2 $364.19 @$ hcd30.00 [50.00-390.00] F: FTMS + p ESI Full ms2 364.19@hcd30.00 [50.00-390.00]

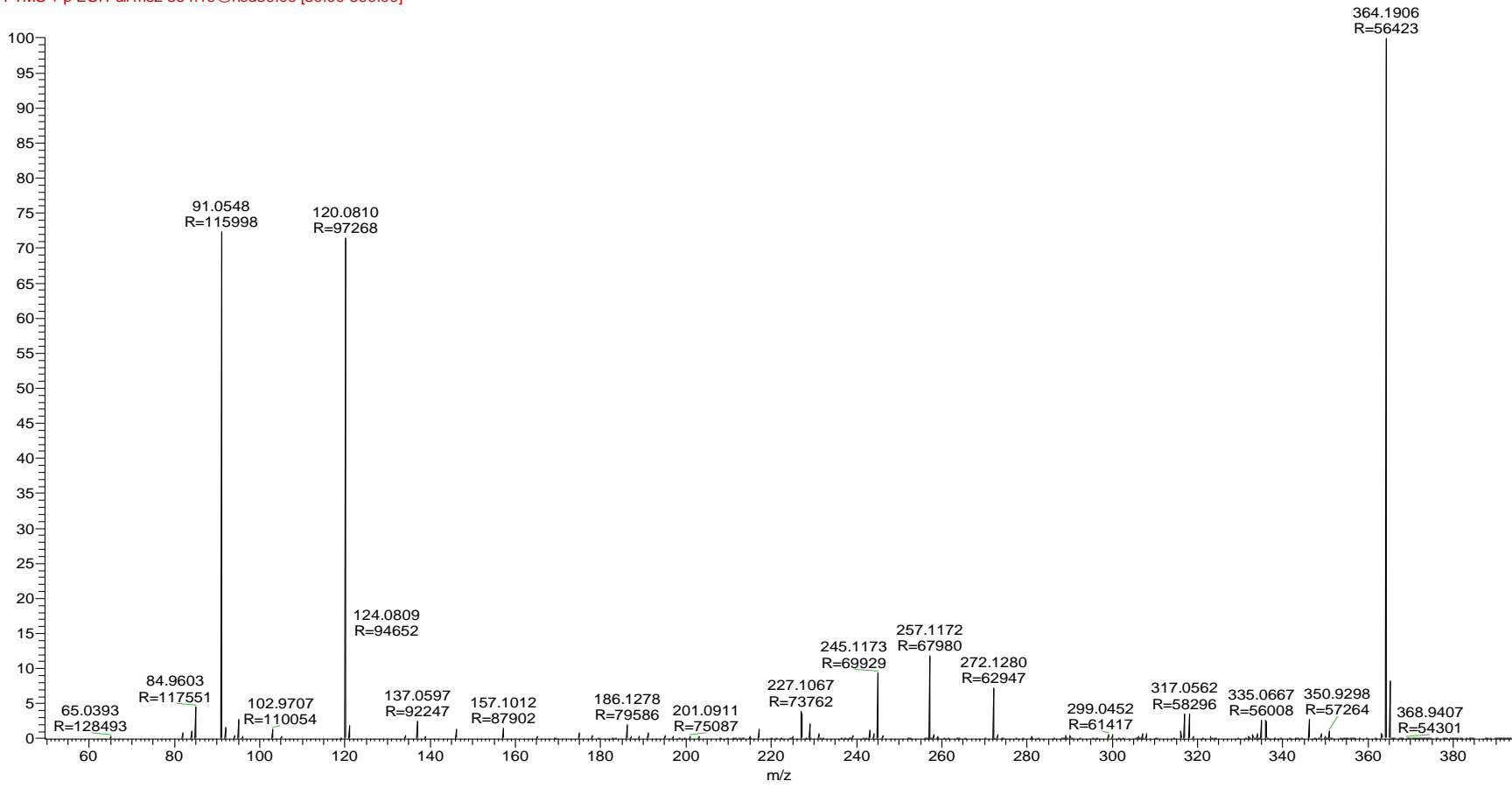




\section{Sample 14}

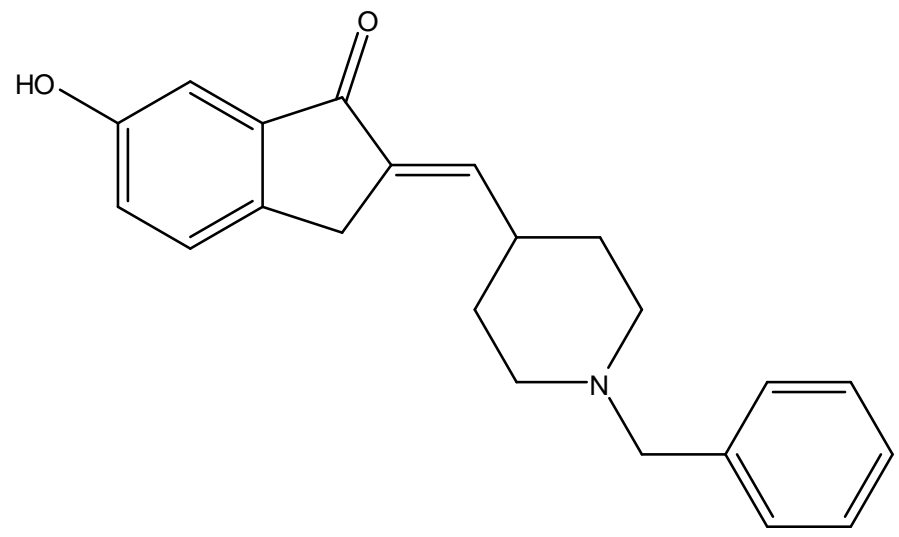

DEMG5_100ppm \#2720 RT: 8.66 AV: 1 SB: 39 0.53-0.62, 0.90-1.06 NL: 9.35E8 F: FTMS + p ESI Full ms2 334.00@hcd30.00 [50.00-360.00]

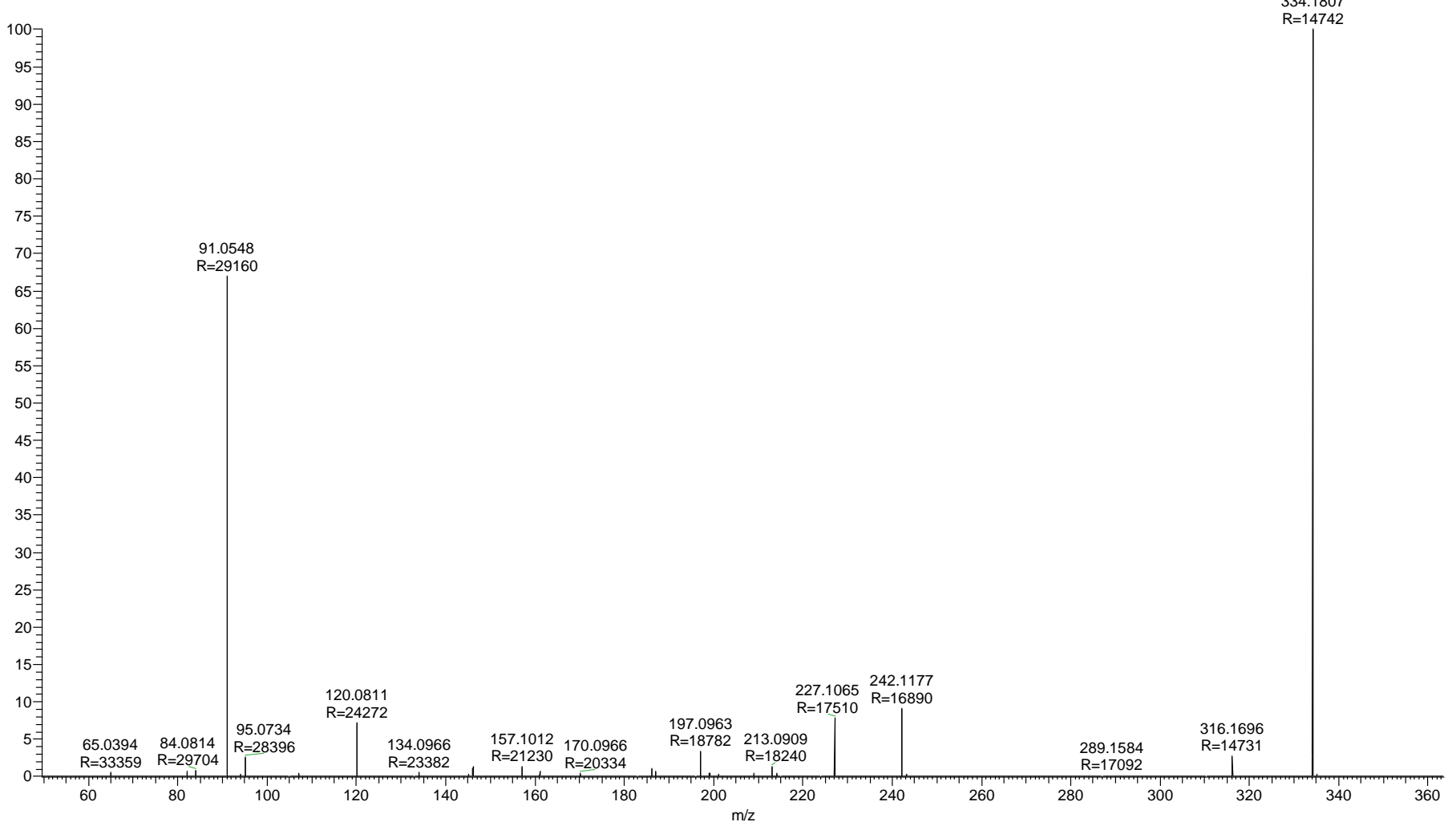




\section{Sample 15}

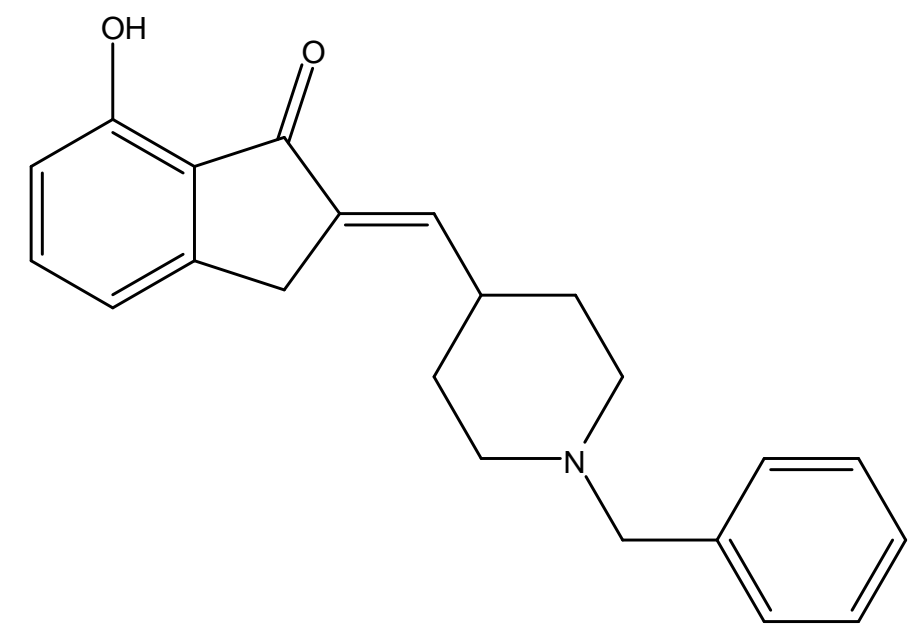

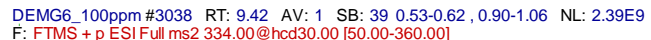

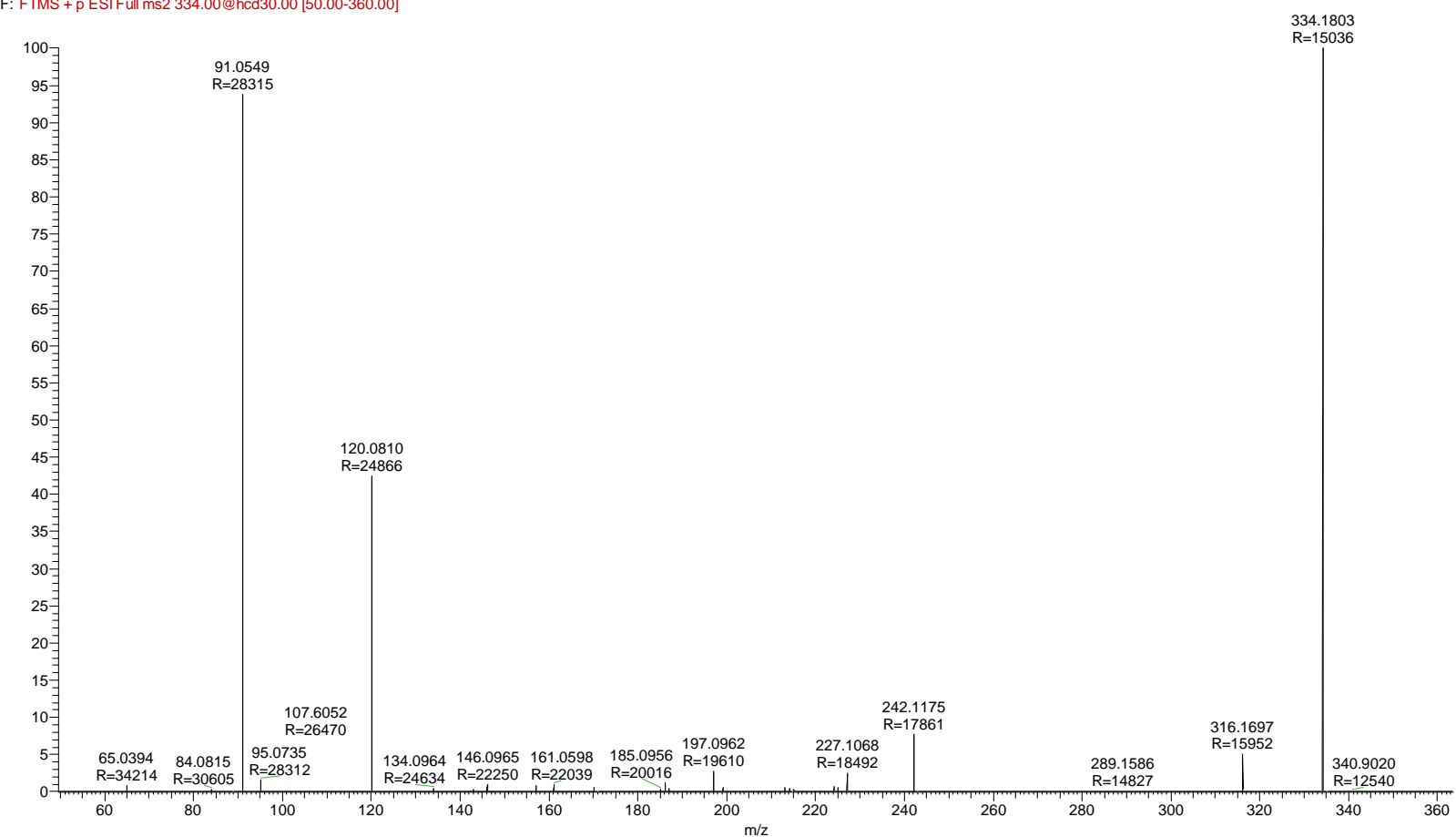


Sample 16

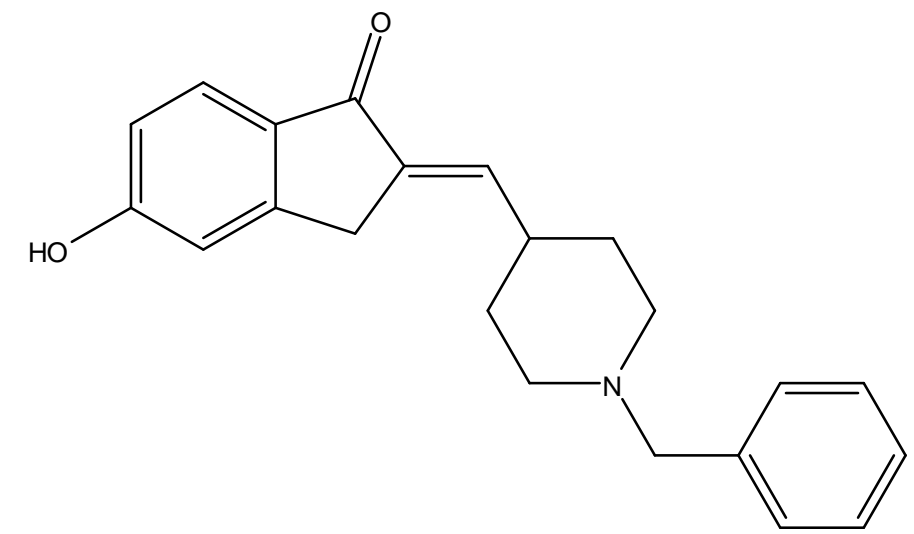

DEMG_BIS_14-04-2015\#1027 RT: 4.58 AV: 1 SB: 57 0.53-0.62, 0.90-1.05 NL: 5.66E9

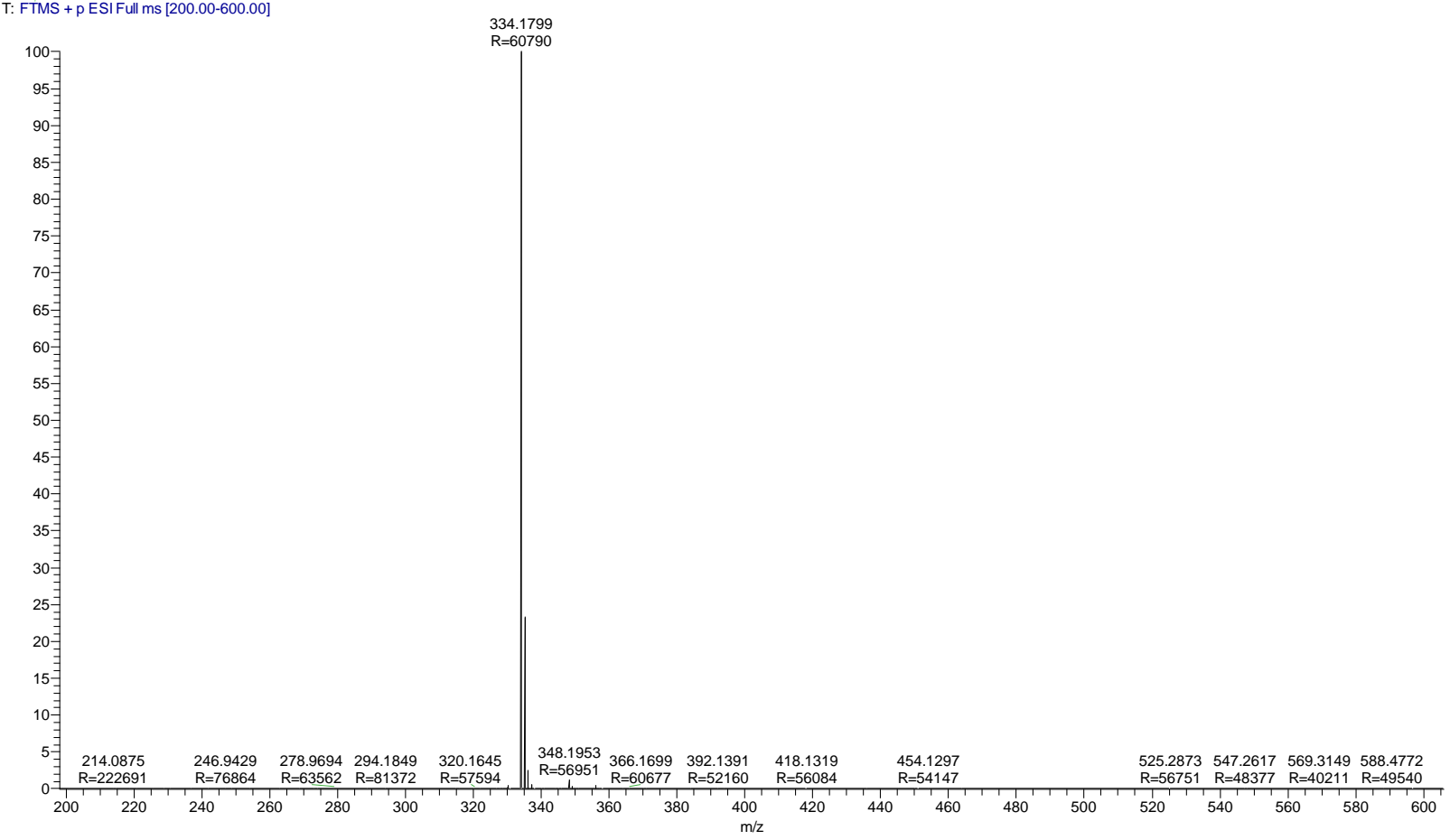




\section{Sample 17}
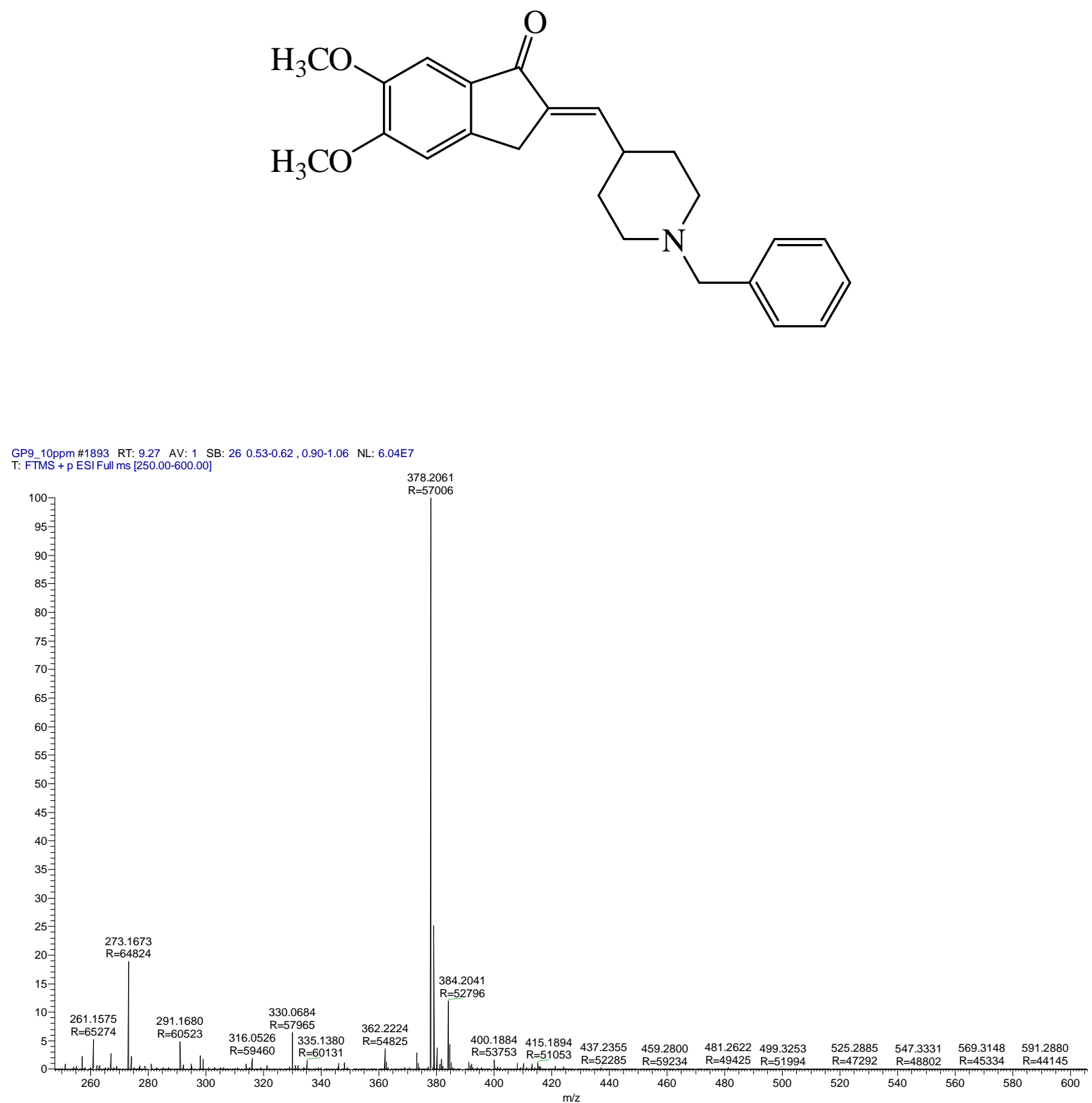


\section{Sample 18}

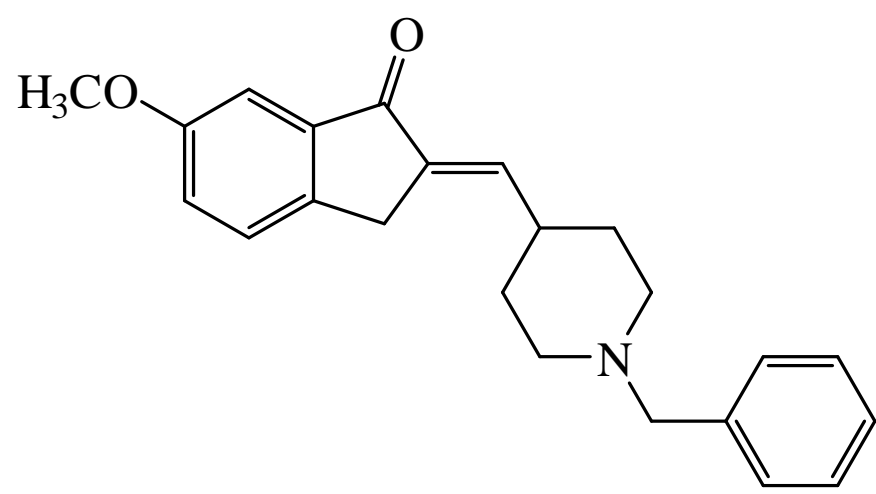

GP11 4ppm \#622 RT: 4.68 AV: 1 SB: 17 0.54-0.62, 0.90-1.06 NL: 2.51E7 T: FTM $S$ + p ESI Full ms [140.00-900.00]

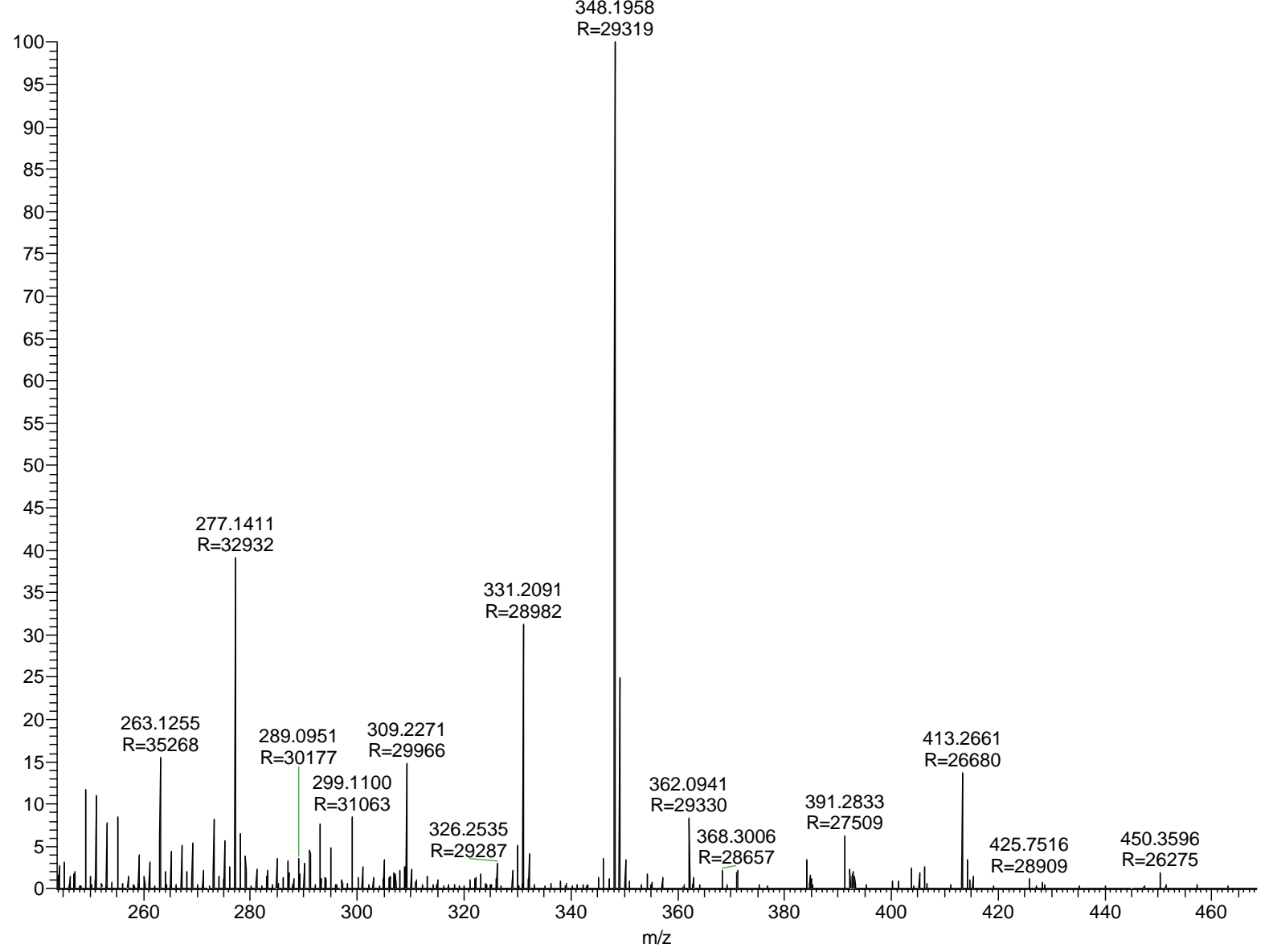




\section{Sample 19}

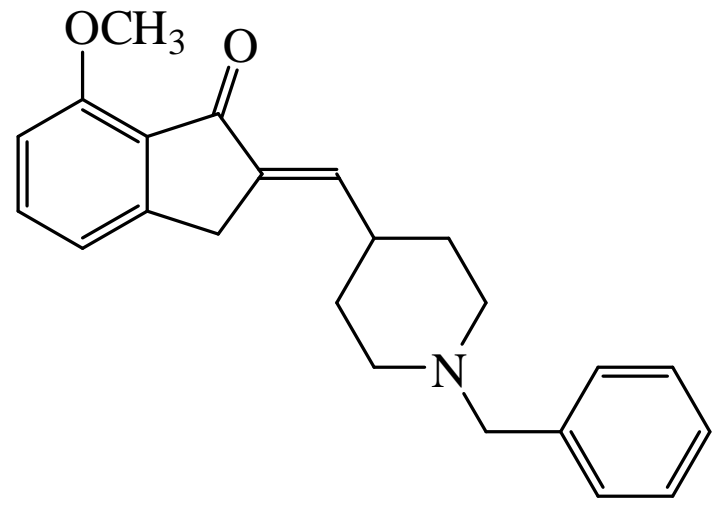

GP12 4ppm \#624 RT: 4.70 AV: 1 SB: 17 0.54-0.62, 0.90-1.06 NL: 2.36E7

T: FTMS + p ESI Full ms [140.00-900.00]

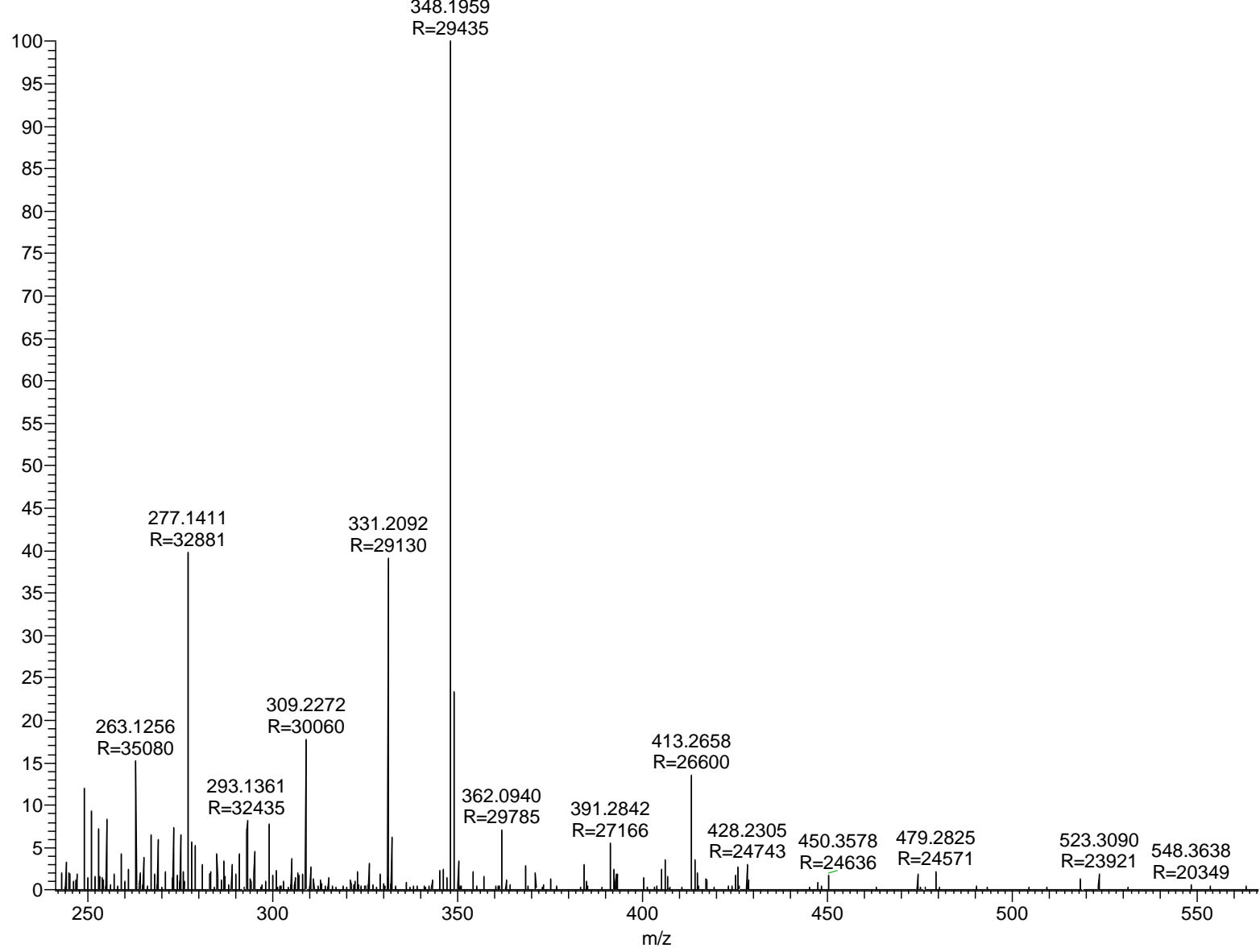




\section{Sample 20}

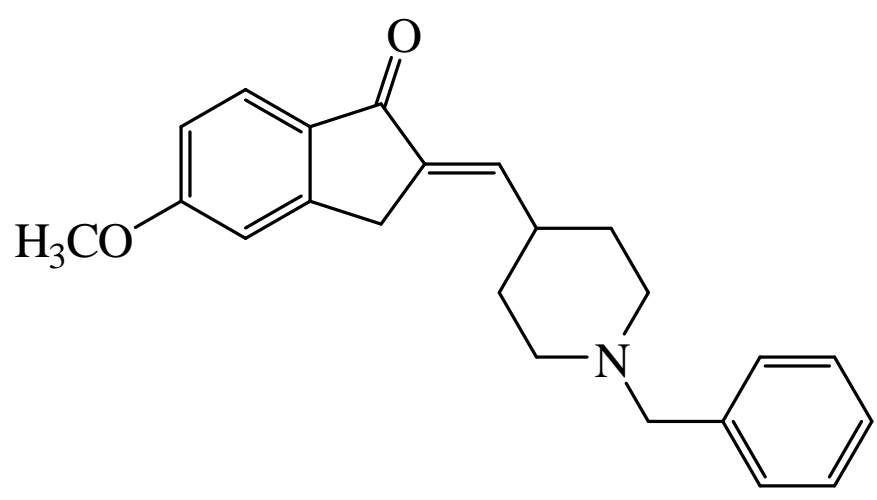

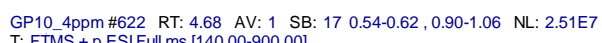

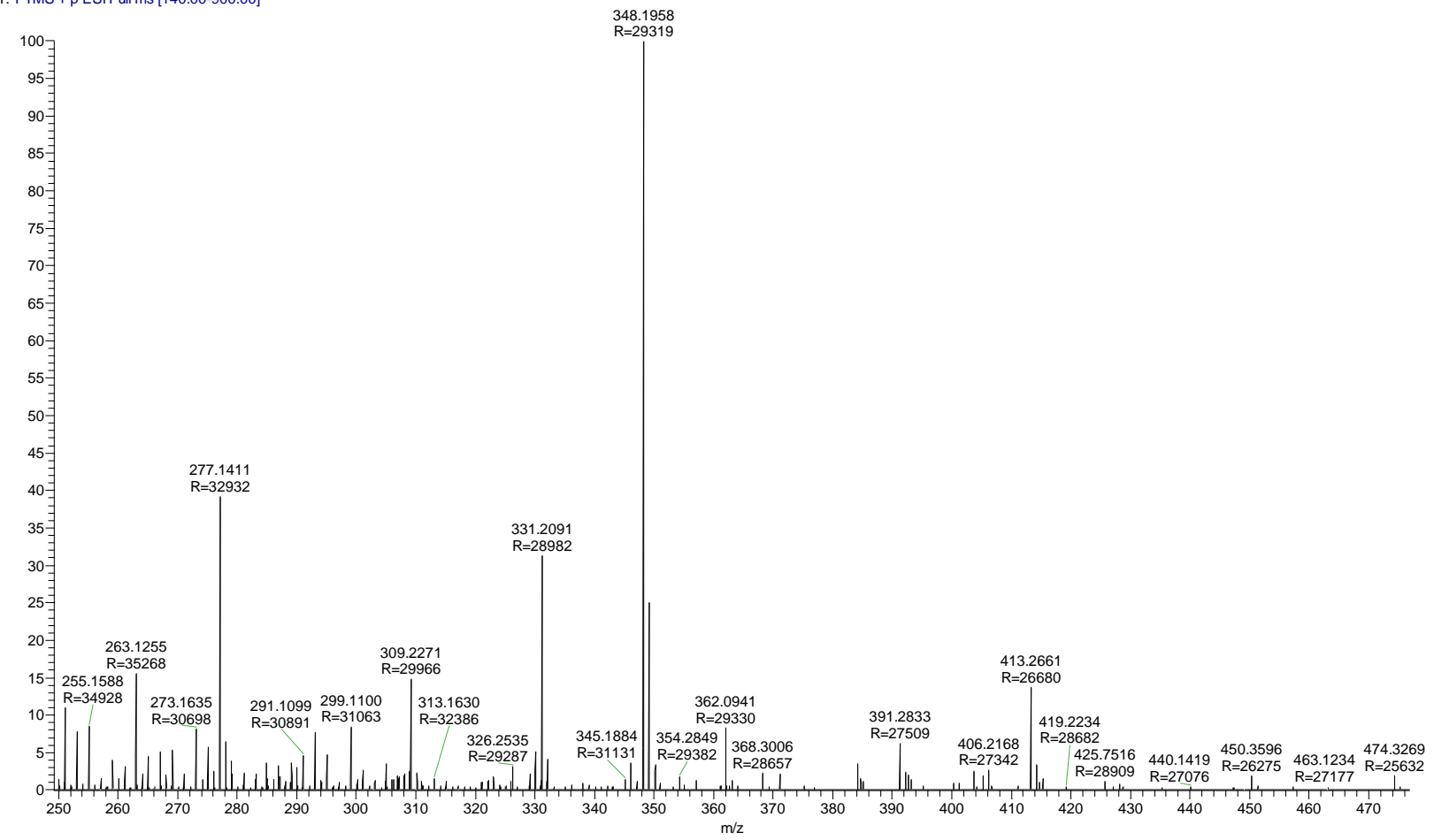




\section{Sample 21}

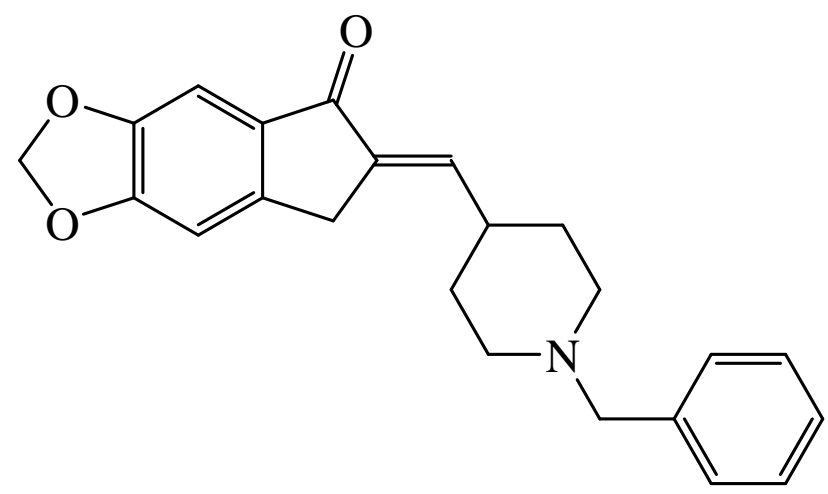

GP17_1ppm \#634 RT: 4.75 AV: 1 SB: 17 0.53-0.62, 0.90-1.06 NL: 8.42E8 T: FTMS + p ESI Full ms [140.00-900.00] 362.1752
$R=27571$

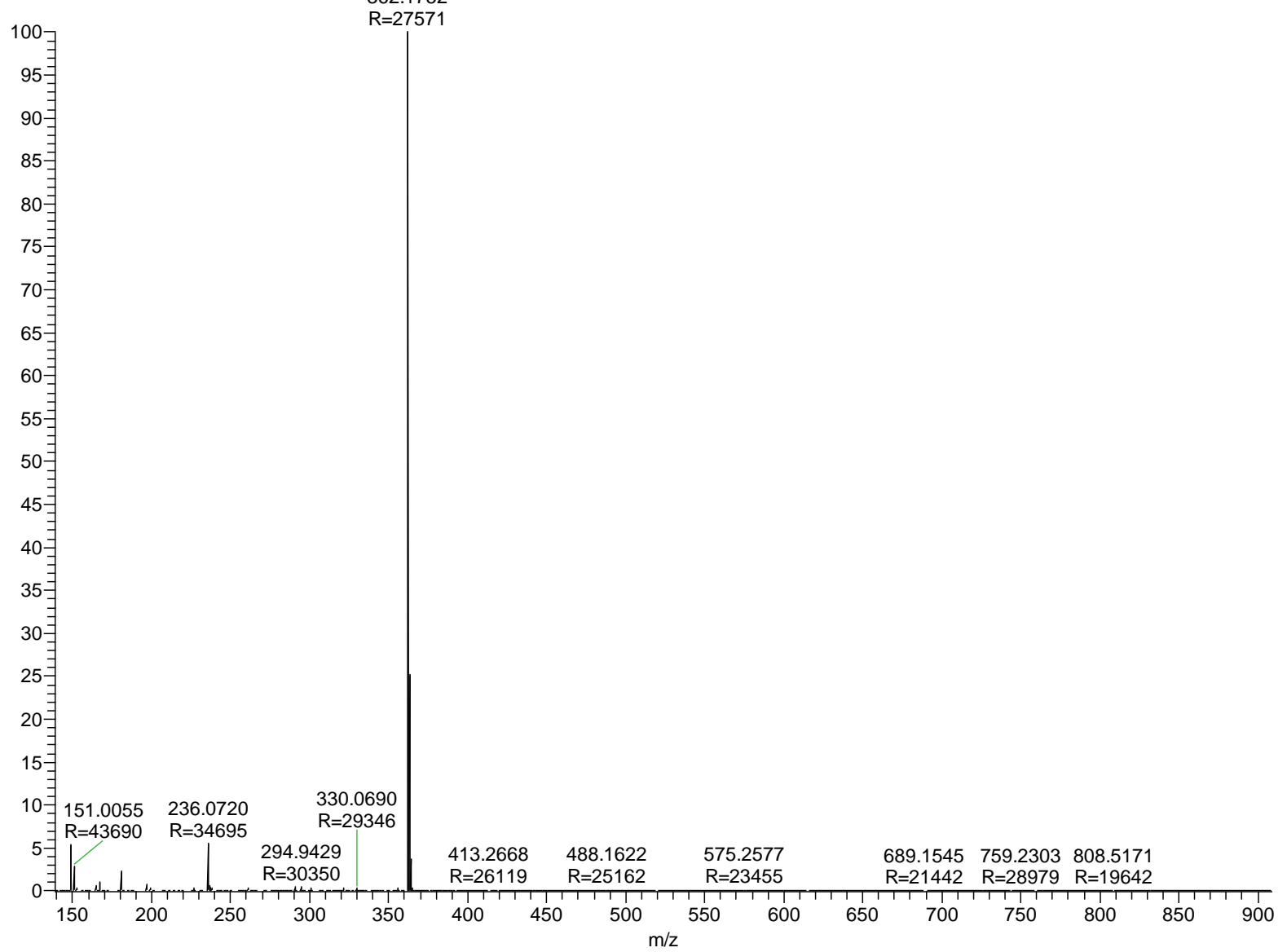




\section{Sample 22}
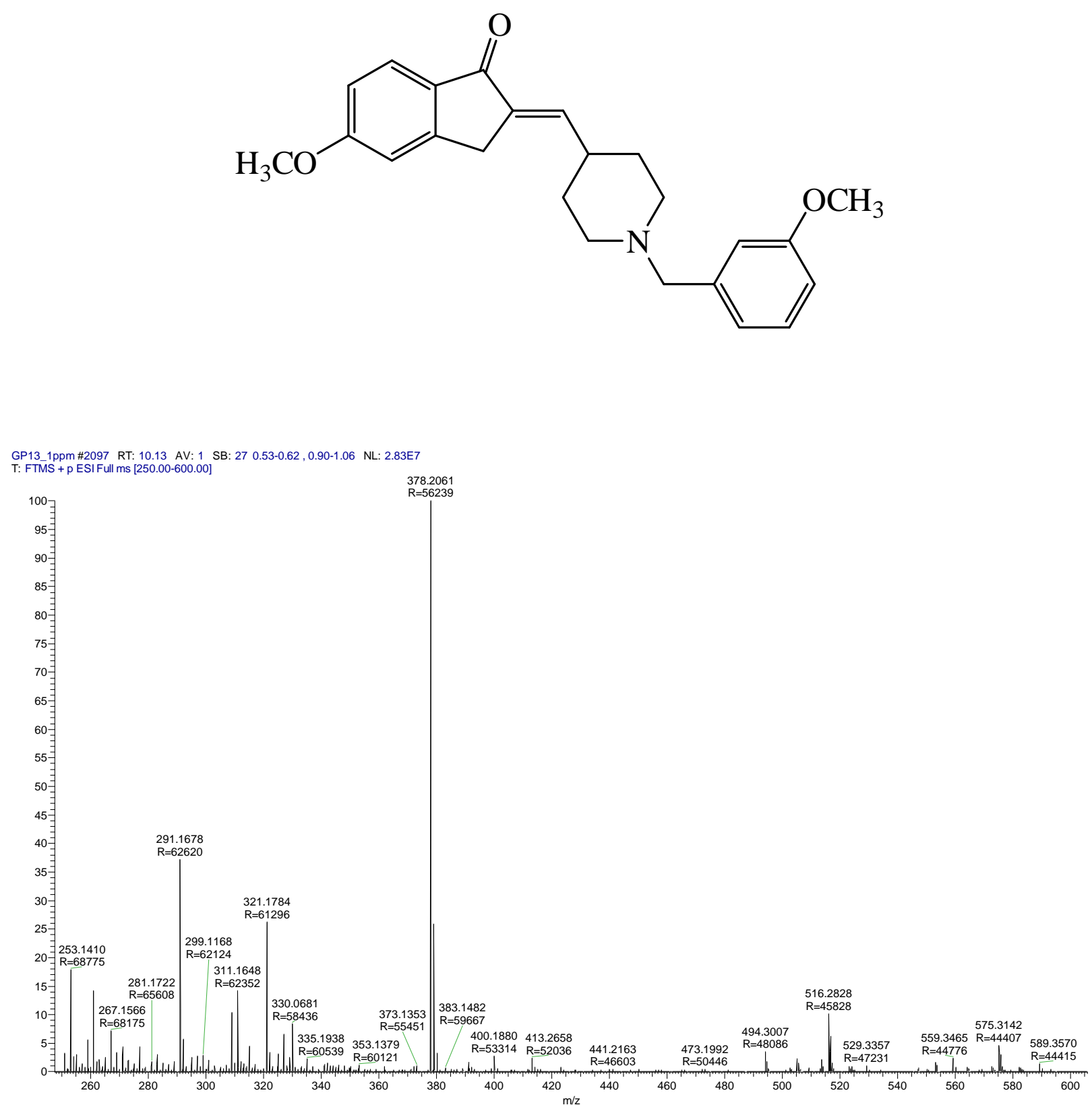


\section{Sample 23}

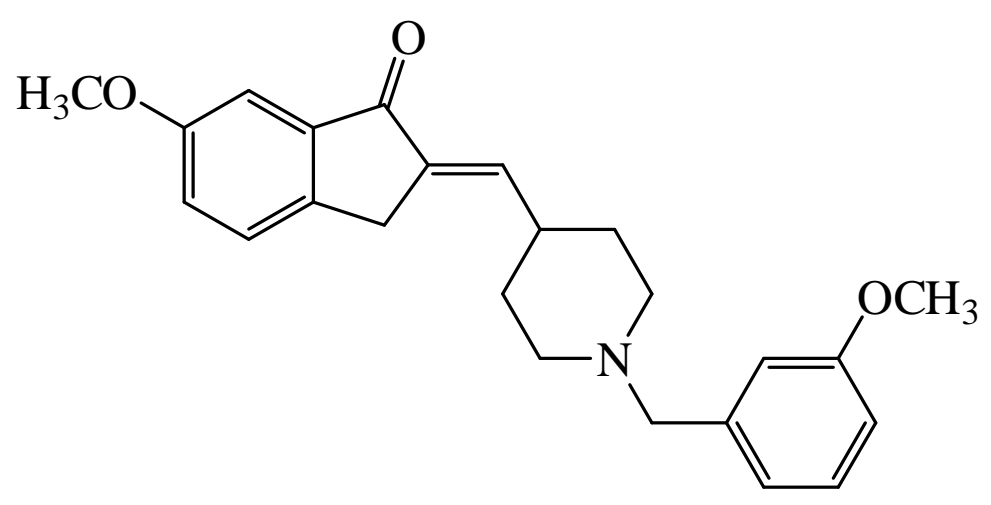

GP15_1ppm \#2093 RT: 10.11 AV: 1 SB: 27 0.53-0.62, 0.90-1.06 NL: $2.29 E 7$

T: FTM $\mathrm{M}+\mathrm{p}$ ESI Full ms [250.00-600.00]

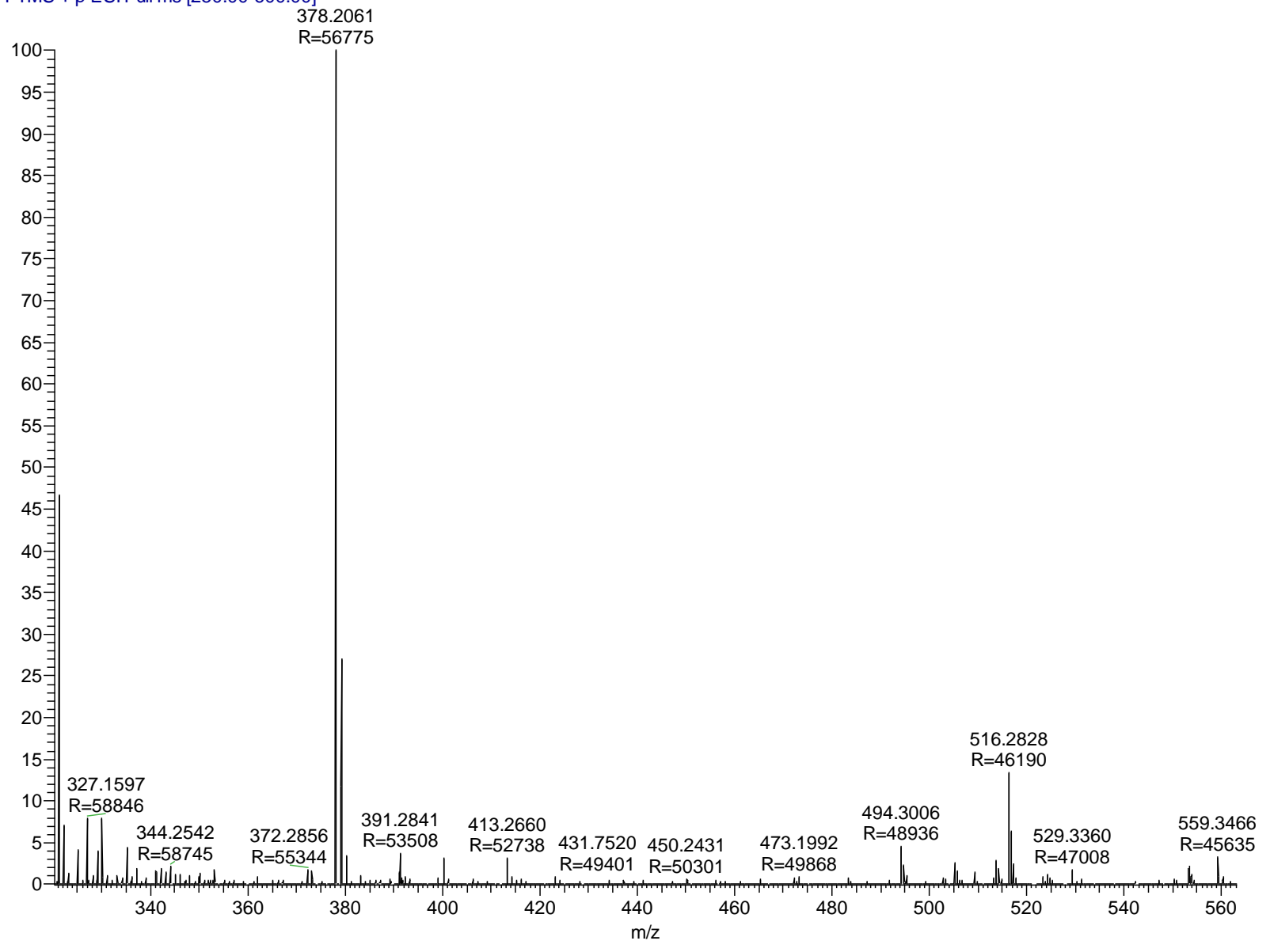




\section{Sample 24}

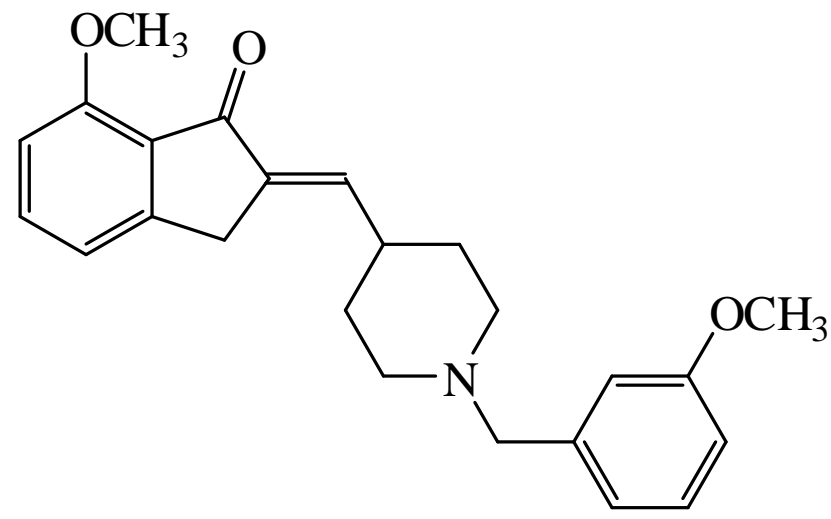

GP16 6ppm \#668 RT: $5.04 \quad$ AV: 1 SB: 17 0.54-0.62, 0.90-1.06 NL: 2.80E7

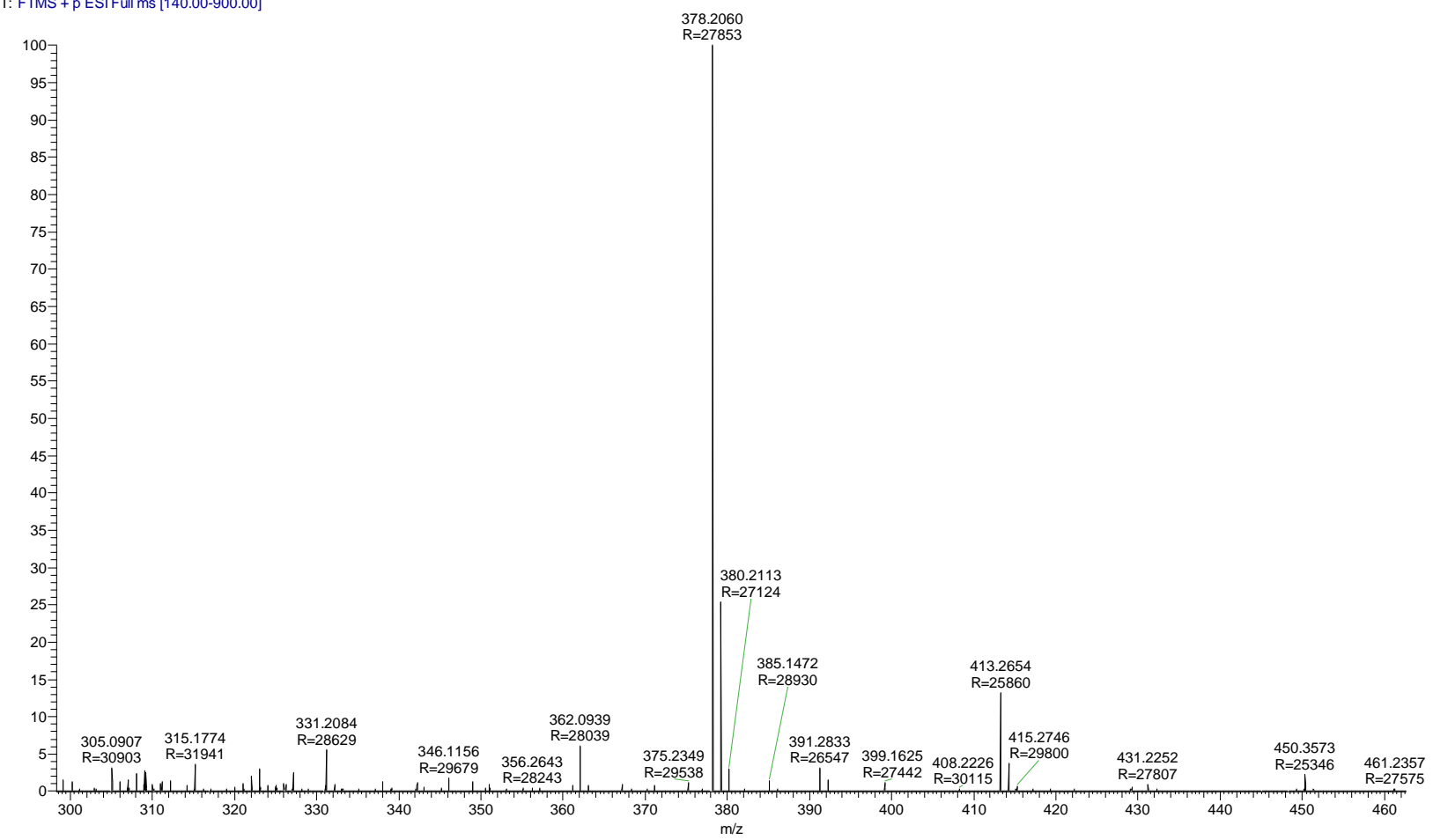




\section{Sample 25}
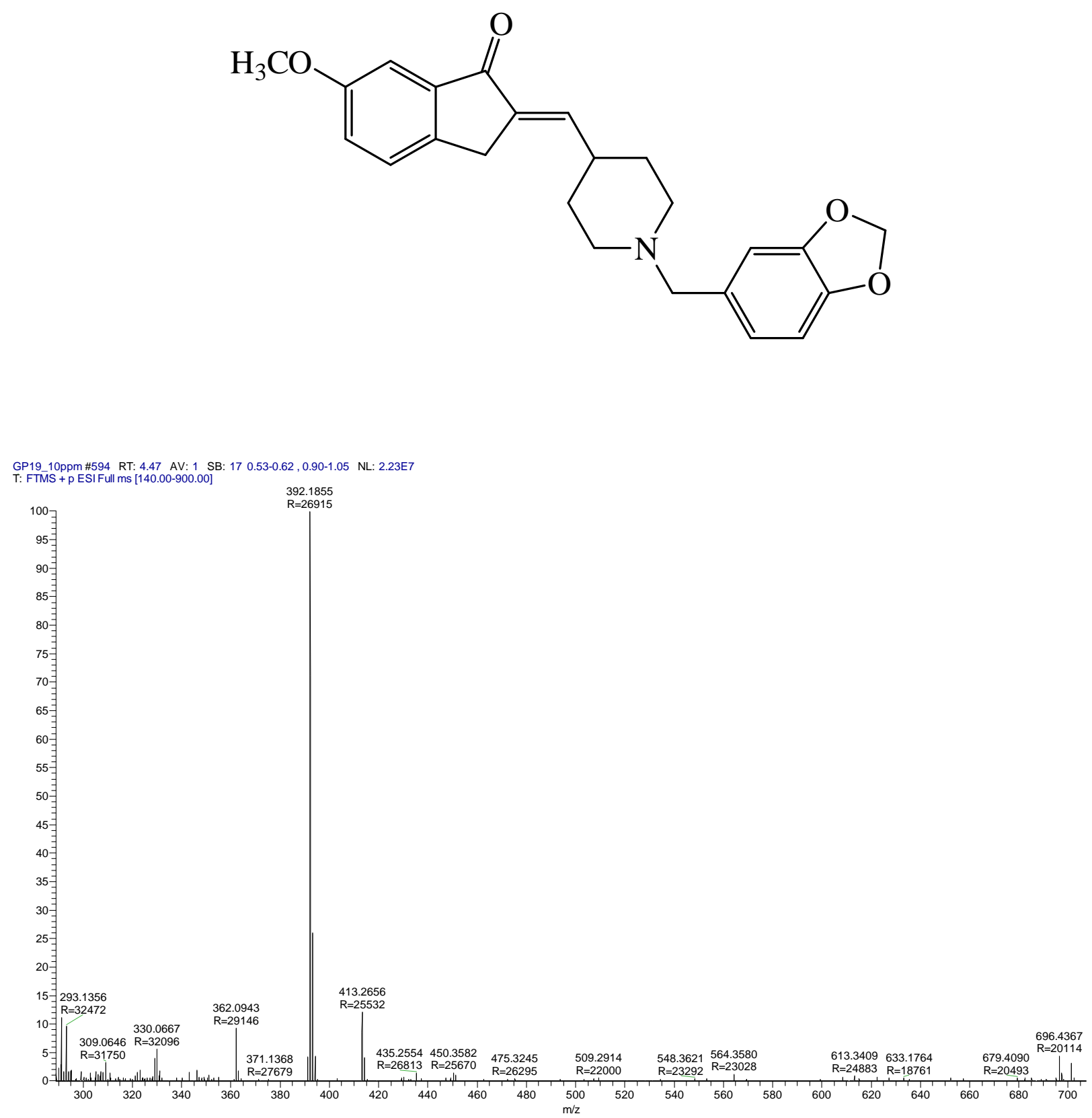


\section{Sample 26}
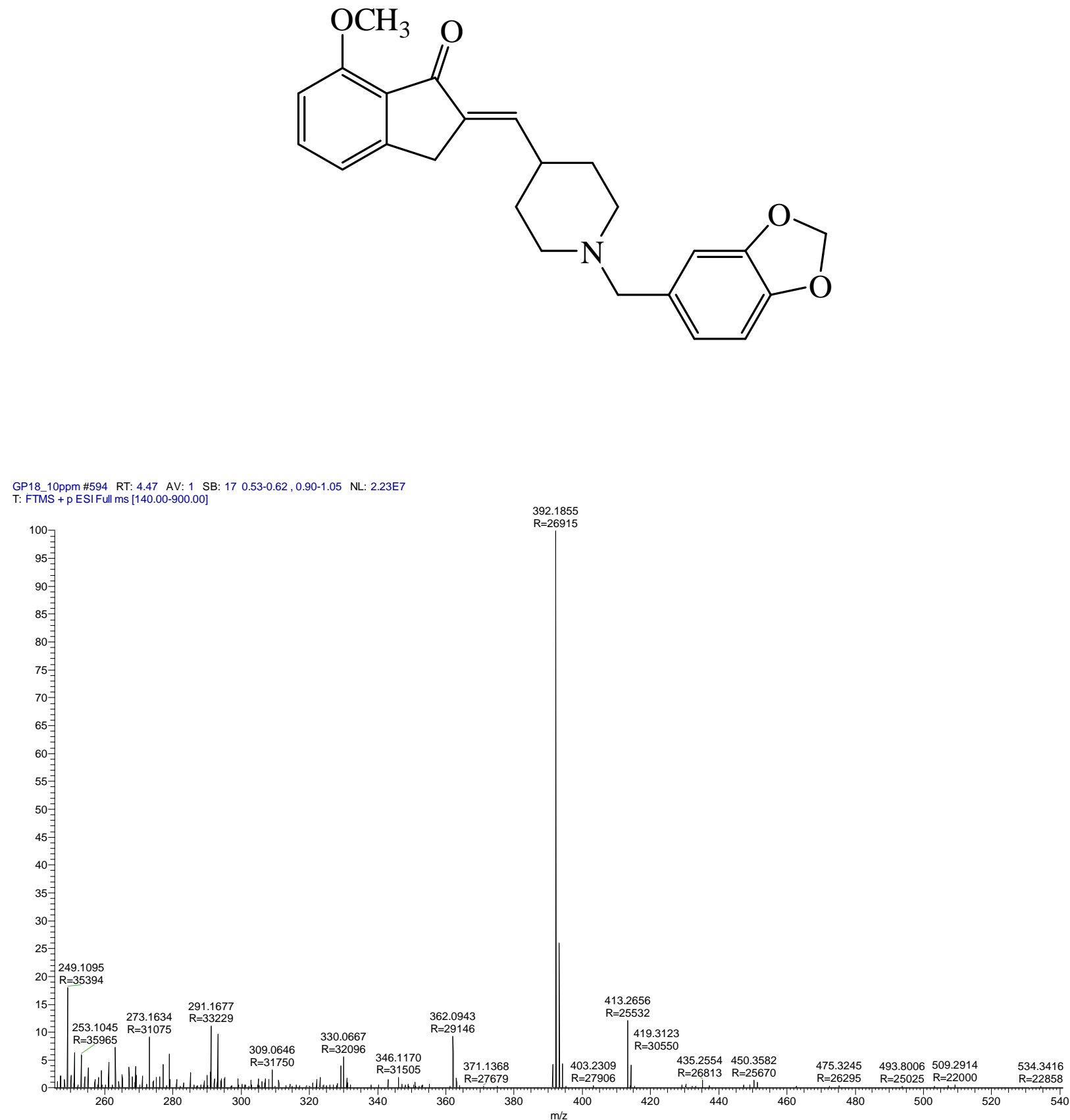


\section{${ }^{1}$ H-NMR Spectra}

\section{Sample 13a/13b}
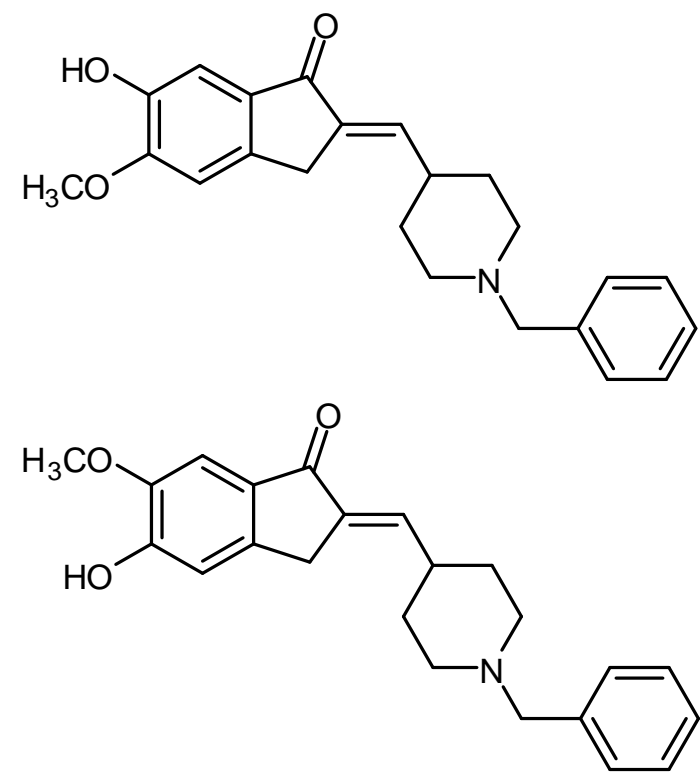

NAME

demg 3

EXPNO

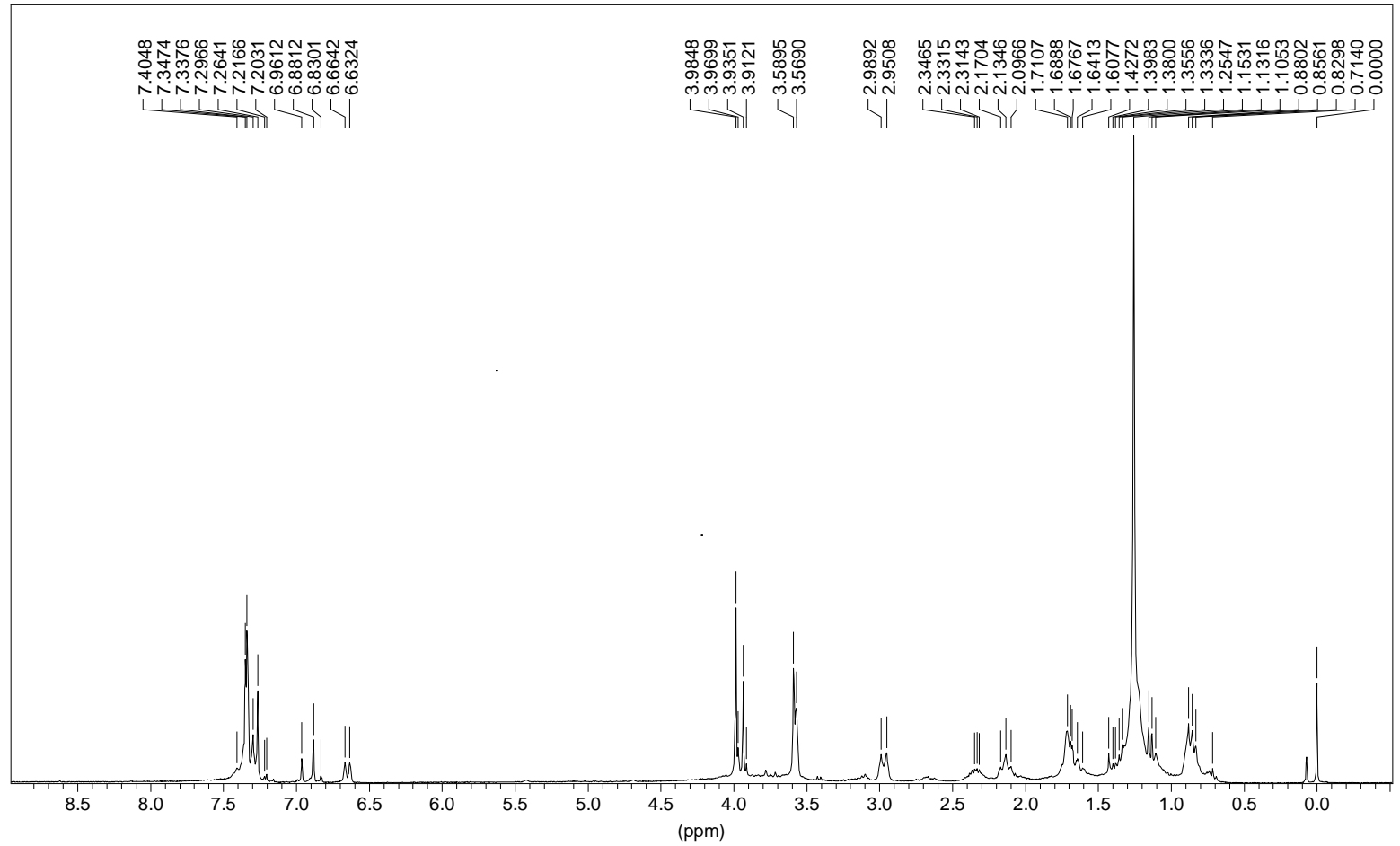




\section{Sample 14}

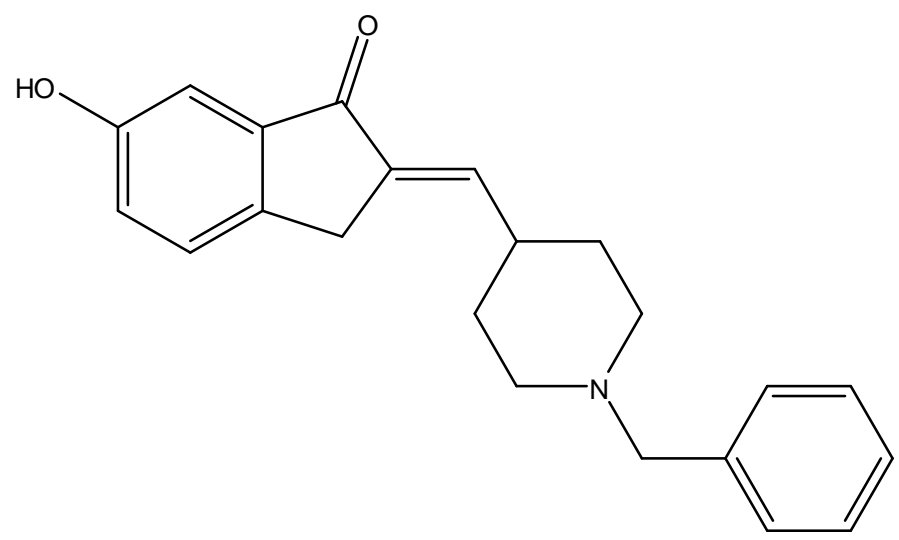

*** Current Data Parameters

NAME : dmemg7

EXPNO : 1

PROCNO

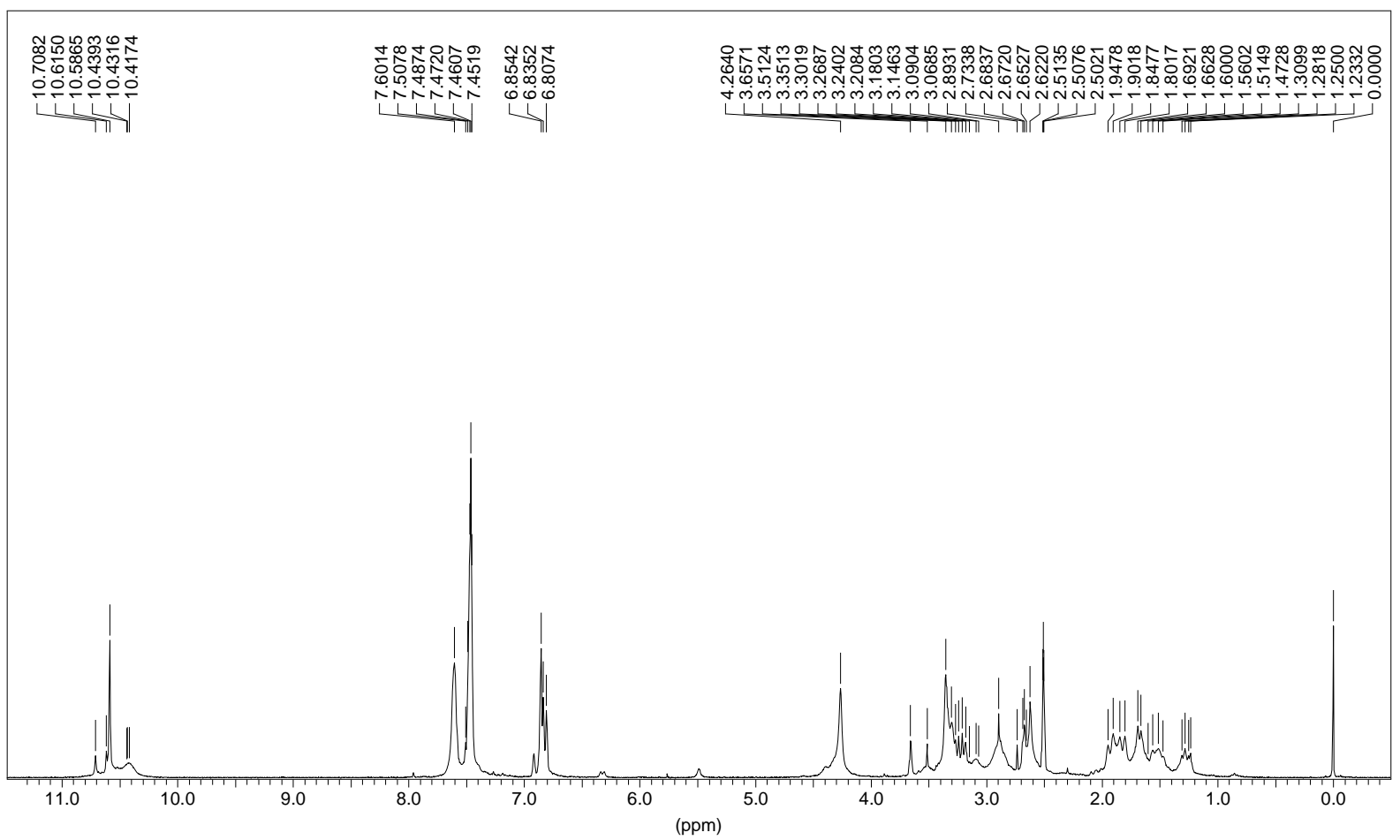




\section{Sample 15}
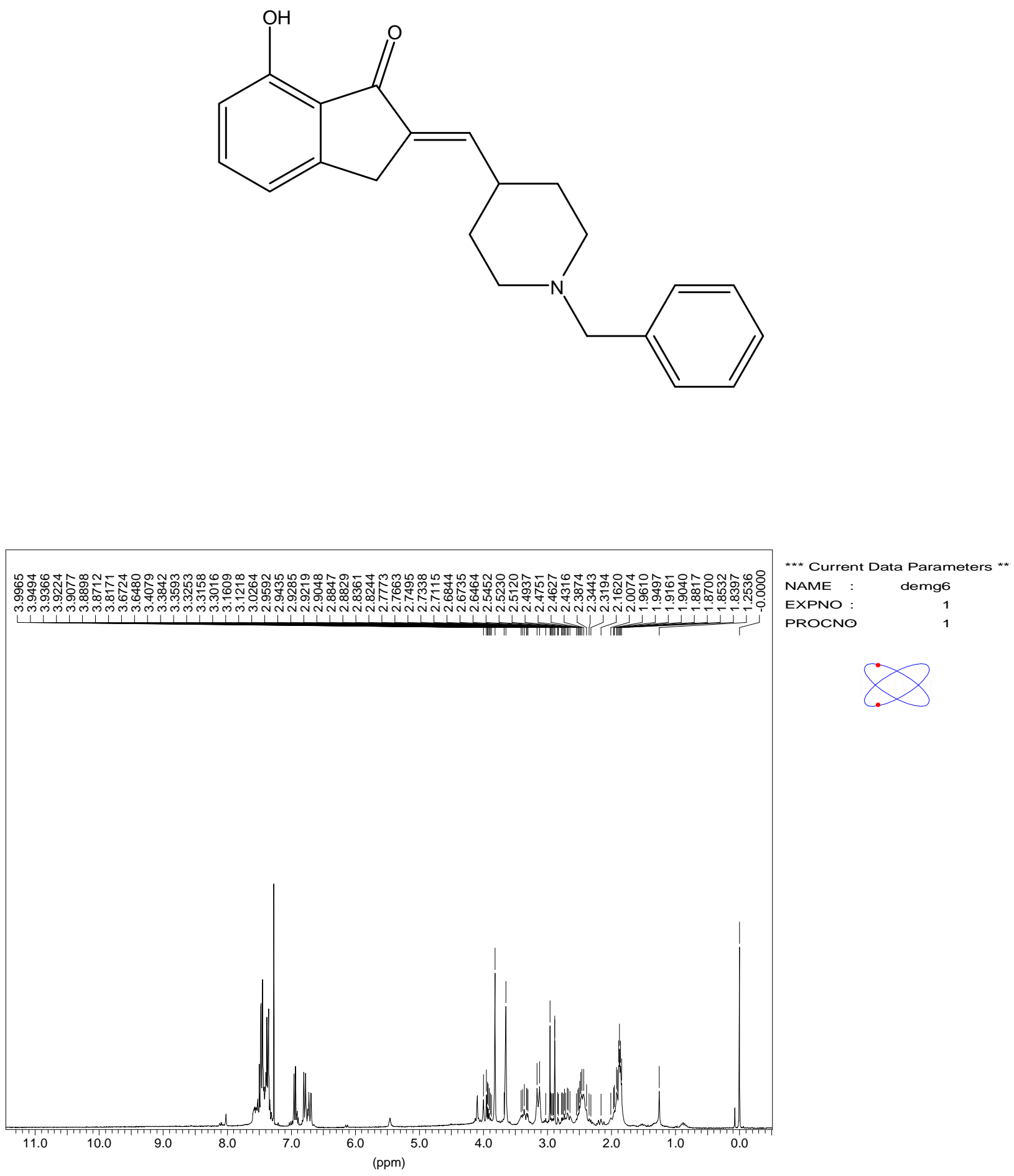


\section{Sample 16}
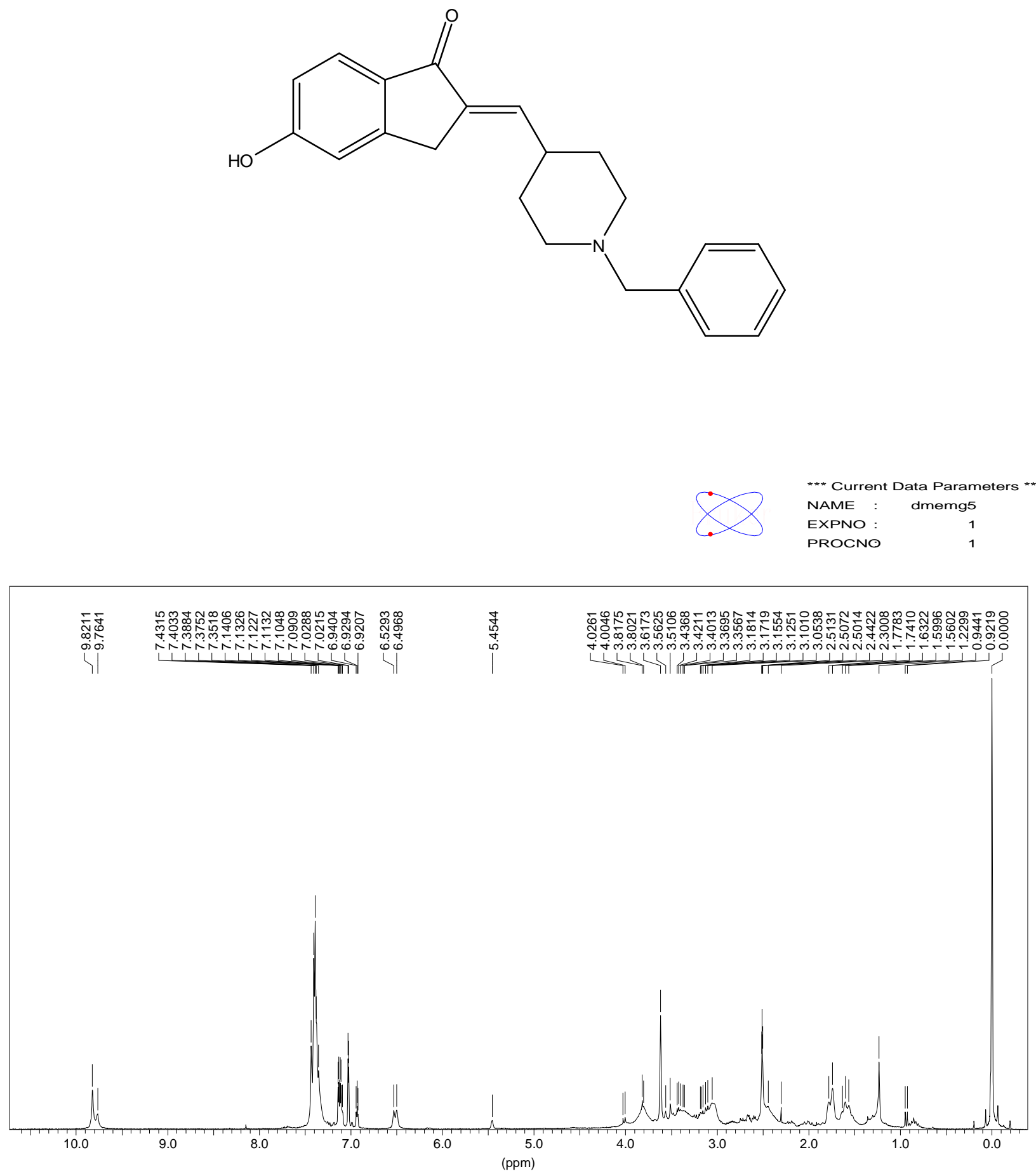


\section{Sample 17}
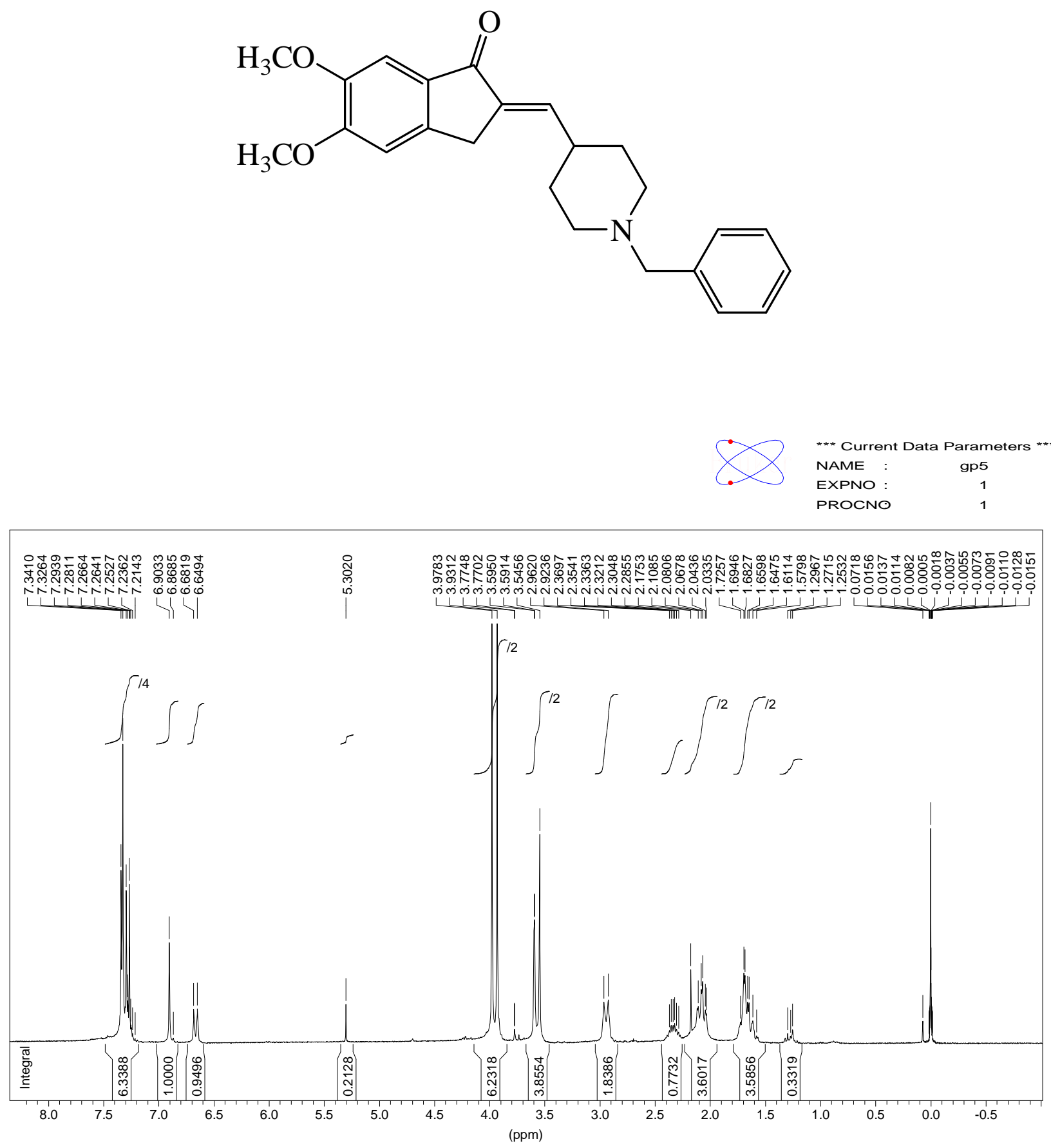


\section{Sample18}
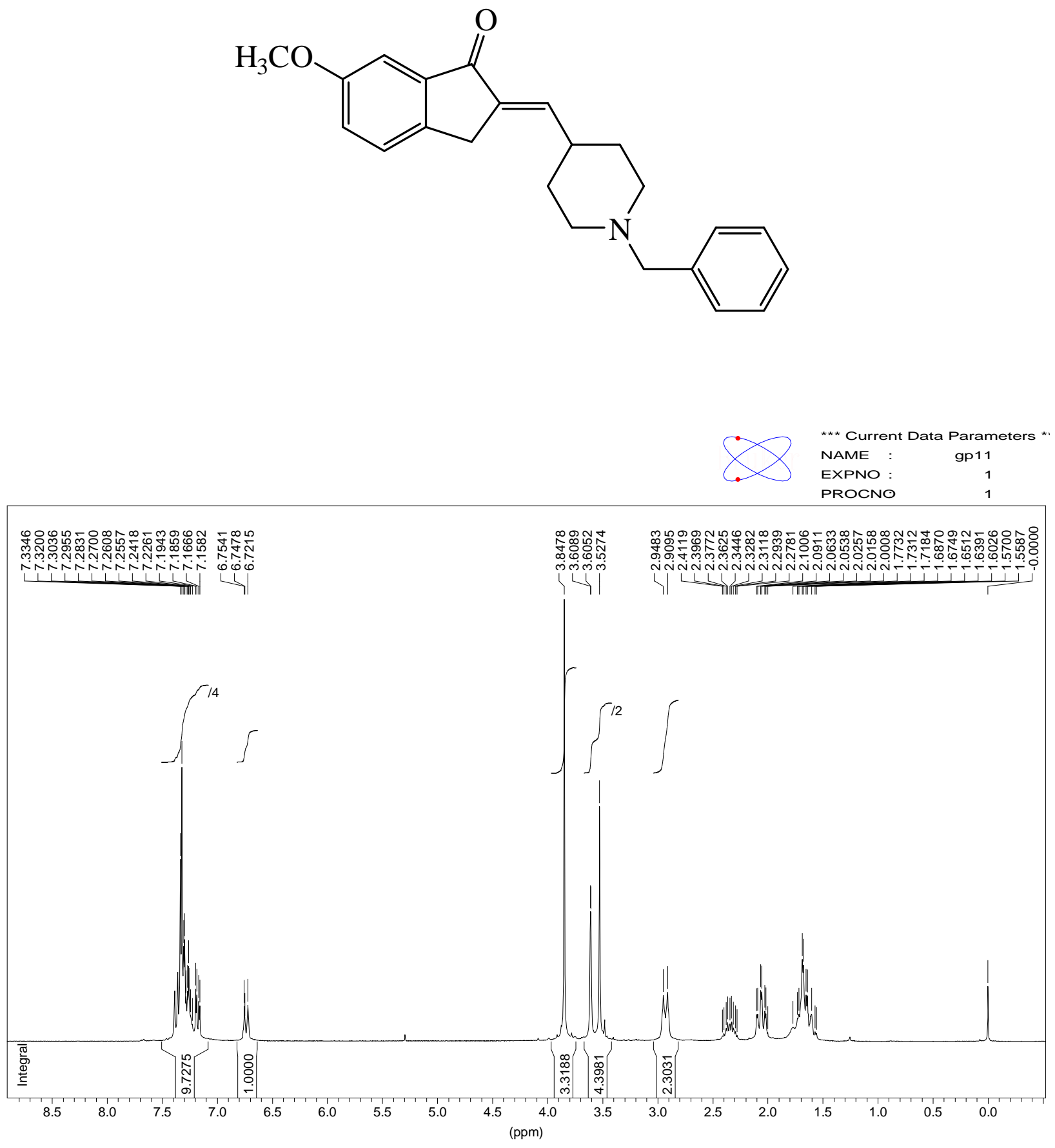


\section{Sample19}
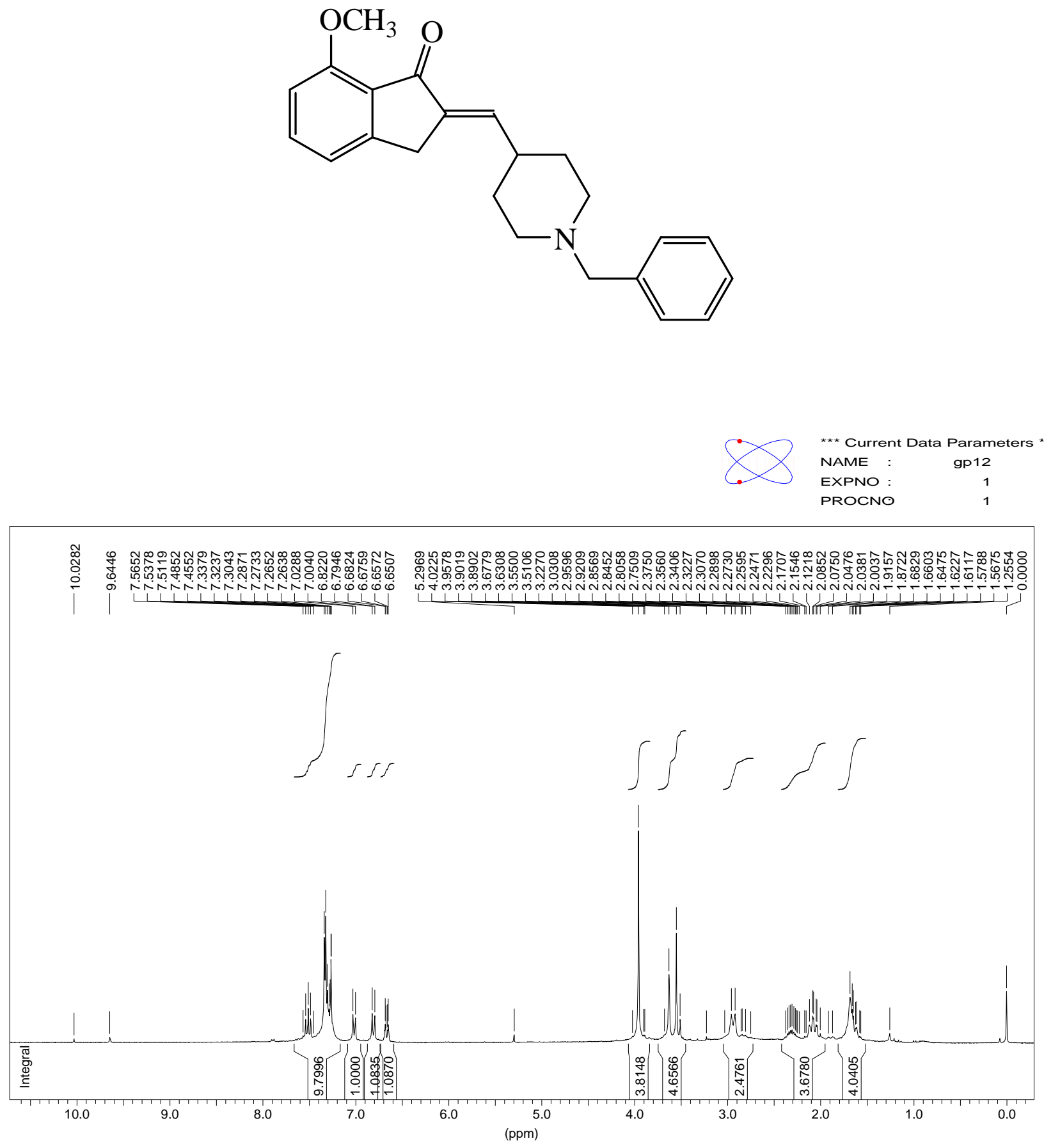


\section{Sample 20}
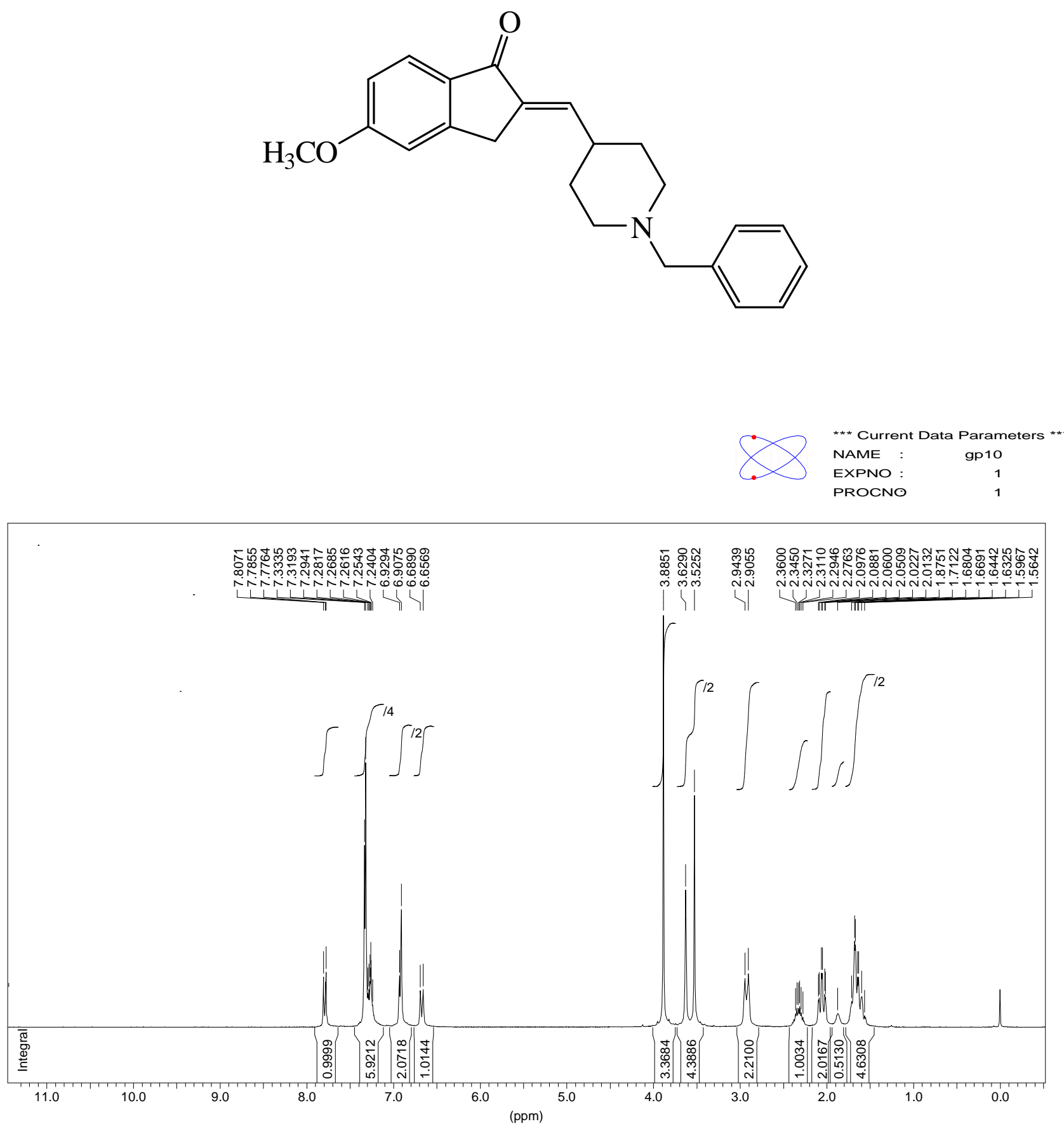


\section{Sample21}

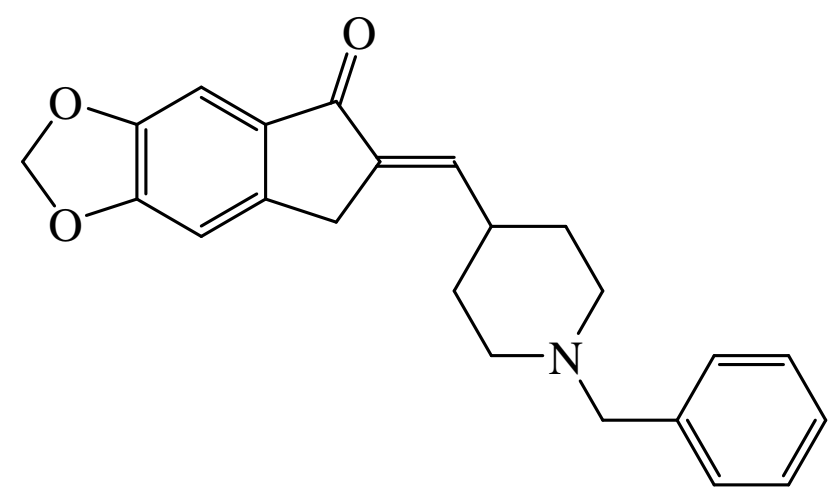

*** Current Data Parameters *

NAME : $\quad 9017$

$\begin{array}{lll}\text { EXENO : } & 1 \\ \text { PROCNO : } & 1\end{array}$

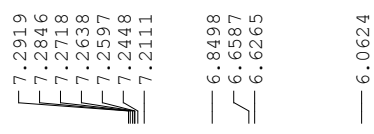

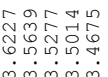

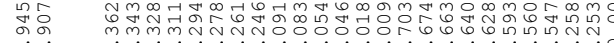

mM
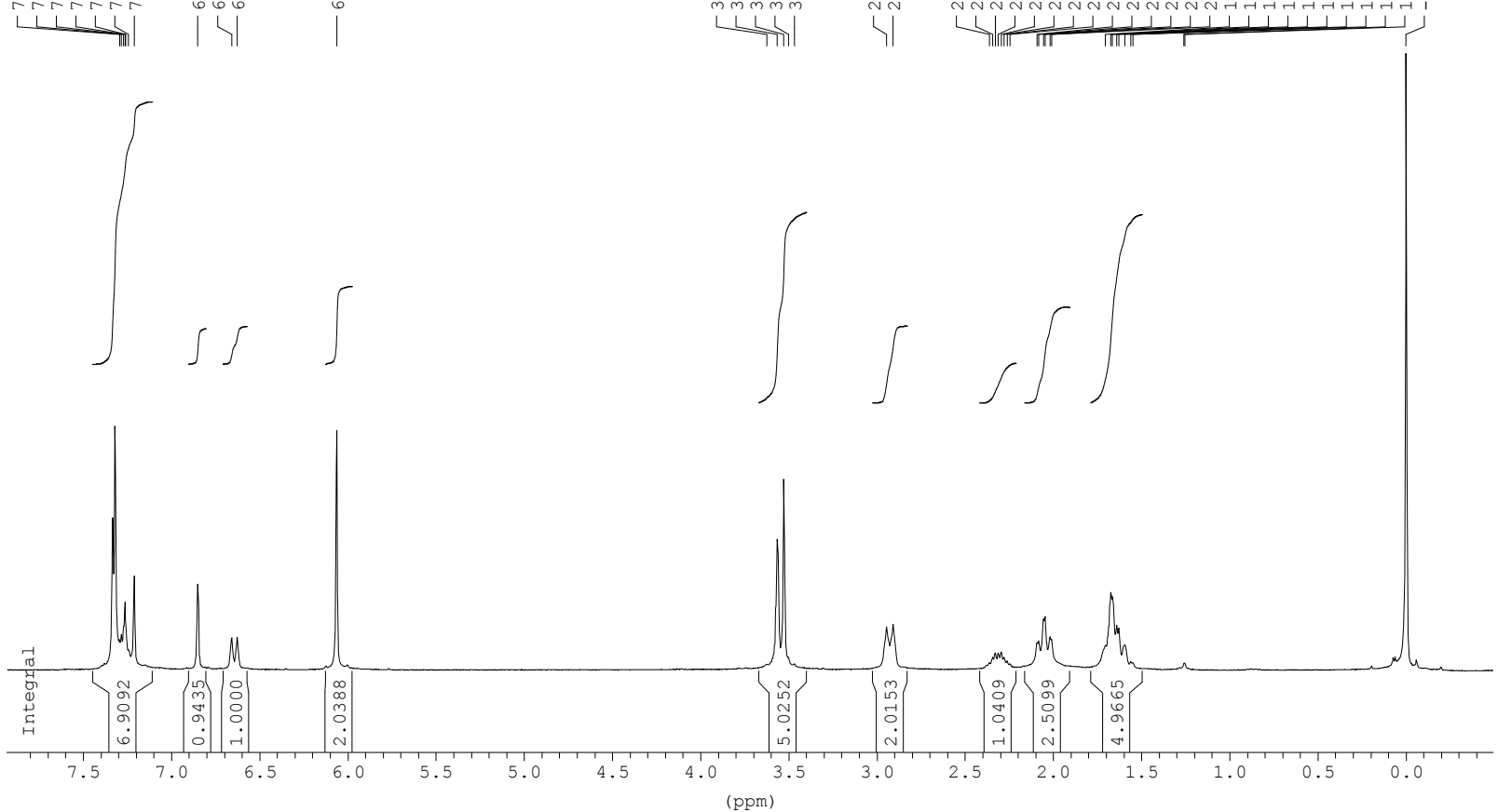


\section{Sample22}

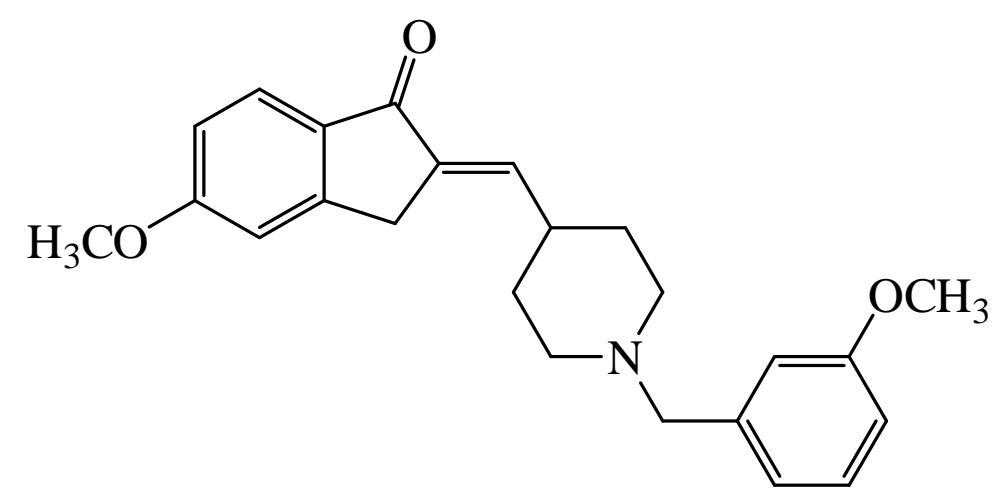

*** Current Data Parameters *

NAM

NAME : $\quad 9 p 14$

PROCNO : 1
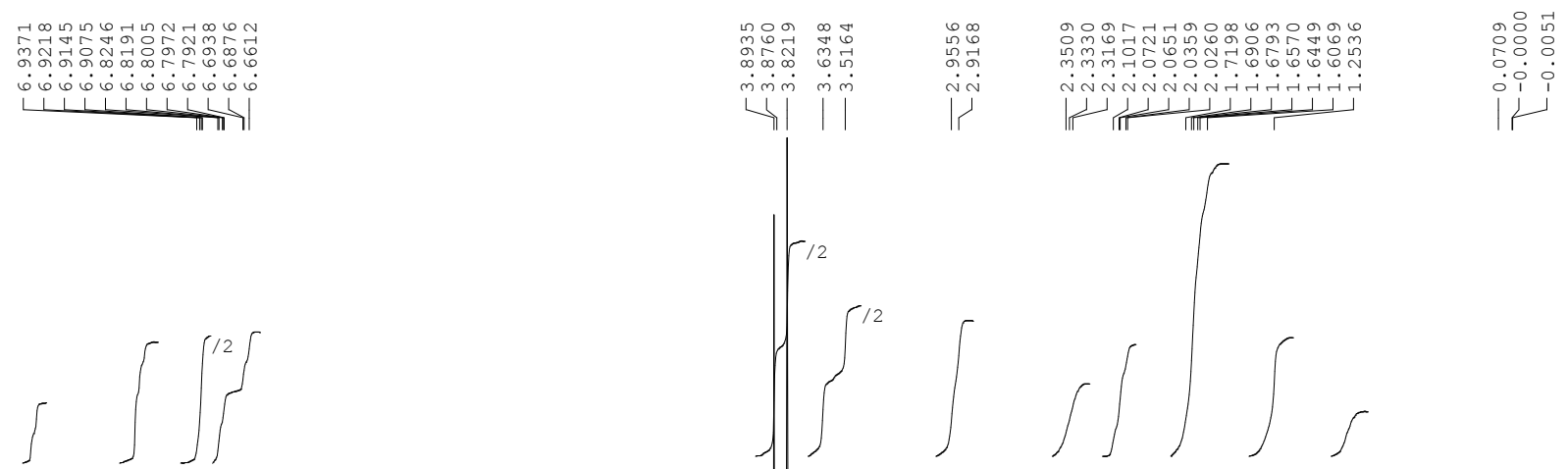

$\begin{array}{ll} & 0 \\ 0 & 0 \\ 0 & 0 \\ 0 & 0 \\ 0 & 1 \\ 1 & 1\end{array}$

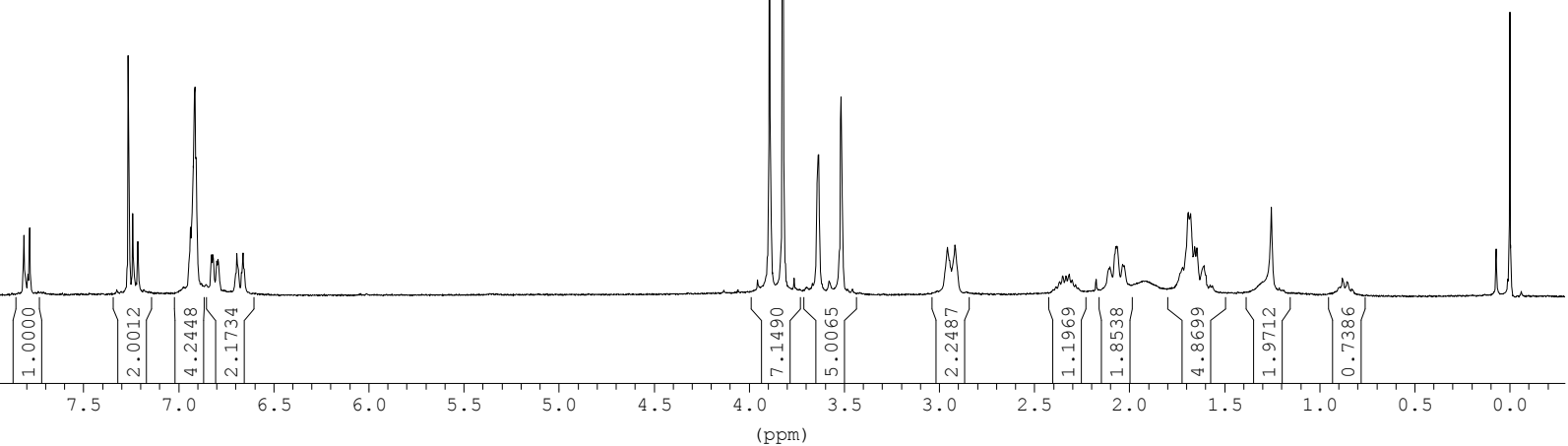




\section{Sample23}

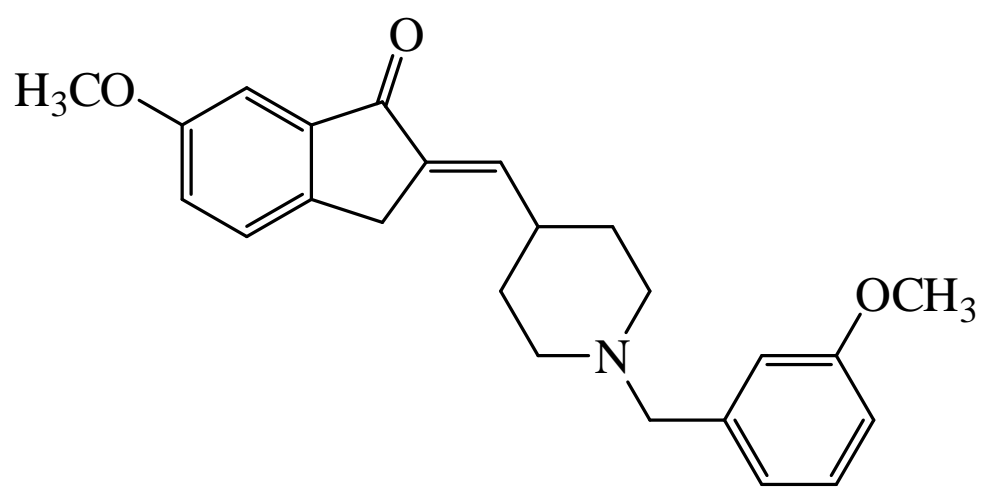

*** Current Data Parameters *

:

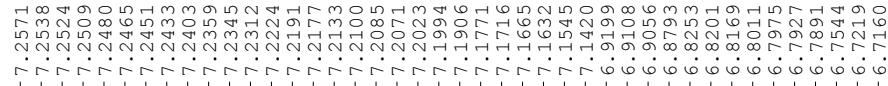

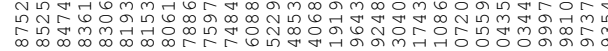

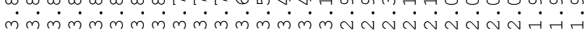

$\frac{1}{1 T ा I I I}$

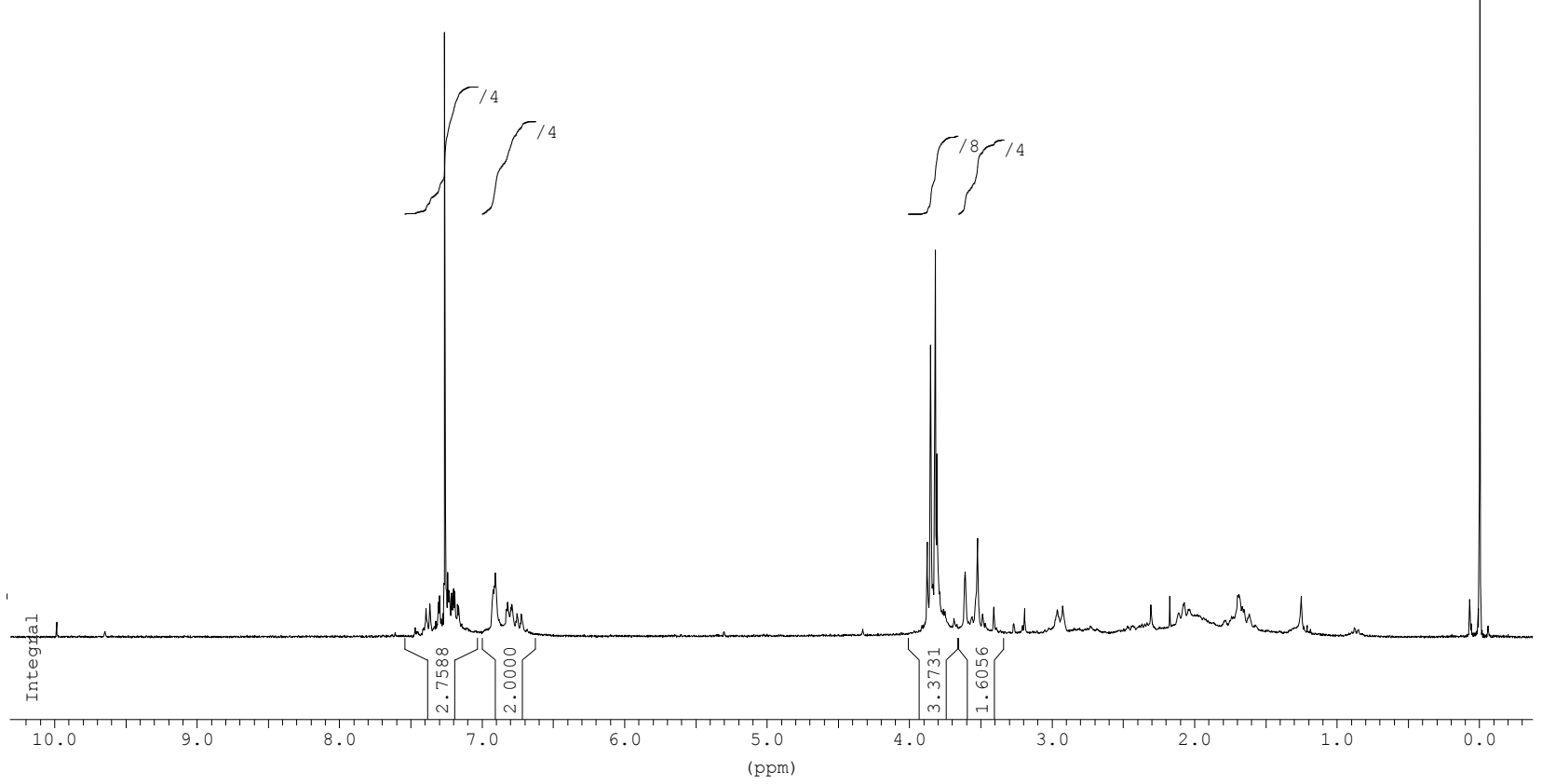




\section{Sample24}

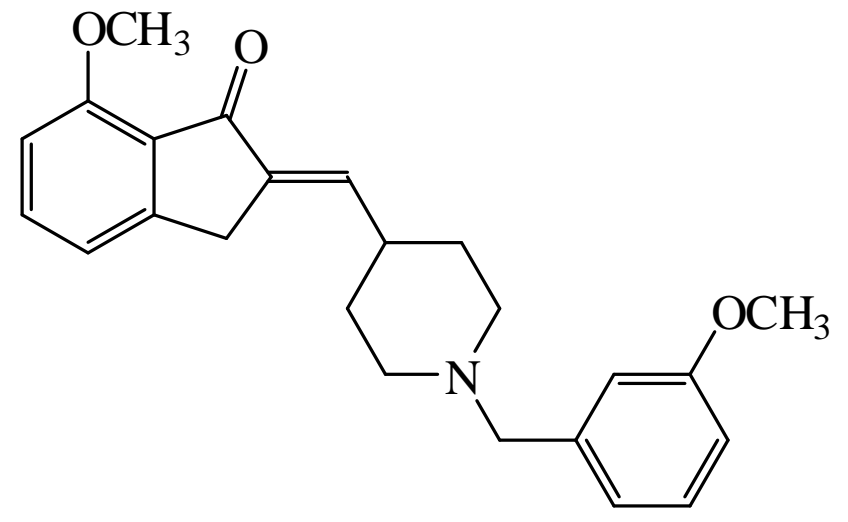

*** Current Data Parameters *

NAME : $\quad 9 \mathrm{p} 16$

EXPNO : $\quad 1$

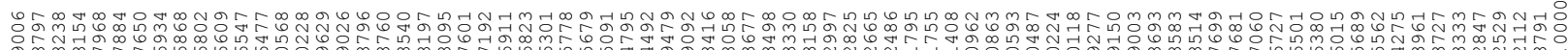
66 666666666 t TाIIIII

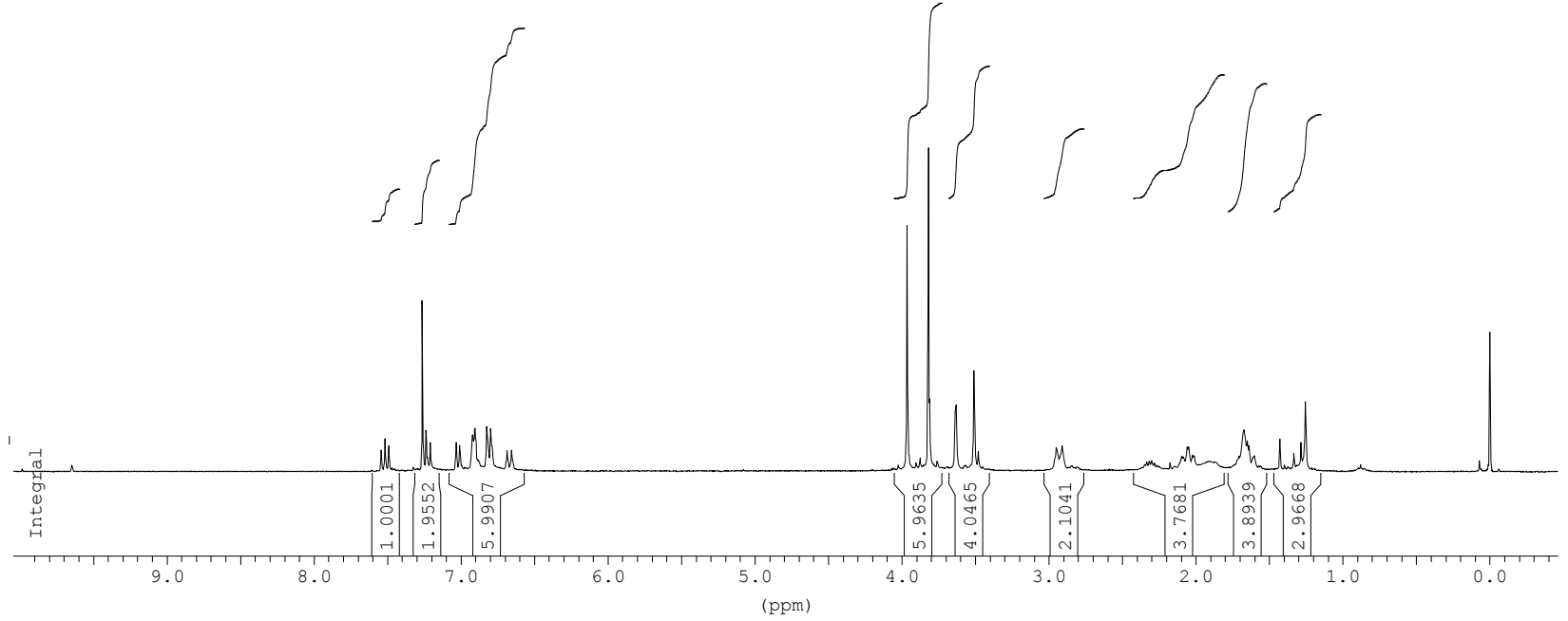




\section{Sample25}

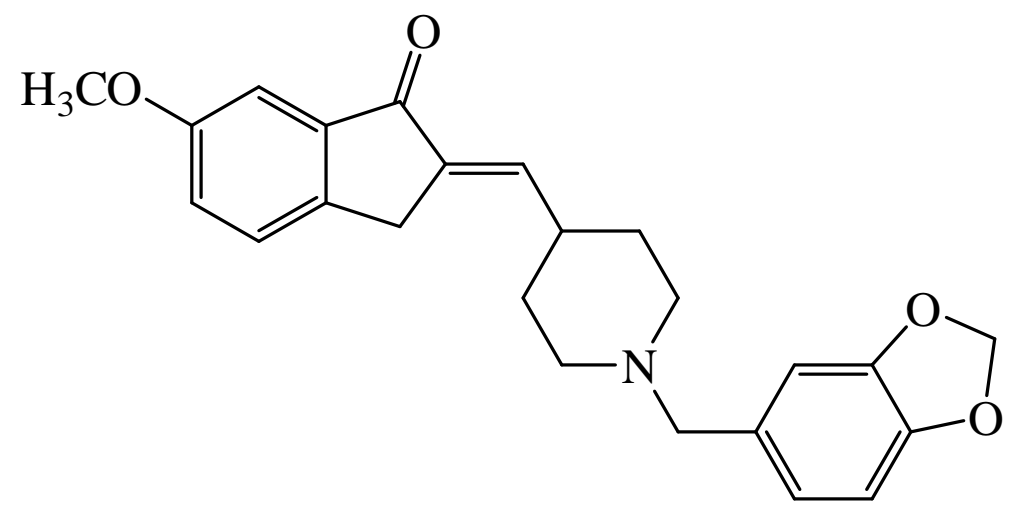

*** Current Data Parameters

NAME : gp19

EXPNO : 1

PROCNO :
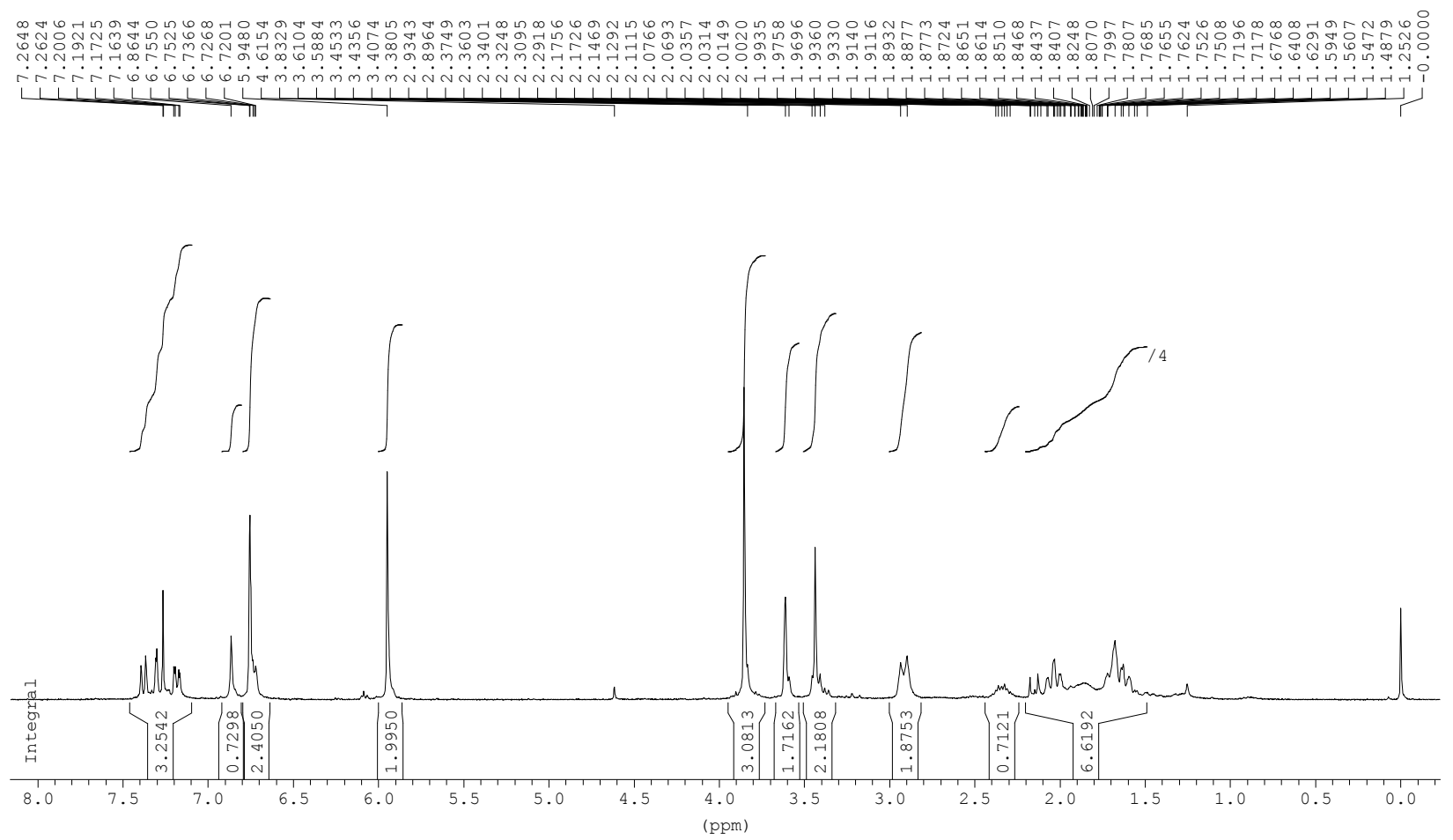


\section{Sample26}

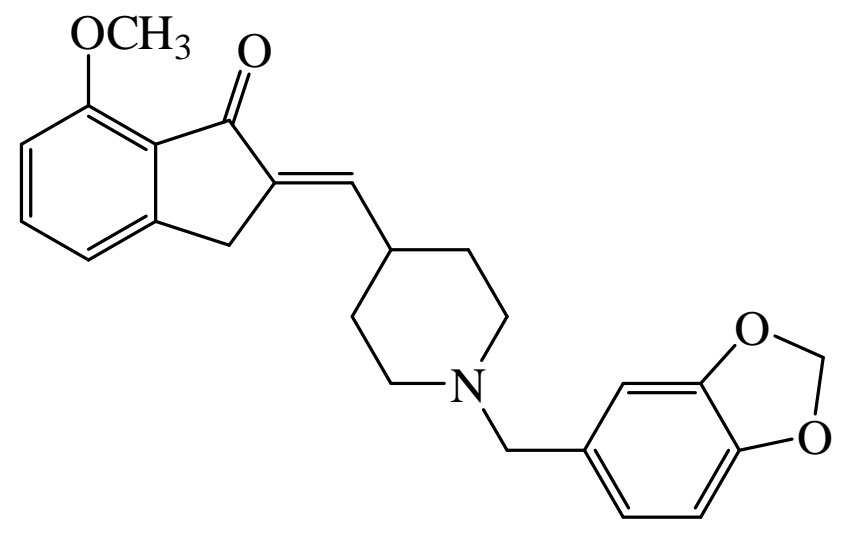

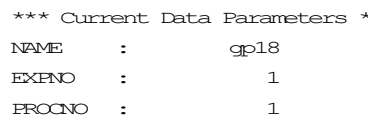
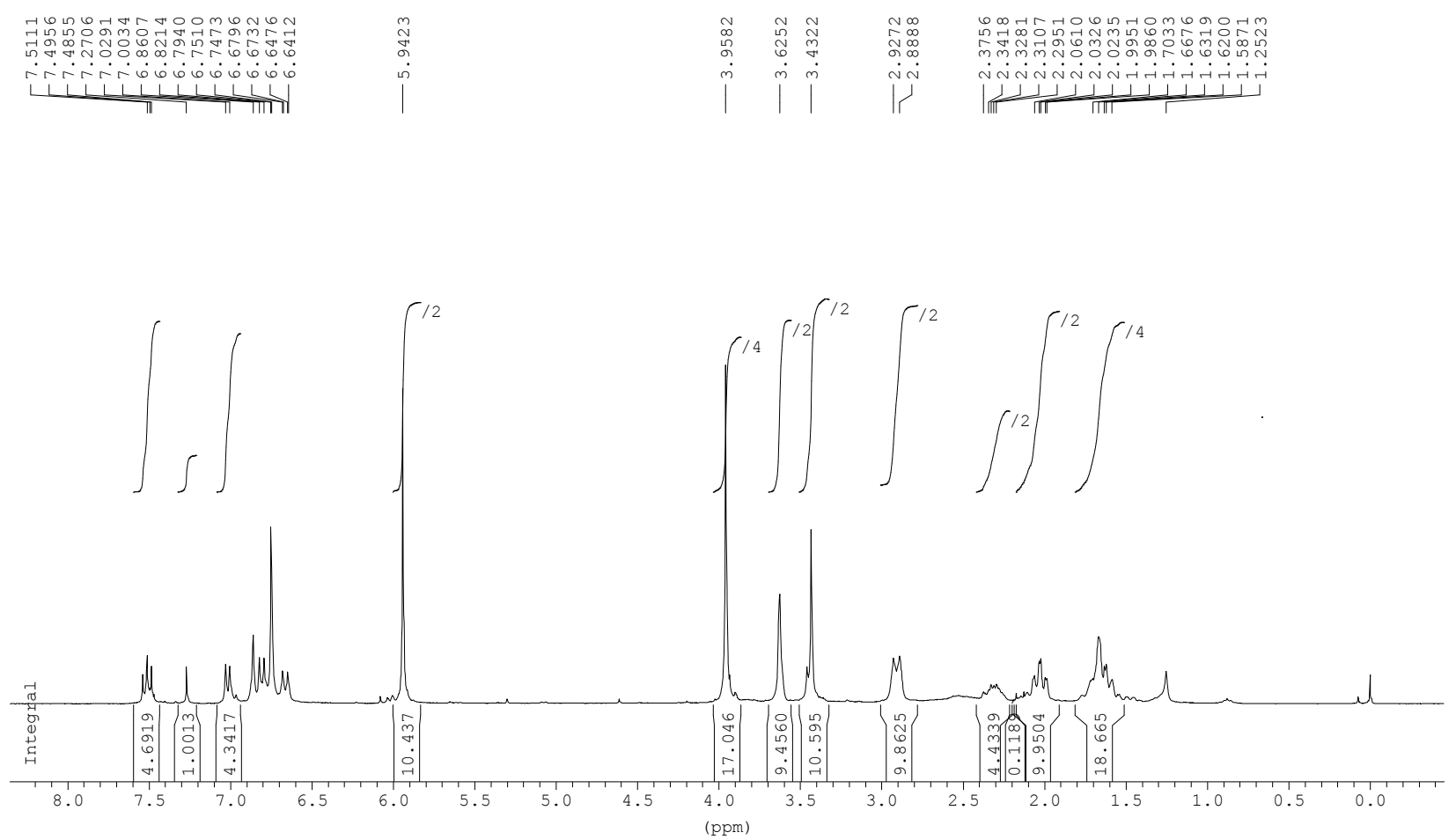


\section{${ }^{13}$ C-NMR Spectra}

Sample 13a/13b
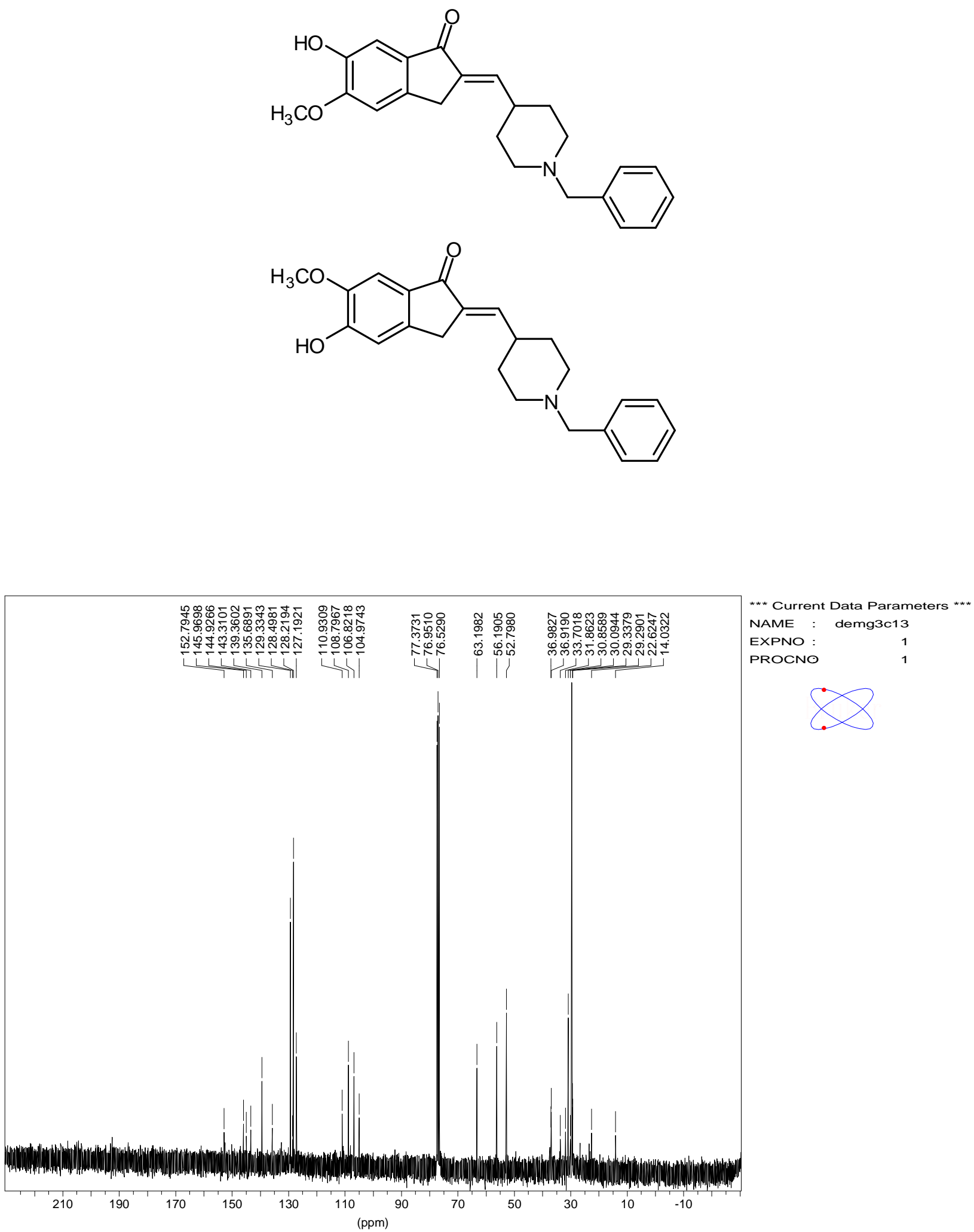


\section{Sample 14}
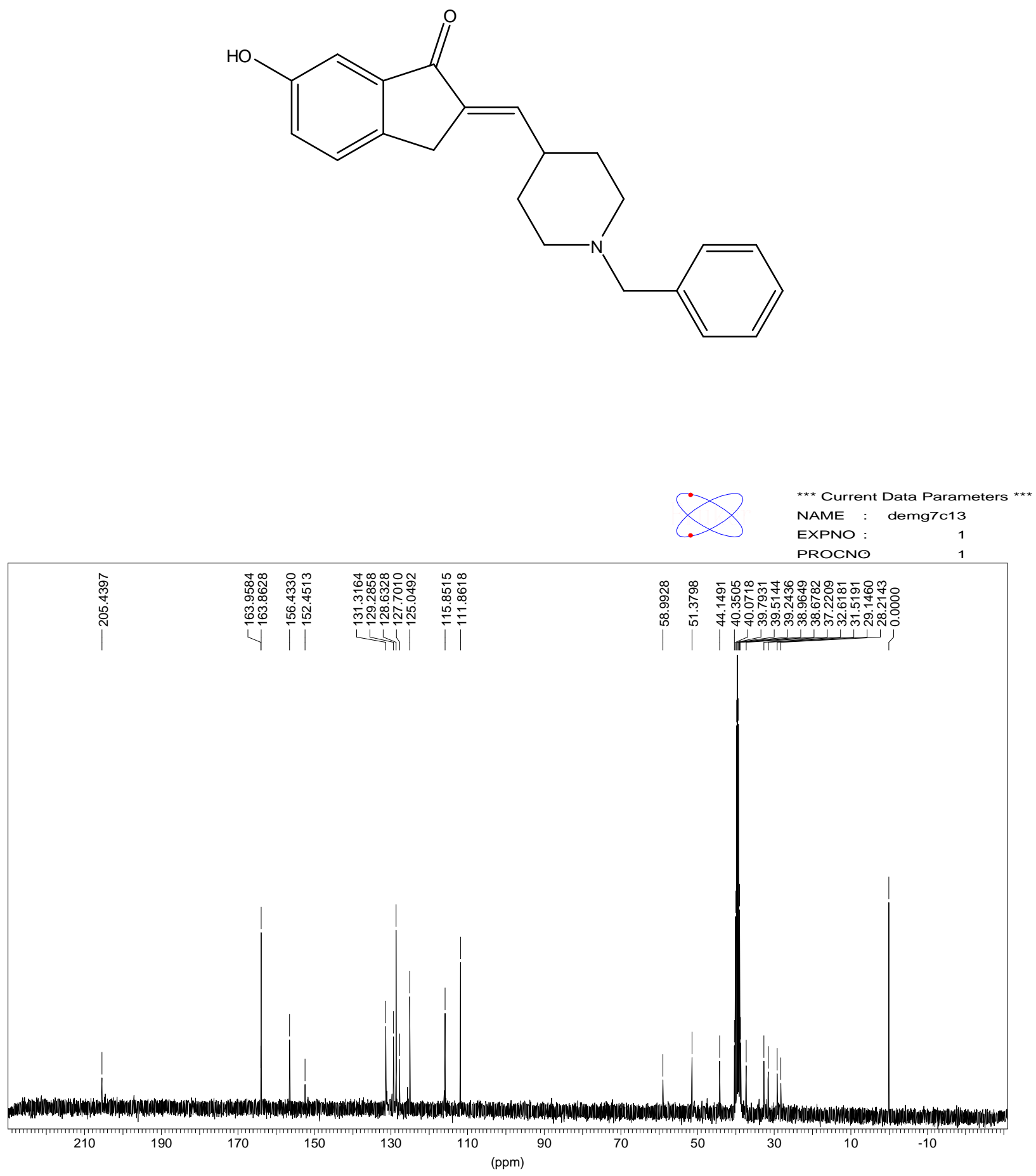


\section{Sample 15}

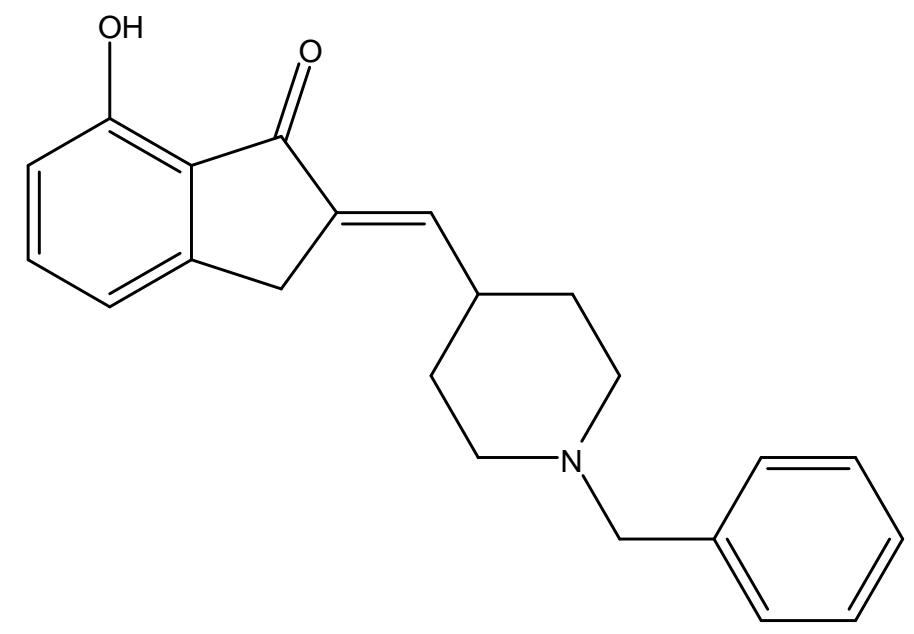

*** Current Data Parameters ***

NAME : dmg6c132

EXPNO :

PROCNO

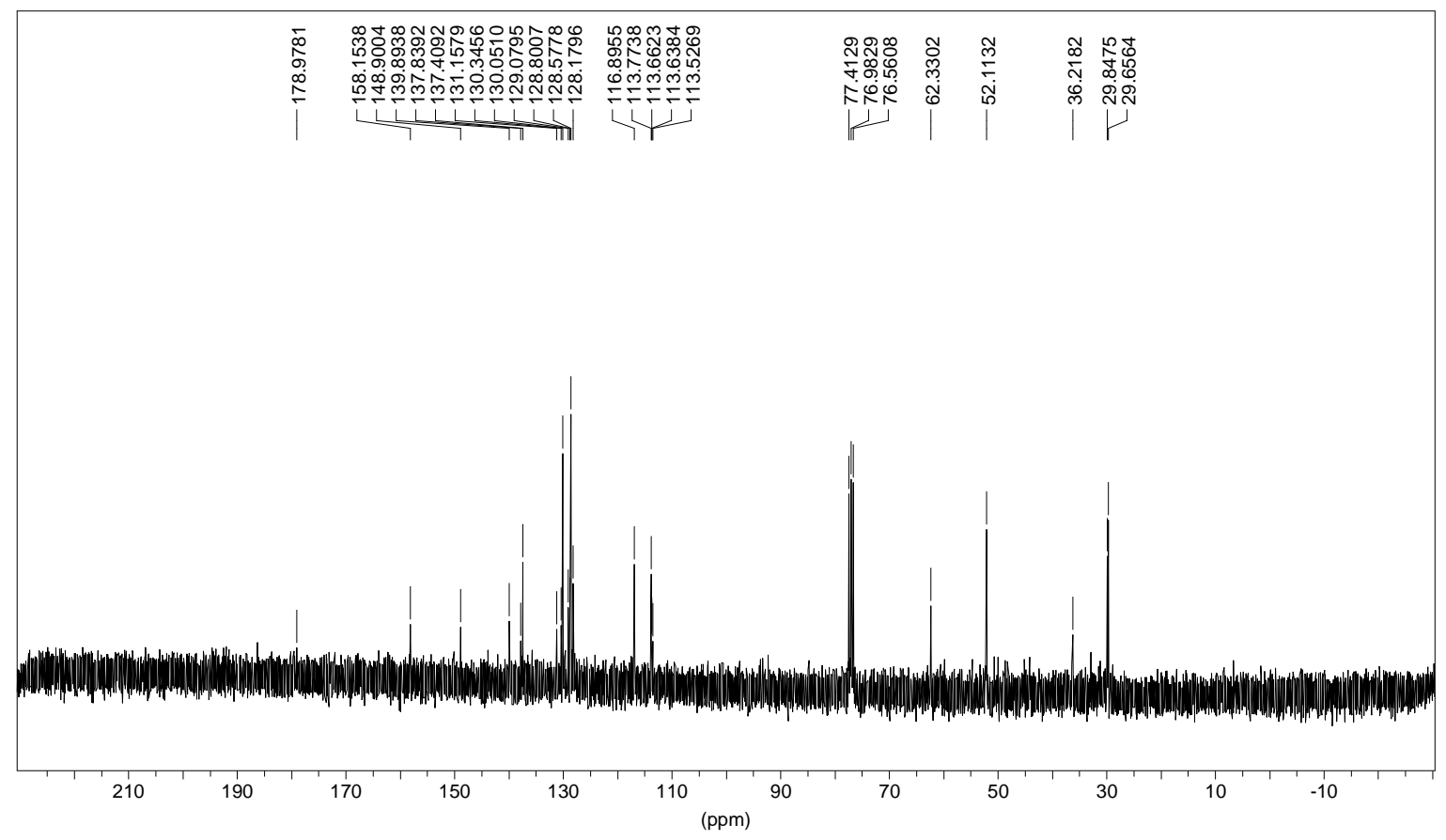




\section{Sample 16}
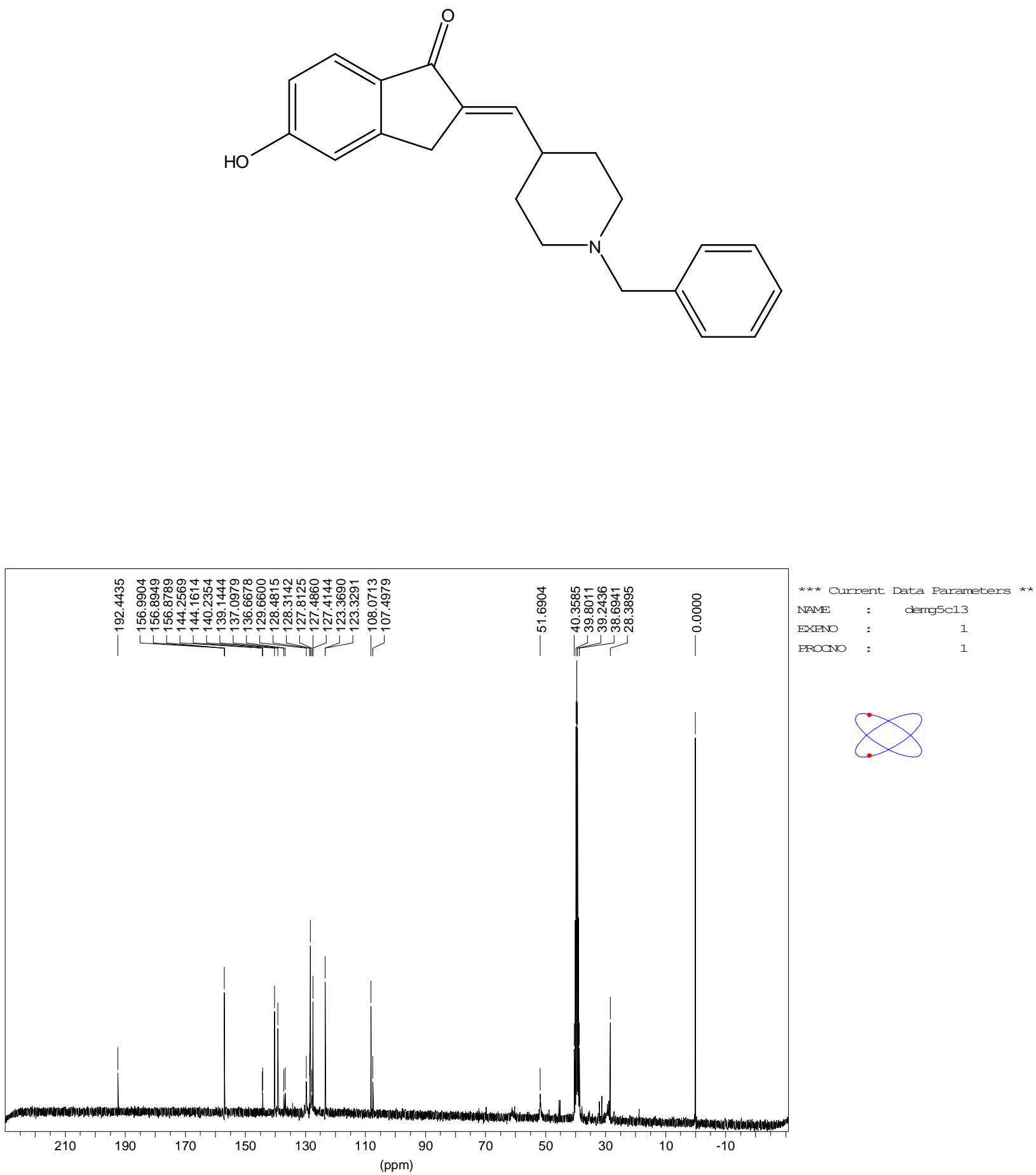


\section{Sample 17}

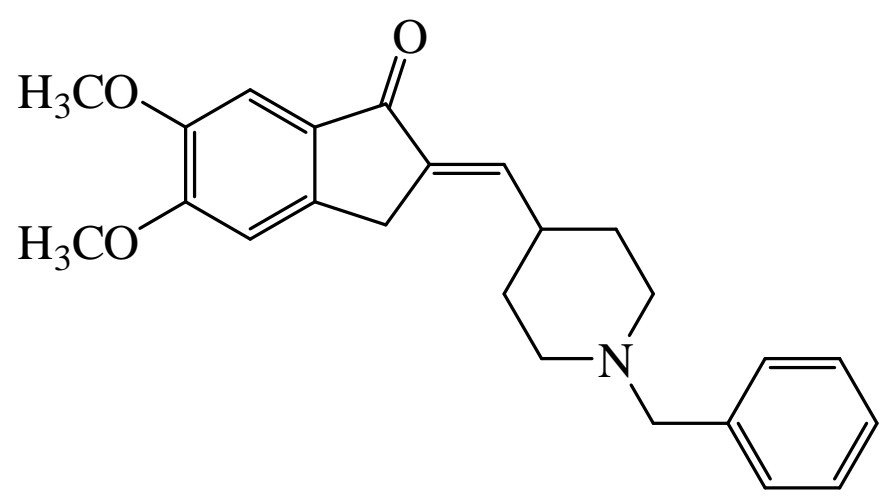

*** Current Data Parameters *

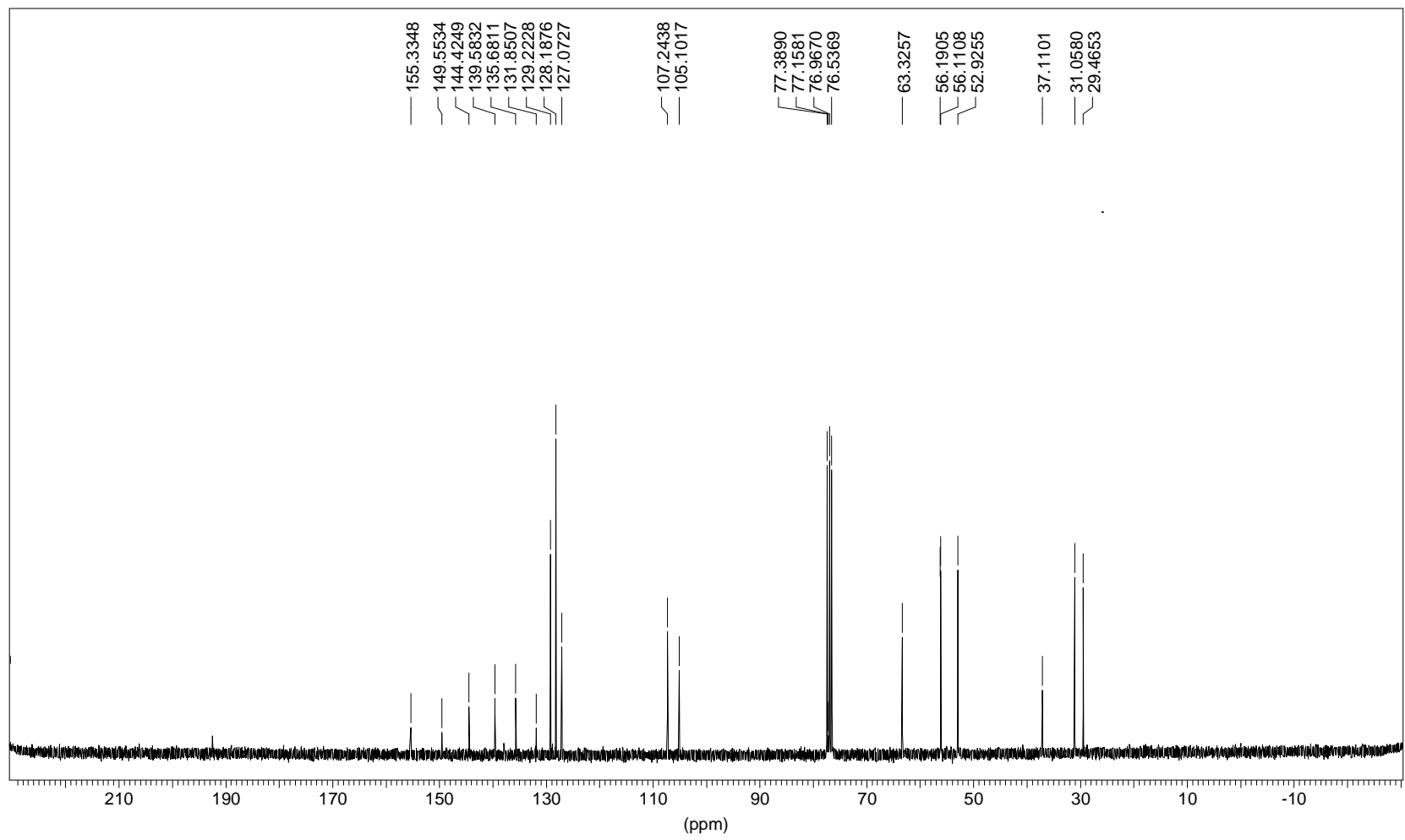




\section{Sample18}
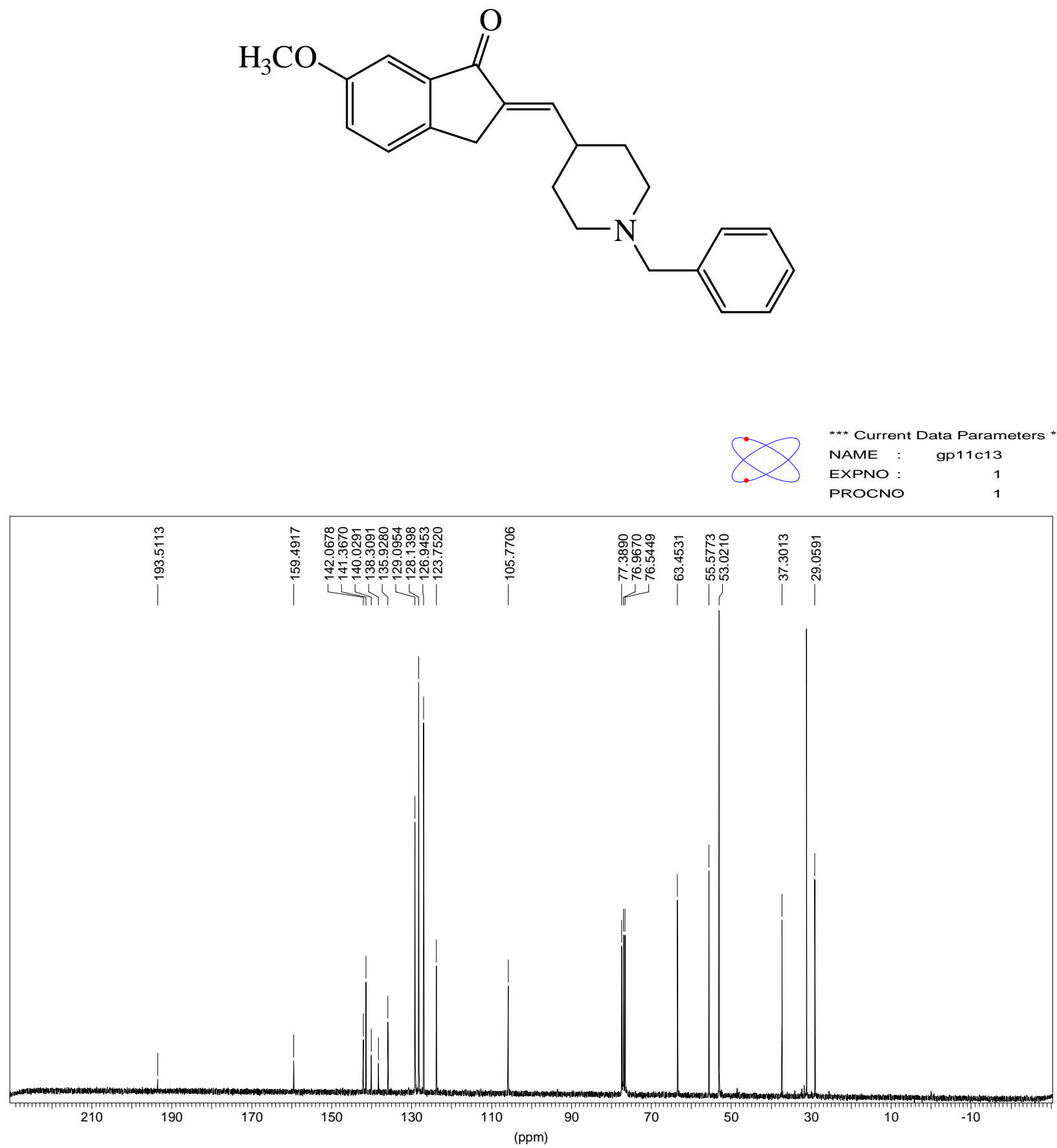
Sample19

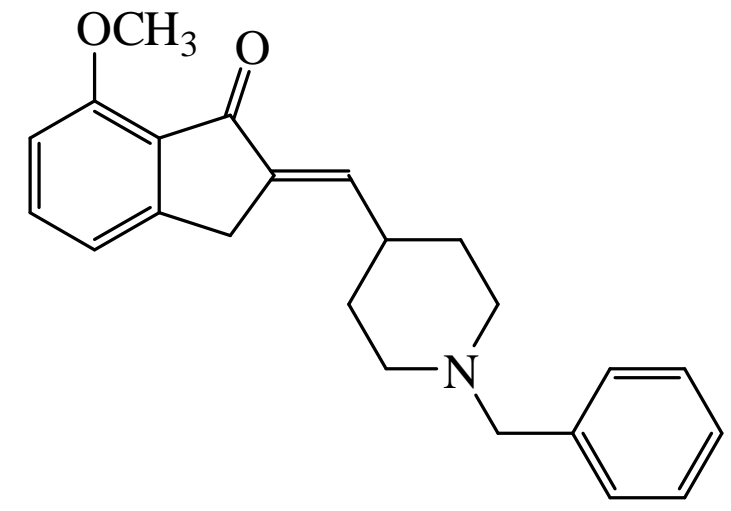

*** Current Data Parameters

NAME : gp12C13

$\begin{array}{lll}\text { EXPNO : } & 5 \\ \text { PROCNO : } & 1\end{array}$

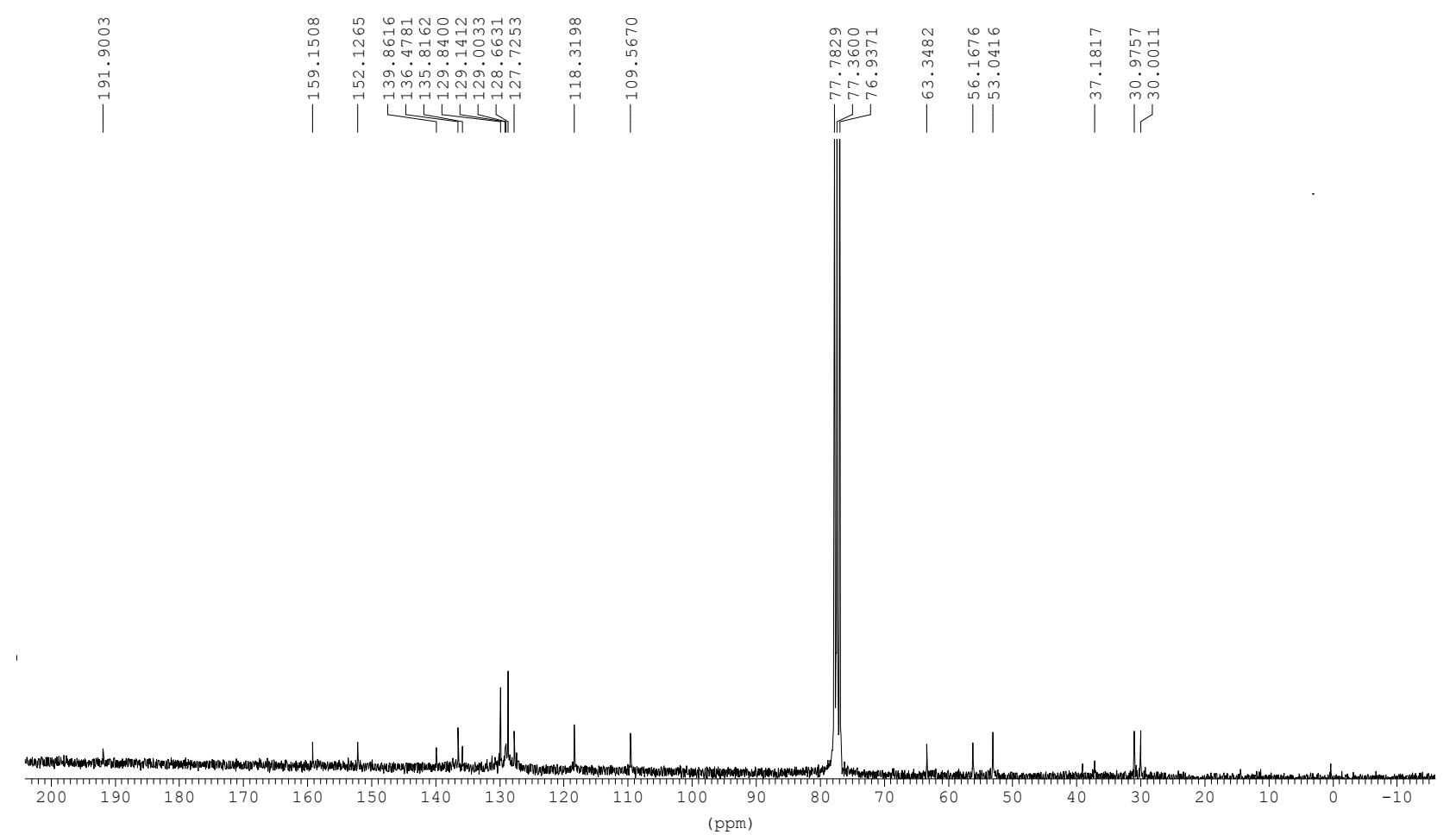


Sample20
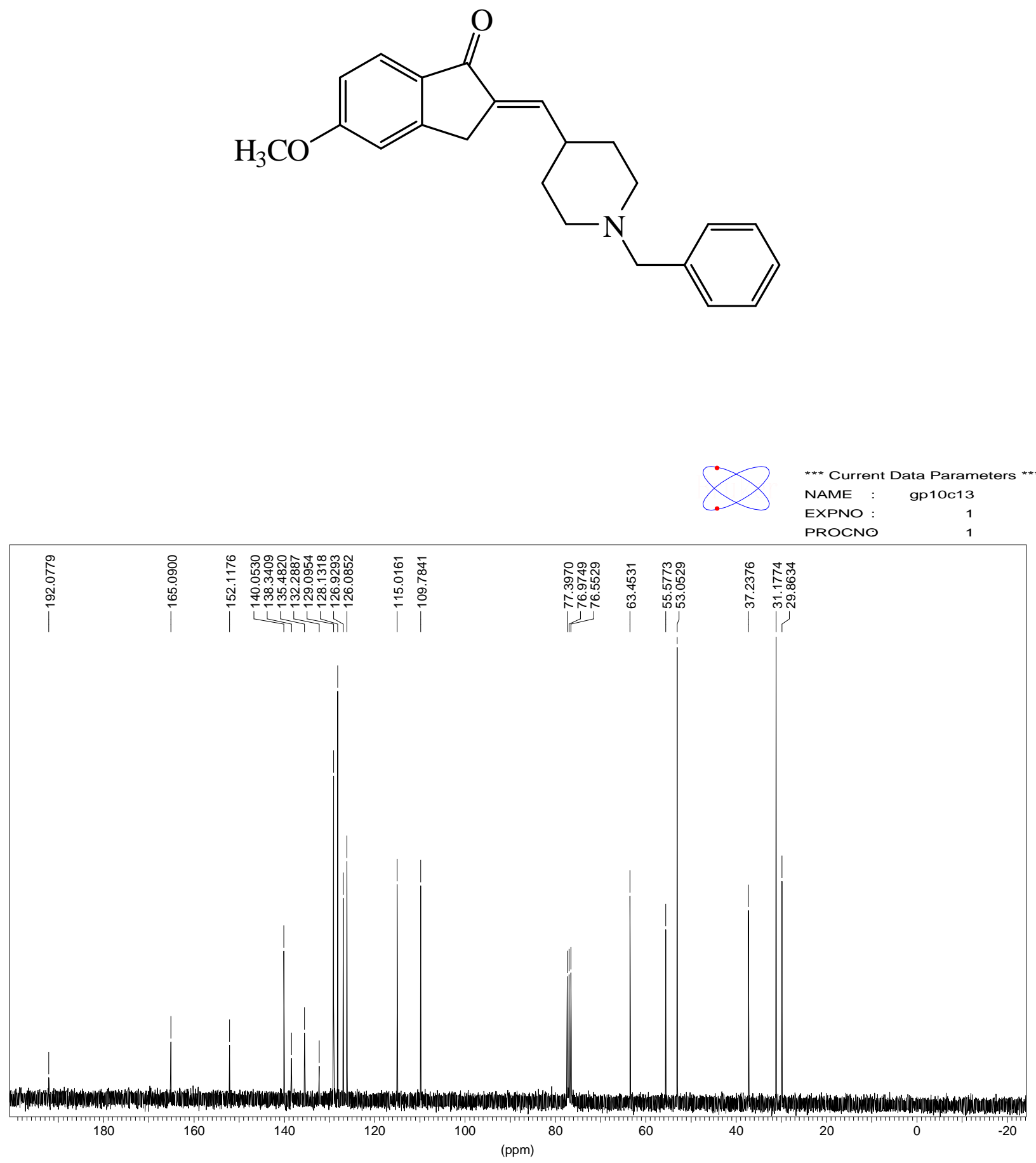


\section{Sample21}

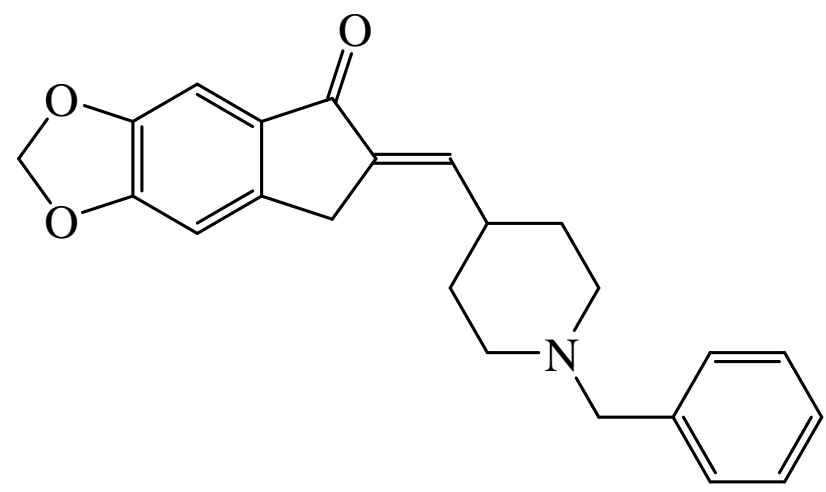

*** Current Data Parameters

NAME :

$\begin{array}{ll}\text { EXPNO : } & 1 \\ \text { PROCNO : } & 1\end{array}$

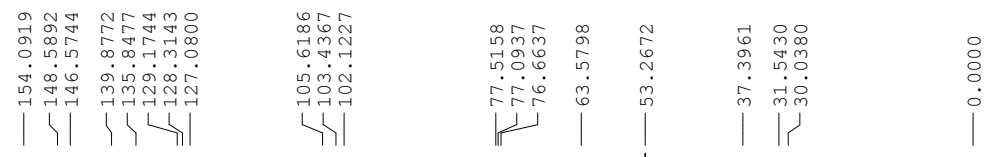

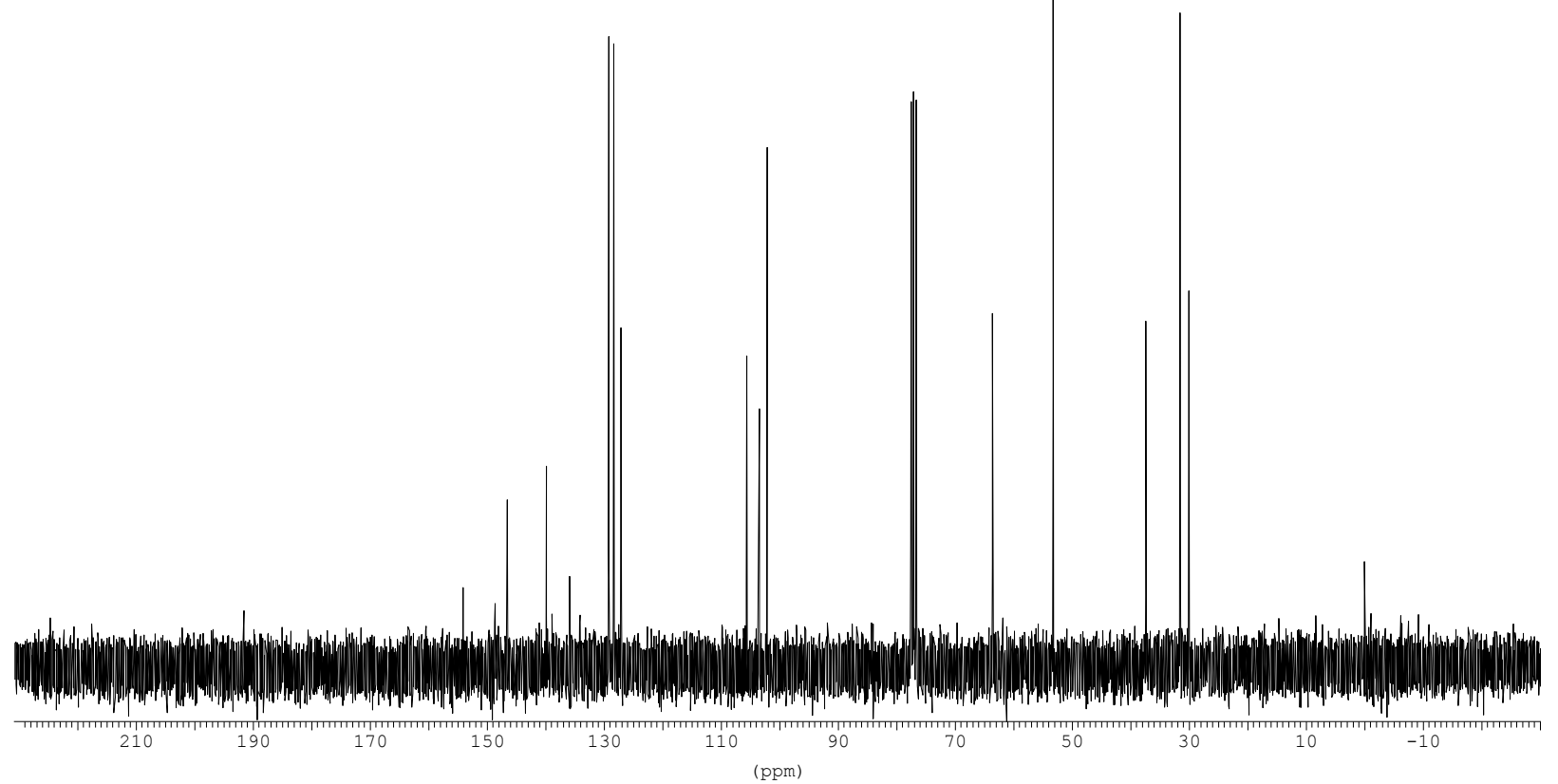




\section{Sample22}

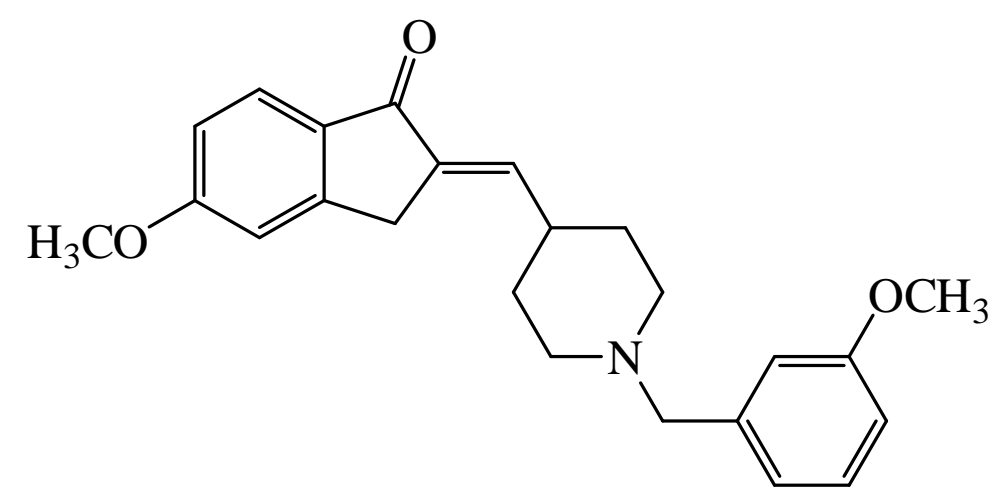

*** Current Data Parameters

NAME : gp14c13

EXPNO : 1

PROCNO : 1

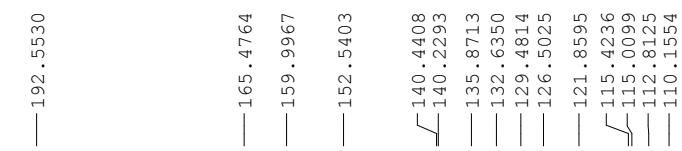

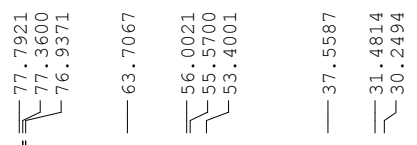

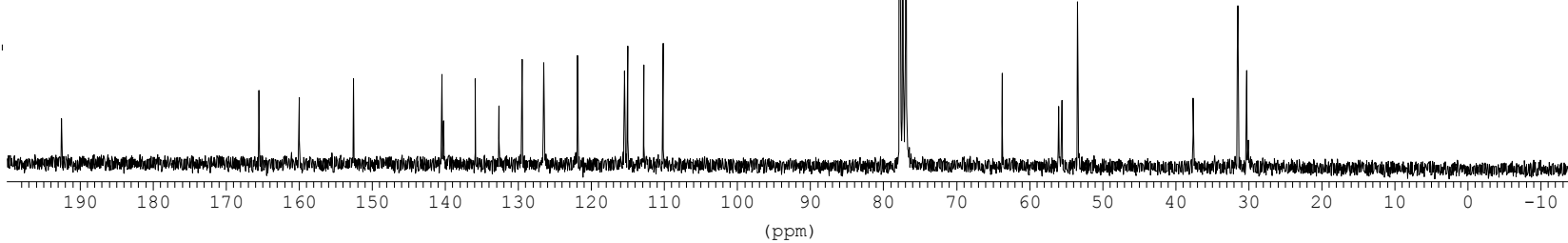


Sample23
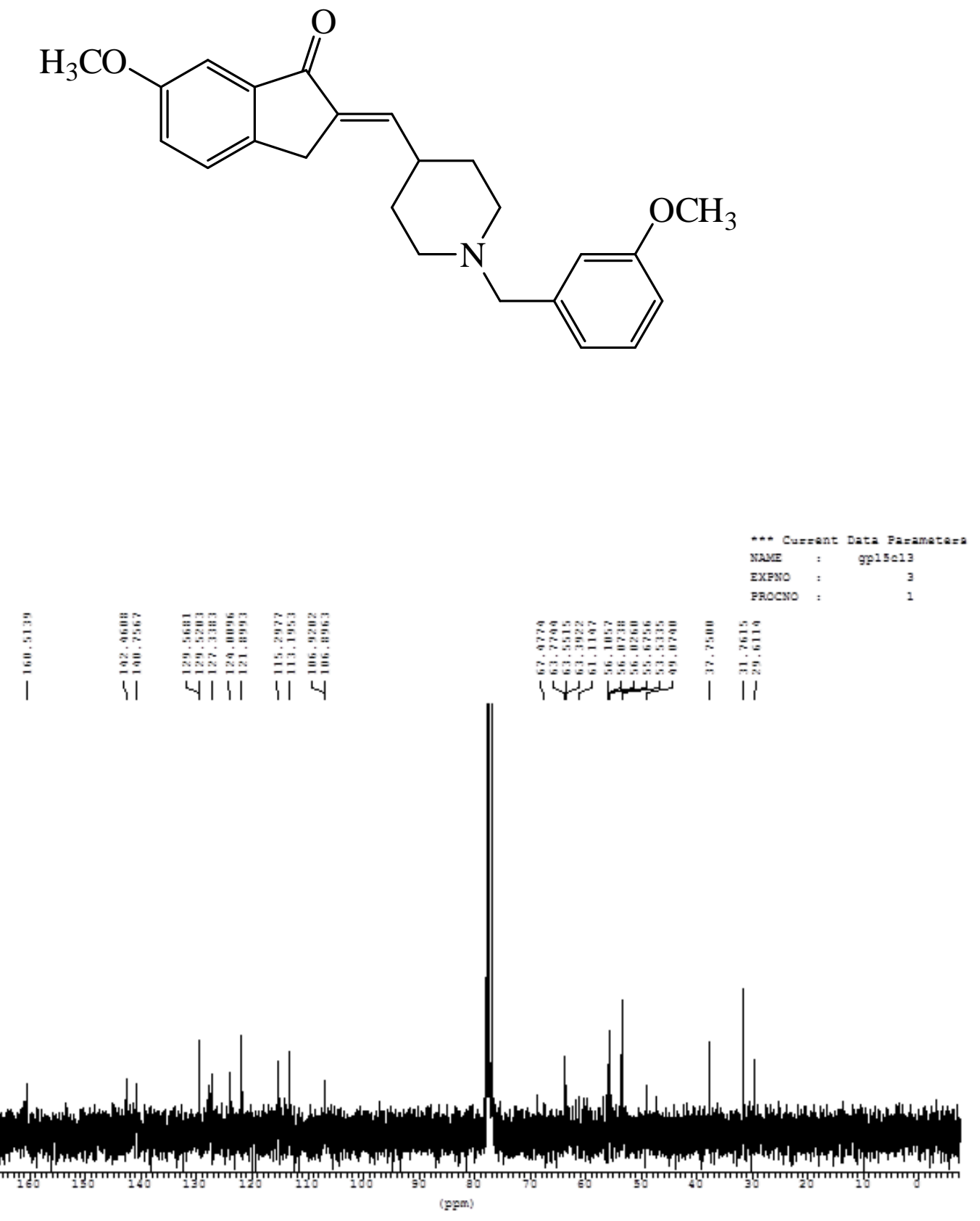
Sample24

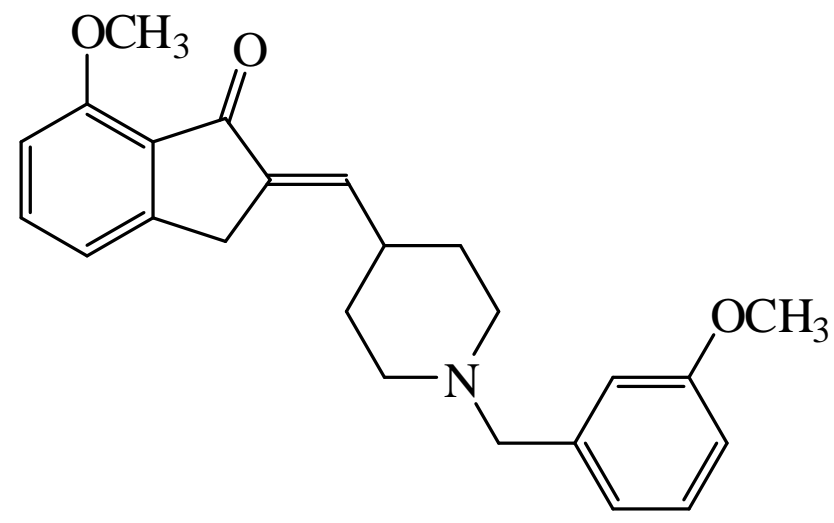

... Curzent Data Farametera

$\begin{array}{ll}\text { EXFNo : } & 1 \\ \text { papcro : } & 1\end{array}$

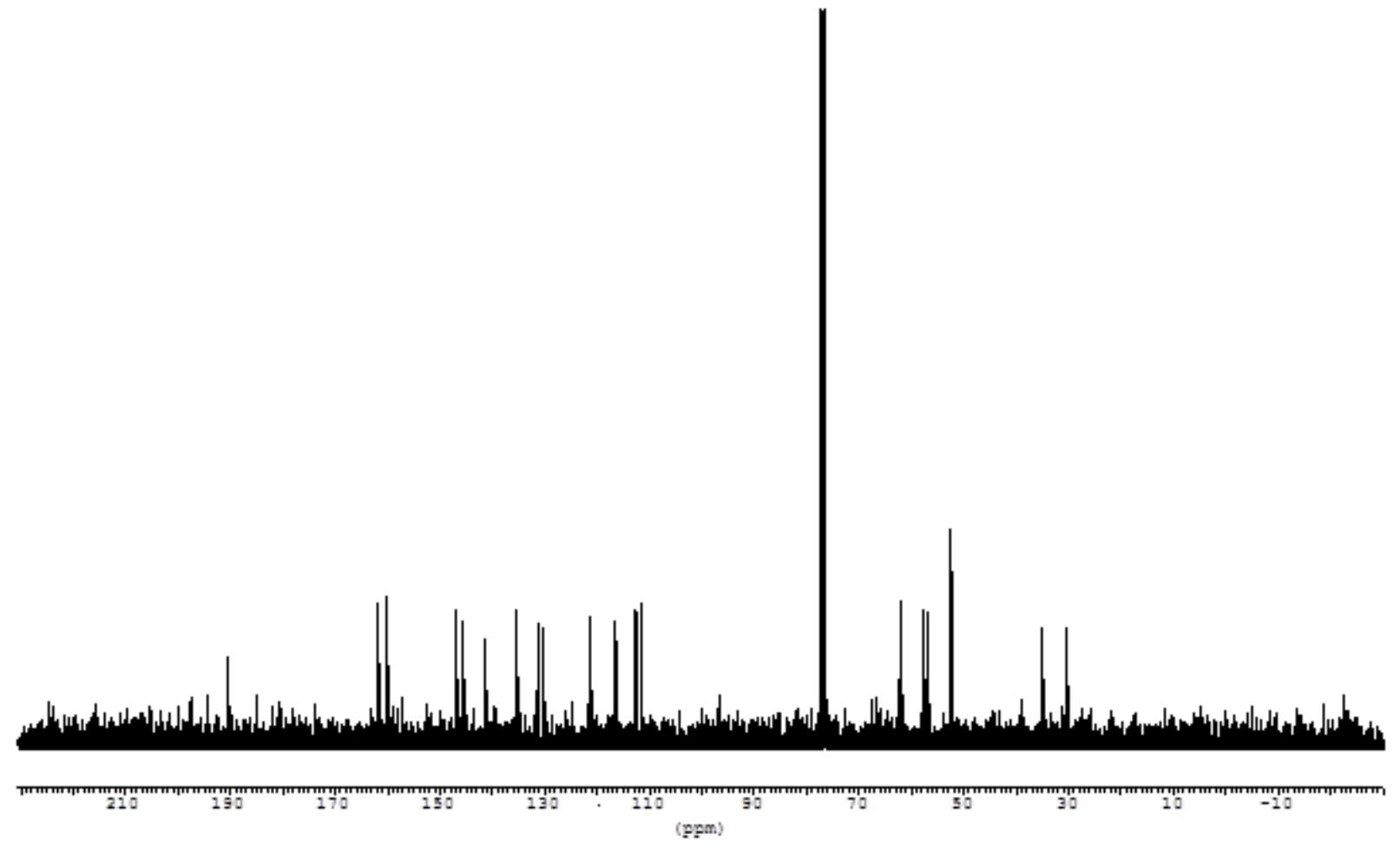




\section{Sample25}

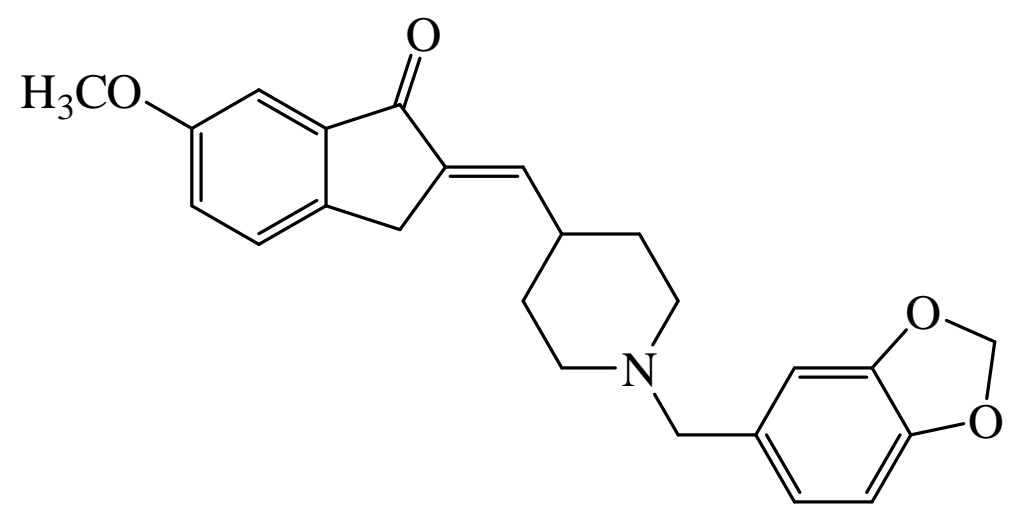

** Current Data Parameters *

NAME : 9p19c13

$\begin{array}{lll}\text { EXPNO : } & 2 \\ \text { PROCNO : } & 1\end{array}$

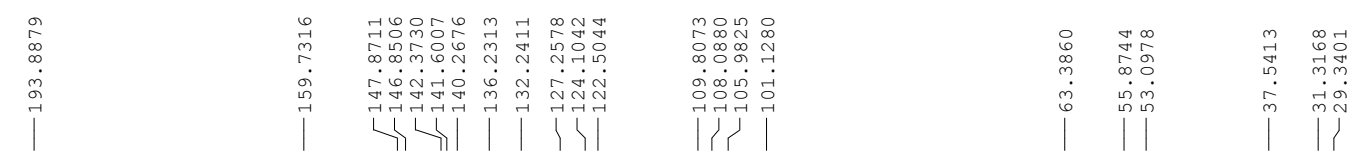

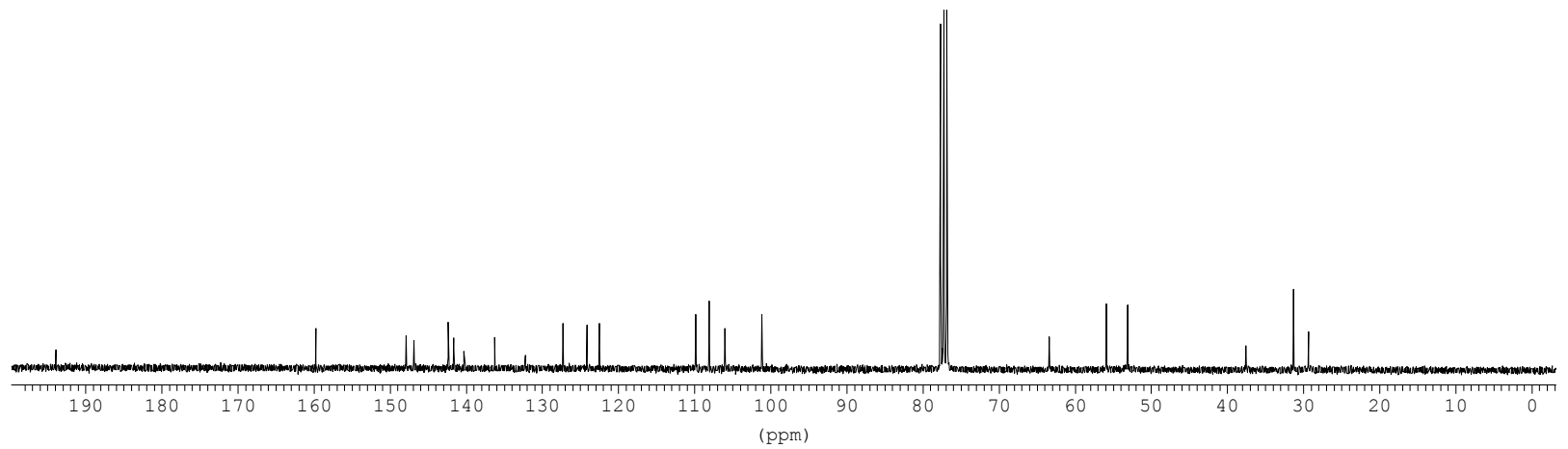


Sample26
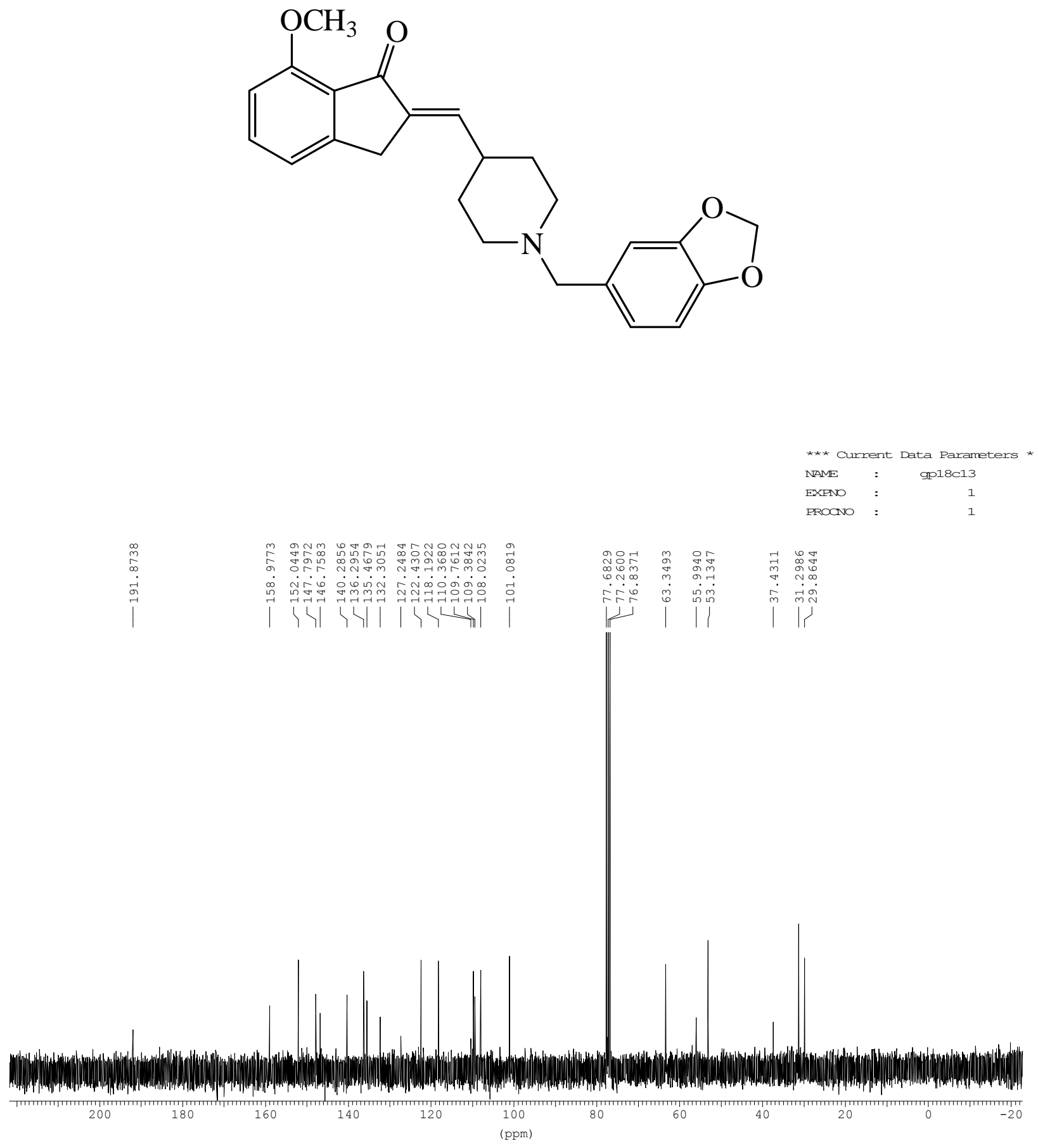
NOESY SPECTRA

Sample 15
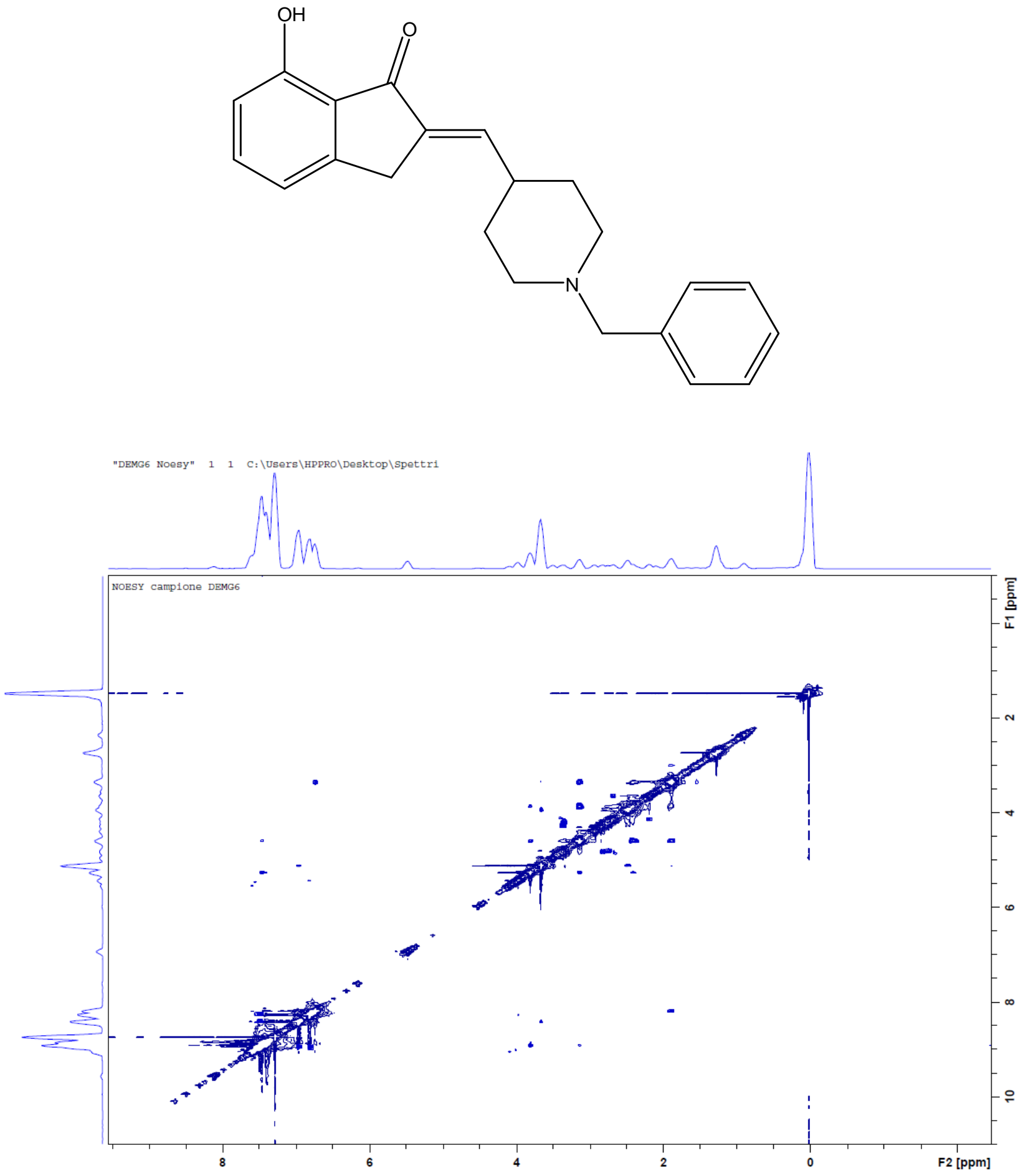
Sample 17
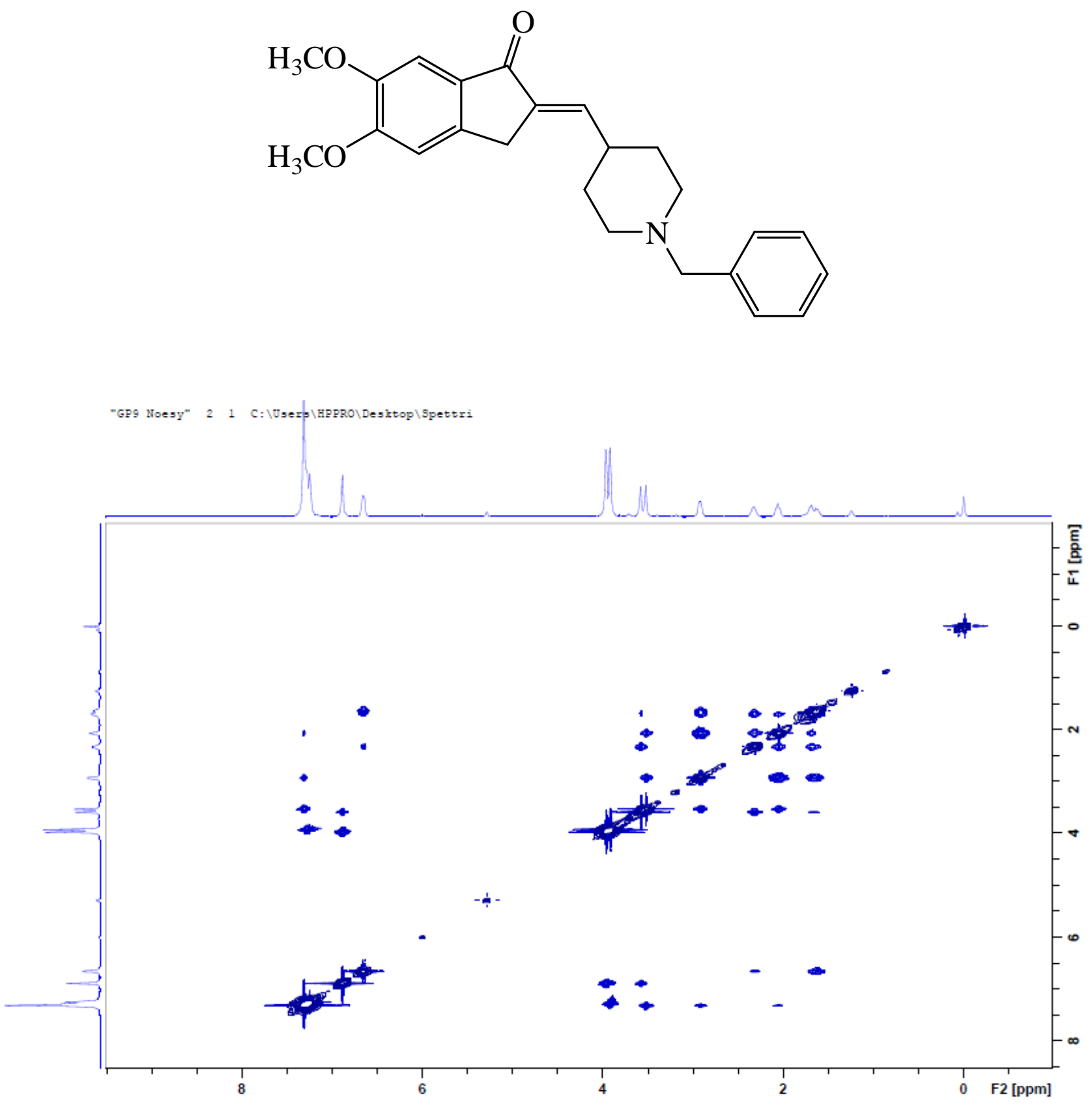
Sample18
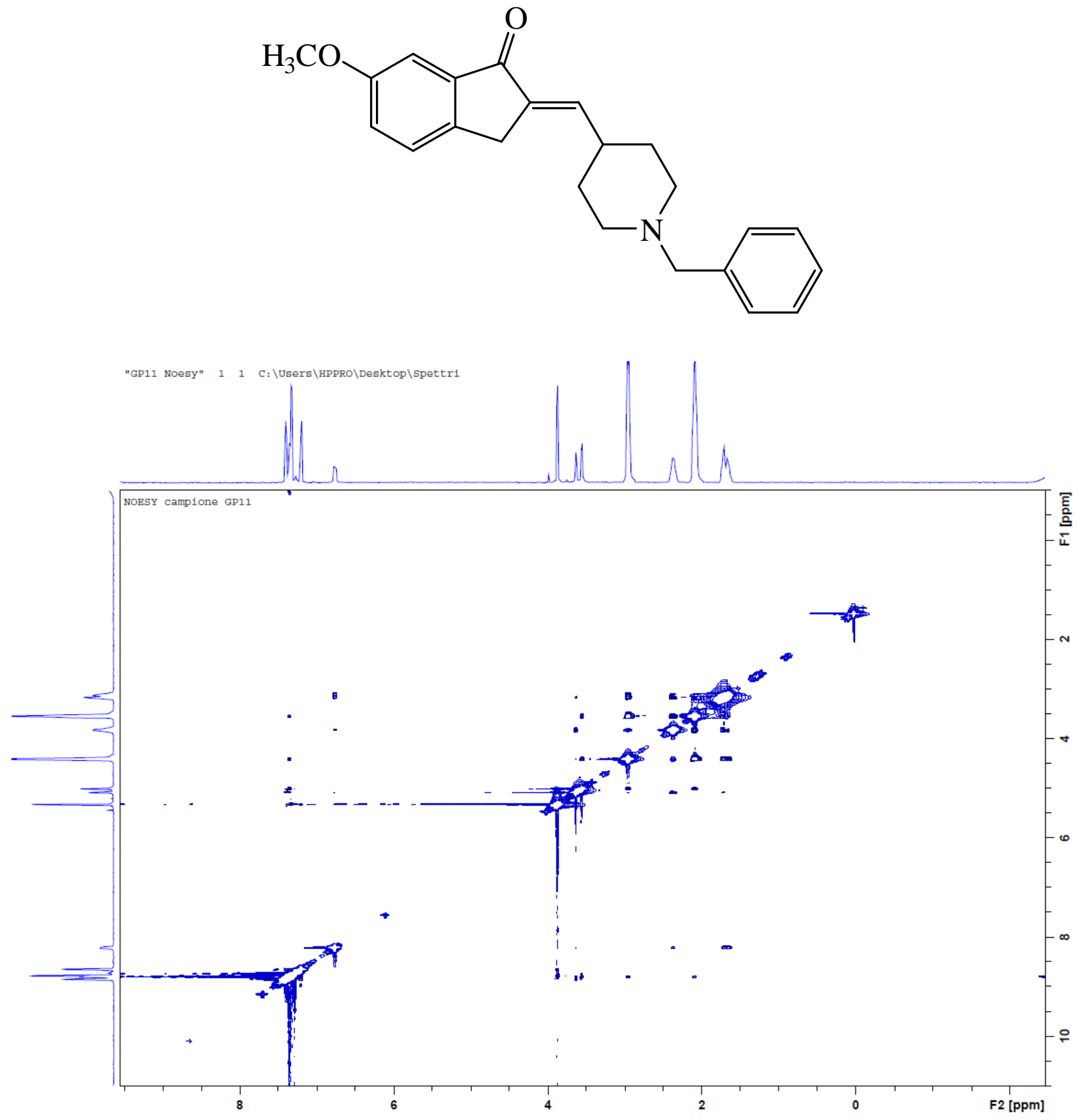
Sample19
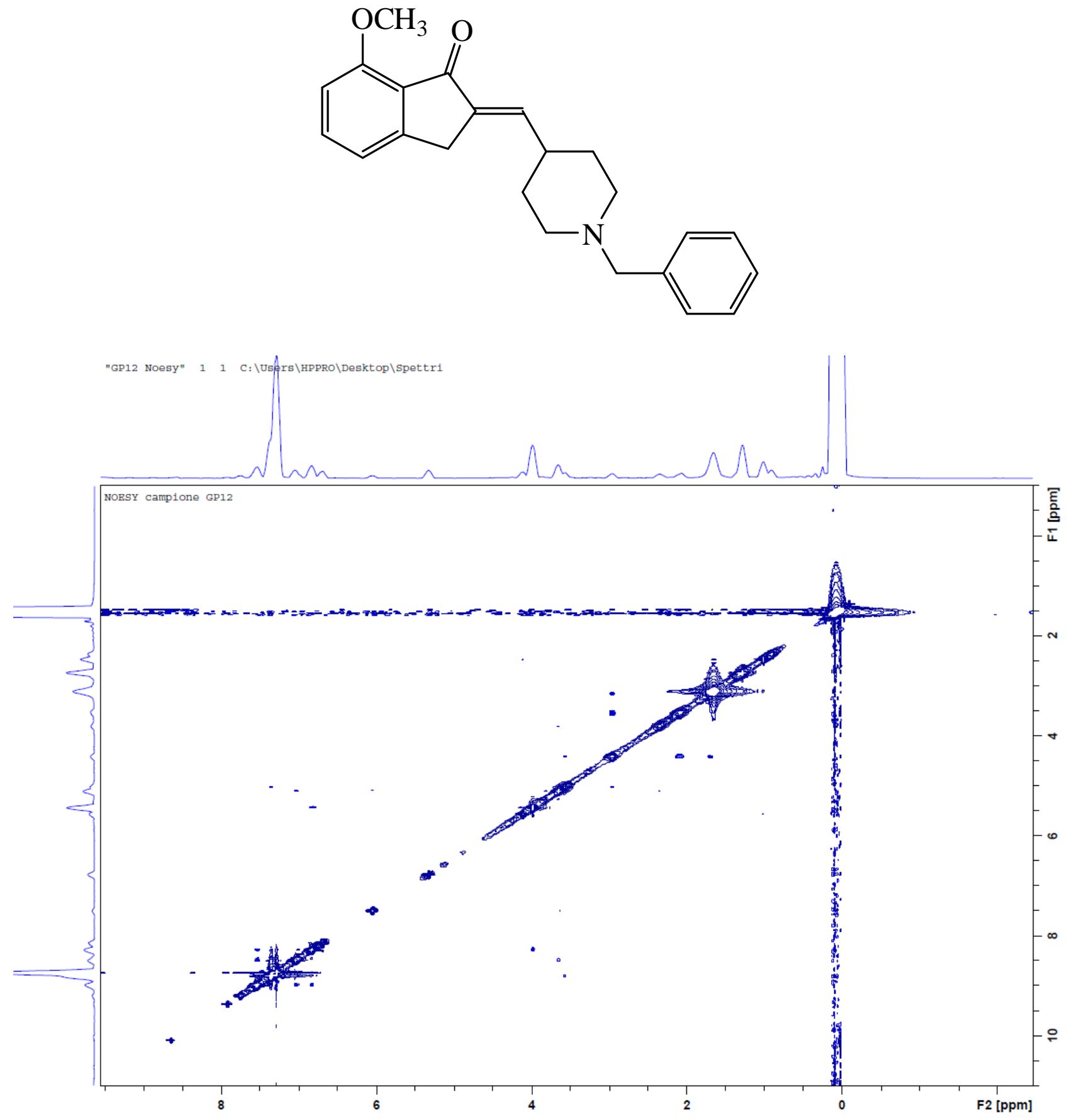
Sample20
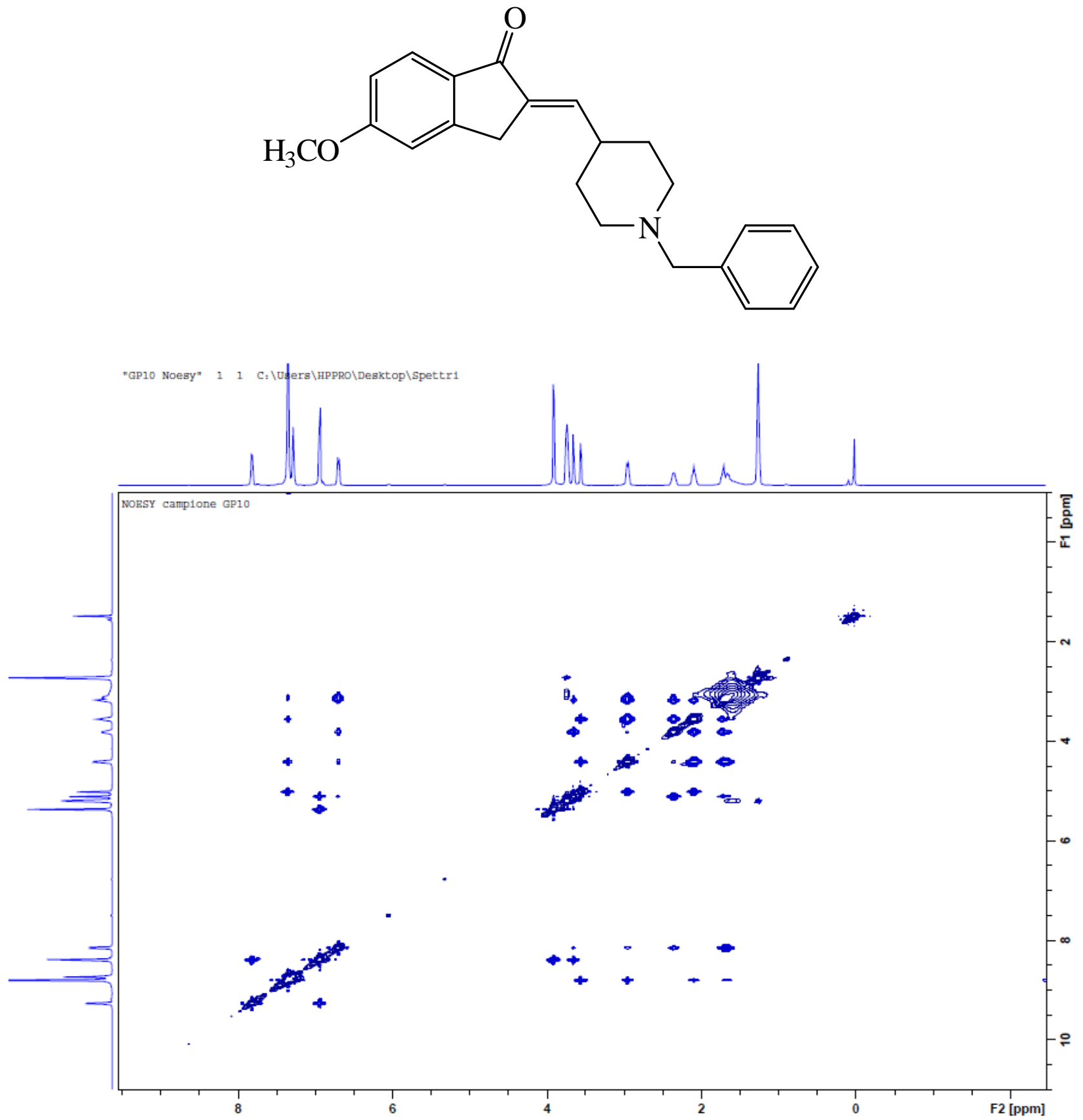